



Zur Kenntniss der adriatischen Ammeliden.

Von Dr. Enil v. Marenzeller.

(Mit 7 Tafeln.)

(Vorgelegt in der Sitzung am 23. April 1874.)

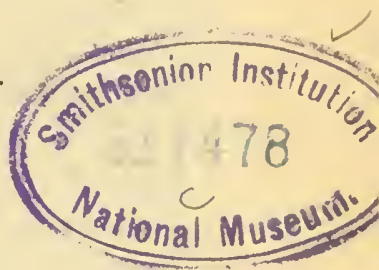

Stellt man dem farbenprächtigen lebensvollen Gemälde, das uns Eduard C lapar ède iiber die Aunelidenwelt des Golfes ron Neapel entrollte, die bisher von Grube, Ehlers u. A. in der Adria gefundenen Arten gegeniuber, und behält man die bestehenden Beziehungen zwischen dem Thierleben des westlichen Mittelmeeres und der Adria im Ange; so eröffnet sich eine weite Perspective für den gleichen Zweig der Fauna unseres Meeres.

Ein vierwöchentlicher Aufenthalt in Zanle (Ostkisste der Bai von Muggia bei Triest) während des Monates August 1872 bot mir Gelegenheit dies zu bestätigen, indem ich theils einer Reihe von bisher unr ans anderen Localitäten bekannten Formen, theils noch nubeschriebenen begegnete. Neben der ausfithrlichen Schilderung der neuen Arten gebe ich im Nachfolgenden auch Ergänzungen zu älteren Beschreibungeı, wo einer grösseren Schärfe der Diagnostik oder dem Fortschritte Rechumg' zu tragen war. Einzehe Arten wurden eingezogen, die rerwandtschaftlichen Verhältuisse anderer vorliufig hervorgehoben; in einem Falle ergab sich die Nothwendigkeit der Benenumng einer mir nur aus der Literatur bekannt gewordenen Art (Polynoë Jolunstoui " sp. ans dem atlant. Ocean fiir die P. scolopendrinu uutorum non Sar.). Es war mein Bestreben, stets mehrere Individuen einer Art in den Kreis der Beobachtung' zu ziehen und die allgemeinen Verhältnisse nach dem lebenden Thiere sofort im Bilde zu fixiren.

Sämmtliche Abbildungen auf den beigegebenen 7 Tafeln sind, mit Ausnalme der Fig. 2 auf Tafel I, der Fig. 3 anf' 'Tafel VII und der Borsten, ein ansgefiihrter Theil der an Ort und stelle 
angefertigten Skizzen. Selbstrerstänllich setzte die kurze $\mathrm{Ar}$. beitszeit gewisse Schranken. So kommt es, dass ieh zmmächst, wiewohl die iibrigen Familien von mir nicht vernachlïssigt wurden, nur die Polynoiden (5 Arten), Phyllodociden (4 Arten). Hesioniden (2 Arten), Syllideen (13 Arten), Euniciden (3 Arten), Nereiden (1 Art), Opheliiden (1 Art), Amphicteniden (1 Art) und Ampharetiden (1 Art) beriilure.

Von diesen 31 Arten sind 10 itberhaupt neu: Palynö̈ lormprophthalmu, Polynoë crussipalpu, Grubeu dolichoposta, Syllis: macrocolu, Odlontosyllis virescens. Pterosyllis plectorhynchu. Proceraca luxuriuns. Proceruea bruchycephulu. Armandia oligops, Melinna adriatic'u. 8 Arten waren bisher nur von anderen Localitäten bekannt, 6 hievon bereits ans dem Nittelmeere (Neapel, Port St. Vendres, Camnes): Polynö reticulatu. Stheneluis fuliginosa, Eulalia pullida, Paedophylax claviger. Spharorosyllis hystrix, Gruben pusillı; 2, die Nereis diversicolor O. F. M iill. und die Murphysu Bellii erst ans dem atlantischen Ocean. Mit der oben angefiihrten Art erseheint die Gattung Melinun zum ersten Male im Mittelmeere.

Der grösste Theil der von mir untersuchten Ameliden waren kleine Formen, -- 2-20 Mm. lang - alle aber gehören der Littoral-Fauna im strengsten Sinne des Wortes an; denn ich habe sie an Stellen, welche die unbedeutende Ebbe trocken gelegt oder mit nur wenig $W$ asser bedeckt lässt, gesammelt oder von Steinen und Algen abgelesen, die mit der Zange heraufgeholt wurden. Das Maximum der Tiefe war die Länge der Zangenstange $6-8^{\prime}$.

\section{Polynoё lamprophthalme n. sp.}

('Tafel I, Fig. 1.)

Körper 3.5 und $7 \mathrm{Mm}$. lang, mit den Borsten 1.5 und $2.5 \mathrm{Mm}$. breit. Gegen den Kopf im ersten Viertel, gegen das Leibesende in den zwei letzten allmälig verschmälert. Selbst die mit Elytren bedeckten Thiere vollkommen durchsichtig, farblos; der Kopflappen allein gelblich. Die Auhänge des Kopflappens, des ersten Segmentes und die Riickencirren in ihrer oberen Hälfte mit undurchsichtigen schwärzlichen Stellen. 
Der schwach gewölbte Kopflappen (Fig. 1 k) hexagonal, breiter als lang, mit sehr schmalem, glasigem Saume und namentlich dentlich abgermudeten Vorderecken. Der mässig ansgesclmittene Vorderrand nimmt das Wurmelglied des unpaaren Fiihlers auf. Der Hinterrand ist fast geradelinig. 4 schwarze Angen. Die vorderen sind oval, grösser als die hinteren und liegen ganz in den seitlichen Ecken des Kopflappens, ragen aber etwas in die vordere Hälfte desselben hinein. Sie convergiren nach vorne. Dicht hinter ilmen, aber mehr nach innen geriickt, liegt das zweite Augeupaar, nach hinten eonvergirend. An den lebenden Thieren war das Schwarze der hinteren Augen kaum in einem Drittel der Ausdehnung der vorderen Augen siehtbar, das Uebrige war durch einen breiten metalliseh glänzenden, irisirenden Ring verdeckt. Mit diesem eigenthimliehen, sehr. auffallenden Augenringe waren"sie un Weniges kürzer und darun rundlicher als die vorderen. An den in Weingeist conservirten Exemplaren konnte man bei Beleuchtung von oben noch recht gut diese Verlä̈ltnisse erkennen, wenn auch der metallische Glanz verloren gegangen war. Lichtbrechende Körper in den Augen liabe ich nicht beobachtet.

Der Kopflappen tragt 3 F ühler und 2 Palpen. Der unpare (us) ist mit seinem Wurzelgliede, das in dem Ausschuitte des Kopflappens liegt, fast dreimal so lang als dieser und ragt uiberhaupt weiter vor als die Palpen und Fühtercirren. Er ist cylindrisch, in seiner hinteren Hälfte ziemlich gleich breit, nur mit etwas coneaven Seiten, dann verdickt er sich oberhalb der Mitte etwas und erst im letzten Viertel verschmächtigt er sich plötzlich zu einem diinnen Ende. Wo die Ausbauchung stattfindet, ist schwärzlich bräunliches Pigment eingelagert. Die paarigen Fiihler $(p s)$, mit kurzem Wurzelgliede unter dem Vorderrande des Kopflappens entspringend, sind etwas länger als der Kopflappen, nahe zu 21/2 mal kiirzer als der unpaare, flaschenförmig mit einem sehwärzlichen Pigmentflecke in ihrer Mitte. Den drei Fïhlern fehlt wie allen iibrigen Anhängen jeder Stäbchen-Besatz - sie sind vollkommen glatt.

Die Palpen $(p)$ sind kïrzer als der unpaare Stimfiihler und die dorsalen Fiihlereirren ( $d f$ ). Sie sind bis zum letzten Viertel ziemlich eylindrisch. Am Ende des dritten Viertels ist dunkles 
Pigment eingelagert. Oberhalb dieser Stelle zieht sich das Ende zu einer dïnnen Spitze ein. Die Palpen zeigen Andeutungen von Querrunzeln, sind aber ebenfalls vollkommen glatt.

Der Körper hestand bei einer Länge von 7 mid $3.5 \mathrm{Mm}$. aus 32 und 20 Segmenten. Das Bucealsegment ist ron oben nicht sichtbar, ruderlos und tragt 2 Paar Fiihlercirren. Der dorsale Fiihlereirrus ( $d f$ ) hat das Aussehen des mpaaren Fublers und ist absolnt nur um Weniges kiirzer als dieser, aher länger als die Palpen. Der ventrale (v f') hat mehr die Gestalt der paarigen Fiihler oder der Riickeneirren, ist kiirzer als der dorsale, jedoch länger als die Palpen. Anch die Fiihlercirren sind glatt.

Die Segmente sind im Allgemeinen nielit ganz halb so lang als breit. Vor der Leibesmitte sind sie etwas breiter als hinten, die Ruder dafïr kiirzer, wïhrend letztere später etwas liinger werden, so dass die Totalbreite des Körpers inchusive die Ruder nicht wesentlich alterirt wird. Die 10 letzten Segmente versehmälern sich suceessive.

Die Ruder (Fig. 1 A) sind geradle weggestreckt, mit Ausnahme der ganz vordersten und hintersten länger als die Segmente breit. Von oben gesehen erscheinen sie conisch, da ihre Basis breiter ist als das Ende. Der obere Ast (a) ist nur ein papillenartiger Fortsatz, in den eine Acienla eindringt. Der un tere spaltet sich an seinem Ende in 2 Lappen, von welchen der hintere kiirzer ist als der vordere. Beide fallen abgerundet nach unten nnd innen ab. Er besitzt ebenfalls eine Acicula. Dem "beren Aste fehlten bei beiden Individnen die sonst hier antretenden kurzen Borsten. Es mag späteren Funden rorbehalten bleiben, dieses so abuorme Verhalten als etwas Constantes hinzustellen.

Das zwischen den beiden Lappen des unteren Astes austretende Borstenbindel umfasst 14-18 einfache Borsten (Fig. 1 B). Sie sind alle zweizähnig an der Spitze, nur die oberste oder die zwei obersten in dem Biindel (Fig. $1 \boldsymbol{B}$ \%) zeigen hievon erst cine Andeutung. An der Schneide sind alle mit Dörnchen hesetzt, eloenso in werhsehnder Austehnung an Riicken, mit Ansnahme der dureh Küirze und Breite des sägeartigen Endes ansgezeichneten Form $y$, die nahezu die Hälfte des ganzen Bindels 
ausmacht und einen vollkommen glatten Ritcken besitzt. Die vier Formen der Borsten $(\alpha, \beta, \gamma$, o Fig. 1 B) stehen in dem vertical gestellten Biindel ron oben nach abwiirts nach der Reihenfolge der Buclistaben.

Auf dem Riicken der Ruder findet man etwas nach hinten, die Trïiger der Elytren und Riickeneirren. Das grössere Individuum hatte 14 Paar Elytren an ㄹ., 4., 5., 7....23., 26., 29. Segmente; das kleinere nur 9 Pare am 2., 4., 5.....15., 17. Die Elytren (Fig. $1 C$ ) sitzen dreicekig-ovalen Trägern auf. Sie sind unregehmässig rundlich, rundlich länglich, meist mit etwas ausgeschweiftem Vorderrande, vollk o m men glatt und d u rehsichtig ohne Papillen und Pigment. Ein zartes Netz feiner Nervenfäden und kleiner Ganglien, das seinen Ausgang von einer grossen Ganglienzelle in Centrum der Elytren nimmt (Aubeftungsstelle an den Träger), gibt ihnen ein geadertes Aussehen. Die Elytren beriihren sieh mit ihren medialen Rändernnieht - die Mitte des Rickensbleibtfrei - und reichen lateral bis nahe an das Ende des Ruders.

Die R ii ekene irren (Fig. $1 A r c)$ sind eylindriseh-flaschenförmig mit dinnem Ende. Auch sie sind vollkommen glatt und zeigen, bevor sie in das diune Ende ausgehen, einen dunklen breiten Pigmentfleck, der aber weniger intensir gefürbt ist als bei den Fïhlern und Fiilılercirren. Die Riuckencirren sind nahezu 2 mal so lang als die Segmente breit, iiberragen die Ruder fast um ein Drittel ihrer Läinge und stehen weit unter den Elytren ror.

Die kurzen $\mathrm{B}$ a u clıciren ( $\mathrm{Fi}_{c} .1 A b c$ ) entspringen ans einem niedrigen Wurzelgliede nicht ganz in der Mitte der unteren und hinteren Fläche des unteren Astes, sondern dem Körper näher. Etwas banchig an der Basis rerjuingen sie sich gegen die Spitze und bleiben ron dem Ende des Ruders so weit entfernt als ilıre eigene Länge betragt.

Das Aftersegment mit zwei dicht aneinander liegenden an der Basis kolbigen und dann sich allmälig verdiunnenden Endcirren, von der Länge der letzten 5 Segmente. Die Aftereirren sind kuirzer, aber etwas breiter als die Riickeneirren. Am schmalen vorletzten Segmente steht jederseits ein oberer und untere stumpfer Höcker - die Andentung des Ruders und Cirrus. 
Die Ruisselröhre reieht bis zum Anfange des 3. Segmentes. Mit dem 4 . begann der 0.09 breit gelbliehe Magen, an dessen Eingange 4 braune hakige Kiefer standen. Der Magen nahm das $4 ., 5 ., 6$. Segment ein. Hieranf folgte ein gleiehweiter nieht eingesehniirter Darmabsehnitt im 7., 8., 9., 10. Segmente, mod erst rom 11. traten die gewöhnlichen taschenförmigen Ansstiilpungen des Darmes auf.

2 Exemplare bei St. Servola. Auf Steinen.

\section{Polymoё reticulata.}

('la par ède, Annél. du golfe de Naples. Supplém. Mém. d. I. Société de Physique et d'Hist. nat. de Genève. Tome XX. see. partie 1870 p. 374, pl. 1, Fig. 1.

Diese Art traf ich in jugendlichen Exemplaren massenhaft zwischen Algen. Die grössten waren 4-6 Mm. lang und höehstens $2 \mathrm{Mm}$. breit. An den $6 \mathrm{Mm}$. langen Thieren waren bereits alle Segmente ansgebildet. Ausserdem fand ich dieselbe Art im Hafen von Triest in einem 12 Mm. langen und $5 \mathrm{Mm}$. breiten Exemplare. Die charakteristisehe Färbung der Elytren ist an den Jungen noeh nieht recht dentlich. Man begegnet iberhaupt verschiedenen Farbentönen von dem Grauliehen bis ins Branne. Clapa rèd e bildet ( $l c$ Taf. I, Fig. 1) den unpaaren Fiihler nur als Stumpf ab. Er ist vorhanden und fast $21 / 2$ mal so lang als die paarigen nud ragt weiter vor als die dorsalen Fühereirren, deren Gestalt und Aussehen er theilt. Die ans dem Wurzelgliede der Fühlereirren neben dem Kopflappen austretenden kurzen Borsten sind an ihrer convexen Seite gezähnt. Besonders ausgezeiehnet ist diese Art dureh die selır langen an Ende geknöpften Stäbehen, welehe Fïhler und Cirren besetzen.

\section{Polynoё crassipalpa n. sp}

(Taf. II, Fig. 1.)

Diese Form gehört in die Gruppe der langgestreekten Polynoën (Polynoë Sav. sequ. K in bergr \& M almgren; Lepidonotus Quutref.) Die Elytren sind klein, lassen die Mitte des Riiekens frei und fehlen vom 32. rudertragenden Segmente an. Die Exem- 
plare hatten bei einer Länge von 10, 16 nud 35 Mm., eine Breite von 2-3.5 Mm. Der Körper erscheint ziemlich gleichbreit; die grösste Breite ist in ersten Drittel. Von da versehmälert er sich ummerklich gegen das Ende, um erst mit den letzten Segmenten in eine stumpfe Spitze iiberzugehen. Der Riicken ist gewöll,t, obne warzenartige Hervorragungen. Die Wulbung fällt auf jedem Segmente in eine dreieckige, mit der spitze nach aussen gerichtete vertiefte Stelle ab, die den Riicken der Ruderbasis einnimmt. Die Banchfläche zeigt eine ticfe unl breite von 2 seitlichen Wiilsten begrenzte Längsfurehe (Fig. $1 \boldsymbol{A} f$ ). Die Grundfarbe des Körpers ist mit Ausnahme des röthlieh gefürbten Kopflappens, auf dem 4 Angen stehen, eine gelblich graue oder bräunliche nit einer dunkelbrannen Zeichnung über den ganzen Riicken und anf der ventralen Fläche der hinteren Körperhälfte. Die Zeichnung variirt etwas nach den Regionen und nach dem Alter der Thiere. Bei Lupenvergrösserung sieht man an den kleinen Exemplaren brame Querlinien am Anfange der Segmente und iiber die ganze Riickenfläche lauft eine unterbrochene, brame Längslinie, die gegen das Hinterende an Deutliehkeit verliert. Das Mikroskop lïst die Querlinien in etwas hinter dem Anfange der Segmente gelegene Doppellinien anf und unter diesen erseheinen 2-3 nиг die Nitte eimnelımende kurze brame Linien, welehe aber den Findruck einer Längslinie hervorrufen. Die Querlinien ziehen sich nieht auf die Ruderbasis hin, wohl aber liegen dort an der hinteren Segmentgrenze feine braune Linien reehts und links. In der hinteren Körperhälfte verliert die Zeichnung an Dentlichkeit, das Pigment nimmt ab, während das Querband noch an Breite gewinnt, die kurzen Querlinien versehwinden. Bei ailteren Individuen bemerkt man mit der Lupe iiber die Mitte der Segmente nahe dem Vorderrande ein brames Band, das sich lateral verschmïlert, schief abfällt und in der erwïhnten Vertiefung anf dem Riicken der Ruderbasis endet. Unterhalb liegt in der Mittellinie ein brauner Pigmentfleck, der mit obiger Binde verschmilzt. Ebenso findet man an dem Hinterrande der Segmente scitlich kurze braune Streifen. Unter dem Mikroskope erscheint dic Haut fein geringelt und die erwähnte Zeiehmung zerfällt in ein System von braunen Linien, die durch hellere Zwischenräume getrennt sind. Das Anffallende in der Färbung dieser Thiere 
auf der Bauchflä،he hegt in dem Auftreten einer charakteristisehen Zcichnung erst in der hinteren Körperhälfte. An den jiingeren Individuen bemerkt man auf jedem Segmente 4 braune Punkte oder Fleeken, zwei in der medialen Furche, jedoch so, dass die Mittellinie selbst frei bleibt und zwei an der änsseren Seite der lateralen Wiilste medial ron den papillenartigen Höcker an der Rutlerbasis. In weiterer Ausbildung werden die correspondirenden Flecken durch ein iiber die seitlichen Wiilste laufendes Querband in Verbindung gebraelit. Die Breite dieses all dem Hinterrande der Segmente gelegenen Bandes und die Grösse der Flecken ist inconstant. In einem Falle rerbanden sich auch die in der Furehe gelegenen Flecken miteinander; gewöhnlieh bleibt aber die Mittellinie pigmentlos. Das Pigment ist zumal in den Flecken viel dunkler und reieher entwickelt, die feine Ringlung der Haut noch zarter als auf dem Riicken.

Der Kopflappen (Fig. $1 k$ ) hat eine mnregelmässig hexagonale Form mit mässig abgerundeten Eeken und ausgeschnittenem Vorderrande. Er ist etwas gewölbt, von hinten nach vorne abschiissig, breiter als lang. Die grösste Breite liegt vor den hinteren Augen von einer seitlichen Ecke zur anderen. Der Vorderrand ist ein nach vorne offener fast rechter Winkel. Von der Spitze dieses Winkels setzen sich die stark glasigen Ränder eng aneinanderliegend noch weiter in der Mittellinie fort, so dass der Kopflappen bis nahe in die halbe Länge unvollkommen halbirt erscheint. Der Hinterrand ist fast geradelinig. Von den 4 sehwarzen Angen sind clie vorderen oral und stehen ziemlich nahe den Vorderecken, hart an den Seitenrand geriickt. Sie sind weiter von einander entfernt als die hinteren, kleineren kugligen, knapl vor dem Hinterrande aber etwas mehr nach innen liegenden. Liclitbrechende Körper tehlen.

Der Kopflappen tragt 3 Fiilıler und 2 Palpen. Der un pa a re F iilıler (us) ist 21/2 mal so lang als der Kopflappen und iiberragt alle iibrigen Anhänge. Er entspringt mit einem kurzen Wur\%clgliede nicht von der Unterseite des Kopflappens allein, sondern sich in den Aussehnitt des Vorderrandes hineinlegend gleichzeitig von der oberen Fläche, wo er sich mit nach hinten sehmïler werdender liasis in der Mittellinie festsetzt. Die zwei pa a rigen $\mathrm{F}$ ii hler $(p s)$ sind etwas kïrzer als der Kopflappen, 
also mehr als 21 a mal kitrzer als der unpaare Fithler. Sie sind anch kiirer als dic Palpen. Ihre Wurzelghlierler entspringen seitlich ron dem muparen Fithler anf der mnteren Fliche des Kopflappens, stossen in der Mitte zusammen und sind schief nach anssen gerielitet. Yon oben ist mur ein kurzes Stiick derselben siehtbar. Alle 3 Fihler sind flasehenformig in eine gleichbreite diime stumpfe Spitze ausgezogen, die paarigen melu ausgebaucht, der mpare ist mehr eylindrisch. Die Wurzelglieder und das Flasehenhals ähnliche Ende sind glatt, der breite An. theil ist von kurzen stumpfen Fortsiitzen (Stäbehen) staehlig.

Die zwei Palpen (p) erreichen nur die Hälfte des unparren Fiihlers, bleiben anch kiirmer als die dorsalen Fiihlereiren. Sie sind quer geringelt, sehr breit, fast cylindriseh, tragen in dem Centrum des nur unbedentend sehmächtigeren Endes eine kurze stumpfe glatte spitze und sind an ihrer ganzen Peripherie mit dicht gedrängten kurzen Fortsätzen, die eine melı wenger regelmässige radiale dnordnung in Längsieihen zeigen, besetzt. Dic Palpen kömnen sieh um ein Viertel ihrer Länge verkiirzen und dann tritt die Querfaltung sehr dentlieh zu Tage.

Der Körper dieser Thiere wal bei einer Länge ron 10, 16 und $35 \mathrm{Y}$ Mm. aus 56, 69 und 87 segmenten zusammengesetzt, von welchen mit Ausnalime des ersten und letzten Segmentes alle iibrigen Ruder tragen. Die Segmente sind beiläufig $6 \mathrm{mal}$ so breit als lang.

Das Buceal-seguent ist ron oben nicht sichtbar. Seine Anhänge, ein Paar Fiihlereirren jederseits, stehen zu Seiten des Kopflappens. De Wrurelglieder je eines Paares von Fiihlereirren sind urspriinglich nit einander verwachsen, trennen sich aber na chträglich. Das obere Wurgelglied reicht list an die vorderen Ecken des Kopflappens heran und birgt in sich einc Acienla. Yon den beiden Fiihlereirren ist der dorsale ( $d f$ ) länger als der ventrale $(v f)$, auch länger als die Palpen, aber kiurzer als der mittlere Fiilıler. Ilı Aussehen gleicht dem da. Riickencirren.

Die Ruder (Fig. $1 A$ ) sind gerade weggestreckt, mit Ausnahme der vordersten und hintersten länger als die Segmente breit, von vorne nach hinten zusammengedriickt, zweiästig. Der obere Ast (a) ist nur ein papillenartiger Fortsatz mit einer gelben 
Aricula im Imern. Der untere Ast spaltet sich an seinem Ende in zwei vertical gestellte sich deckende Lappen, zwischen welchen das mutere Borstenbiindel austritt. Der vordere ist derber, conisch, mit alogerundeter Spitze. Der untere geradlinige Rand fallt schief nach imnen ab. Unter der stumpfen Spitze ist eine zweite kleine Hervorragung bemerkbar, in welehe die untere grelbe Acicula eindringt. Der hintere Lappen ist diinn abgerundet höher als der vordere, im Übrigen deckt er diesen oder liberragt ihn auch, die Spitze ansgenommen, um ein Geringes. Anf der Ruickenseite der Ruder, aber etwas mach hinten geriickt, stehen die kurzen soliden Träger der Elytren oder die etwas längeren hohlen Träger der Riickeneirren, erstere der Mittellinie näher. Zwischen diesen Trägern und dem oberen Aste des Ruders liegt ein fï (cherartig ansgebreitetes Biindel ron 6 kurzen cinfachen Borsten (Fig. $1 B \alpha$ ), ron welchen eine meist länger ist. Sie sind säbelformig an ihrer oberen convexen Scite mit feinen Dornen besetzt. Die Spitze selbst ist glatt. Daneben finclet man immer eine sehr kurze mit sehr banchiger Klinge, deren comvexer Rand ebenfalls bewehrt oder nur wellig ausgerandet ist. Im nnteren Aste sind \&-15 einfache, selır weit hervorragende Borsten; nur in den letzten Rudern sinkt die Zahl auf 5. An den Borsten des unteren Astes kann man zwei Hanptarten unterscheiden. Die eine (Fig. $1 B \boldsymbol{B}$ ) hat Lanzenform, bald beide schmeidenden Seiten mit Dornen besetzt, bald nur die eine vollständig, die andere spärlich. Die zweite Art (Fig. 1 B $\gamma$ ) ist messerfömig mit etwas conearem aber stets glattem Rürken; sie enclet mit 2 Zähnen und hat auf der bauchigen schneidenden Fläche eine Reihe feiner Dörnchen stehen. Inmer ist die oberste Borste in einem liindel von reiner Lanzenform nnd meist breiter und stäker als die iibrigen, ebenso sind die untersten zweizälnnig mit glatten Riicken. Zwischen beiden Arten trifft man aber, das Gegentheil ist ganz ausnahmsweise, in einen mud demselben Ruder Übergangsformen (Fig. 1 b ウे). Diese sind leicht kenntlich, weil, weun sie anch die Gestalt der unteren Borsten angenommen haben, an Rïicken noch feine Dömchen auftreten und das Ende nie so dentlich zweizähnig ist. Das Verhältniss gestaltet sich beispielsweise folgendermassen: 


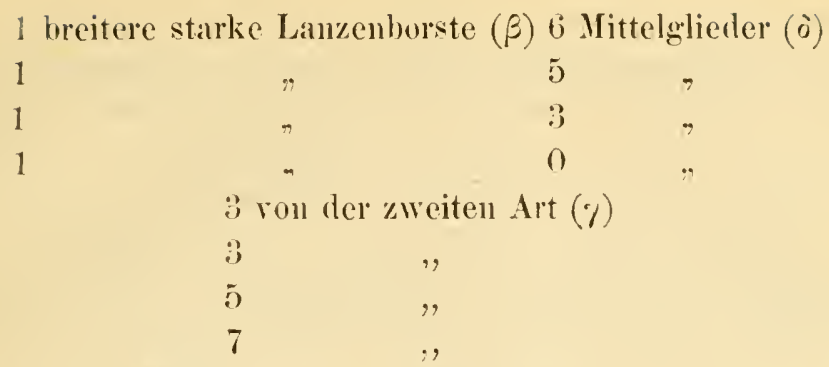

Yon den Mittelglierlem behalten aber eines oder zwei die reine Lanzenform bei, so dass man sagen kamm: In jedem Bündel sind 2-3 Borsten ron reiner Lanzenform mul unter diesen ist die oberste nicht nur stärker als die eine oder die beiden anderen, sonden meist als alle iibrigen Borsten des Biindels. In den 3 oder 4 ersten Rudern sind die nnteren Borsten abweichend gebildet. Ihr Ende ist stiirker gekriimmt nud nicht zweizähnigg, vielmehr in eine sehr feine Spitze ansgezogen. Die Borsten des unteren Ruclerastes haben meist einen stich ins Gelbliche.

Die Elytren (Fig. 1 C) sitzen de $m$ 2., 4., 5., 7., 9.... 23., 26., ‥, 32. segmente auf - im Ganzen 15 Paare. Sie sind bald muregehmässig kreisförmig, ball oral bei einem und demselben Individunm; immer aber ist an dem vorderen Rande der lateralen Hälfte eine schwache Ansbuchtmo bemerkbar. Der mediale Antheil ist in grösserer oder geringerer Ansilehumg. durch aufgelagertes bräunliches Pigment gefärbt; doch bleiben einzelne Stellen pigmentlos. Im Unkreise der rmullich oralen Anheftungsstelle ist ebenfalls ein grall-brämuliches Pigment bemerkbar, das jedoch nicht oberflächlich, sondern zwischen den beiden Platten der Elytren liegt. Sonst ist die Elytre röllig. durchsichtig und pigmentlos. Sowohl der Rand als anch die Fläche der lateralen Hälfte sind nit wenigen kurzen stumpfen Papillen besetzt. Ganz vereinzelt findet man dieselben anch anf der iibrigen Fläche. Die Elytren des ersten Paares sind die grössten, reichen lis an den vorderen Rand des Kopflappens und beriilıren sich fast in der Mittellinie. Die iibrigen decken sieh dachziegelförmig und lassen die ganze Mitte des Riickens frei.

Sie liegen nit ihrem grössten Durehmesser $(0 \cdot 08 \mathrm{Mm}$.) senkrecht anf die Liangsaxe des Körpers, sind demmach breiter als lang, lateral erreichen sie nicht das Ruderende. 
Die Riickencirren (Fig. $1 A r c$ ) ron der Gestalt der parrigen Fihler und Fiihlercirren, wie diese mit Stäbchen besetzt, sind 2-21, mal in der Breite der Segmentgrenzen enthalten. Sie variiren etwas in der Länge, iiberragen Ruder und Elytren, erstrecken sich jedoch nie bis an das Ende des Borstenbindels.

Der kurze Bauchoirrus (Fig. 1 A l c c) steht auf breitem Wurzelgliede ziemlich unter dem Riiekeneirrus, dem Ursprunge des Rnders näher als dessen Ende. Er ist coniseh, breit an der Basis und gleichfalls mit Stäbehen besetzt. Seine Lünge beträgt die Inälfte der Eutfernung seiner Basis von der Ruderspitze.

Medial ron dem Baucheirrus steht sehon dem eigentliehen Körper angehörend ein knrzer stumpfer papillenartiger Fortsatz (Fig. $1 A^{*}$ ).

Das A f tersegment (Fig. 1 J) ist so lange als das rorliergehende Segment, etwas abgerundet und tragt zwei von der L'nterseite entspringende Cirren ( 11 c), die fast so lange sind als die 4 letaten Segmente zusammengenommen.

Der Riissel erstreckt sieh ljis in das 6. Segment. Mit dem 7. beginnt der Hagen, dessen Eingang mit 18 schwarz pigmentirten Papellen besetzt ist. Lmmittelhar hinter diesen stehen 4 starke brame hakig gekriumnte, an ihrer Oberflïche camnellirte Kiefer (Fig. $1 \mathrm{E})$. Der 12 Segmente lange Hagen endet im 18. Breite $0.4 \mathrm{Mm}$.

Vorliegende Art wirde zur Gattung I'olynö̈ sav. mit der von Kinberg und Malmgren aufgefassten Umgrenzung gehören. Allein ein gewisser Zwang misste doch eintreten; denn Il a lm gren (Nordiska Hafs-Annulater. Ofvers. af. kongl. Tetensk. Akad. Förh. 1865. Stockh. 1866, pag. 82) fuihrt unter den Gattungs-Charakteren den Besitz einer einzigen Borste von Lanzenform und eines einzigen Analeirrus an, während die P. crassipulpa 2-3 derartige Borsten und 2 Analcirren besitzt. Nahe stelit ihl die unter dem Namen P. scolopendrina Sar. ron versehiedenen Autoren beschriebene Form. Num ist aber kein Zweifel, dass darmiter verschiedene Arten zu verstehen sind, wie schon Quatrefages 1 mit Recht hervorheht. Die $P$. scolopendrinu ron

1 Hist. nat. d. Annel. Paris 1865, T. I, pg. 261. 
Johnston' mul Malmgren² siml identisch, mag Ersterer immerhin ausdriicklich nu ein Paar Augen angeben und the Lanzenborsten glatt zeidhnen, aber ebenso verselieden ron der ron Savigny anfgestellten P. scolopendrinu. Savigny beschreibt den mpararen Fiihler als viel kiirzer wie die Palpen, und die Fiihlereiren als länger wie diese. Nach Johuston nurl If almgren ist der nuparre Fiihler länger als die Palpen, die Fiihlereirren hingegen sind kiirzer. Haben A ud o u in und Mil ne Edwards ${ }^{4}$ wirklich die P. scolopendrina sariguy's ror sich grehabt, damn ist aurlh ein L'utersehied in der Borstenform zu erkemnen. Die Borsten des oberen Astes sind bei John. und Y a $1 \mathrm{mg}$. grleich breit, an der Spitze abgerundet, bei A ur. und \. Edw. gegen die Spitze schmäler werdent. An den zweigezïlnten Borsten des muteren Astes ist der Lnterschied weniger anffallenl, wiewohl diese Borsten bei A ud. und M. Edw. gegen das Ende allmälig breiter werden und hier etwas gekrimunt erscheinen. Weder Savigny noch A ud. und II. Edw. erwähnen etwas ron den :3 warzenartigen Erhebungen auf dem Riicken der Segmente.

Ich halte daher eine Zerlegung der P. scolopendrinu unturum in zwei Arten für gerechtfertigt. Die eine ist die P. scolopendrinu ron Savigny, die andere muss einen nenen Namen bekommen. Ieh nemne sie P. Johnstoni.

\section{P. scolopendrinc Savigny.}

(Système des Amnél. pag. 25.)

Un parer Fiibler vielkiirzer als die Palpen. Die Fiihlercirren länger als die Palpen. Keine warzenartigen Hervorragungen auf dem Ríicken der Segmente.

P. scolopendrina S av., A u d. und M. Edw. 1. c.

P. variegata. G. K r. Amnulata Oerstediana Videnskabelige Meddelelser Aaret. 1856. Kjöbeuhavn 1856i-1857, pag. 49.

Ich habe zur P. scolopendrinu Sav, anch die I'. variegutu Grube ron Madeira gezogen, da sie einen unpaaren Stirnfuihler

1 Ann. of. nat. Hist. Vol. V 1840, pag. 307, pl. V et Catalog of the British Non Parasitie. Worms, London 1865, pag. 119, pl. XI, Fig. 1-9.

2. c. pag. 82, tab. X, Fig. 11 .

3 Systéme des Annèl. pag. 2\%.

4 Annal. de sciene. nat. I. Sér., 'T. 27,1832, pag. 428 , pl.VII, Fig. 17, 19. 
nur ron der Lüinge des Kopflappens, die Palpen kaum liunger als die Fiihlercirren, keine Riickenhocker lat und die iibrige Beschreibung mit jener von savigny im Einklange steht.

\section{P. Johnstoni n. sp.}

Unpaarer Fiilıler länger als die Palpen. Die Fiihlereirren kiir\%er als die Palpen. "3 warzenartige Hervorragungen auf dem Rücken der Segmente.

P. scolopendrina. Johns to ni l. c. 1840.

'S ars. Uddrag af en Afhandling om de red Norges Kyster forek. Art. af Annel. slaegt. Polynoë Forh. i. Vidensk. Selskab. i Christ atar 1860, ('hristiania 1861, py. 6 ?.

I. scolopendrina. Ma l m gre n l. e. 1865 .

Die P. crassipalpa n. sp. ist, ganz abgesehen von der eigenthiimlichen rentralen Färbung; die sich rollkommen im Alkohol erhält nnd jedem friiheren Beobachter hätte auffallen miissen. durch den Mangel der Riickenlocker, die tiefe Furche auf der Banchfläche, eine andere Gestaltung der Fiihler, Palpen und Fiihlercirren, endlich durch die Länge der Fiihlercirren auf dem ersten Blicke von P. Johnstoni zu trennen. Die Untersehiede zwischen $P$. crassipalpa und $P$. scolopendrina liegen, soweit sich solehe aus den Beschreibungen ron Sarigny und $A$ ud. et M. E dw. deduciren lassen, in der grossen Länge des unpaaren Fiihlers, in anders gestalteten Borsten und der charakteristischen Fïrbung der ersten Art.

\section{Acholoë astericola.}

(Nereis squıamosa, Polynoë astericola Delle ('hiaje.)

Cl a p a r èd e, Annél. chét. du golfe de Naples. Supplèm. Iém de la Société de Physique et d'Hist. nat. de Gen ve 'T. XX, sec. part. 1870, pag. 382, pl. H1, Fig. 1.

Polyıë malleata. Grube, Beschreib. neuer odor wenig bek. Annelirl. Archiv f. Na*urg. Bd. 21, 1855, par. 81, Taf. III, Fig. 1.

Grube selbst erklärte ${ }^{1}$ die in den Ambulacralfurehen von Astropecten lebende Polynoine, welche er 185i) als Polynö̈ malleuta beschrieben, fïr die Nereis squamosu Delle Chiaje. Clapa-

1 Mittheilg. ïber Anfenthaltsorie d. Annel, Ammtl. Ber. d. Königsberg. Naturf. Versammlg. 1860, pg. 85. (Separ. pg. 7.). 
r ì d e hebt diesen Umstand sowie die Synoymie mit der P'. mulleutu nicht herror. Auch M. Sars. 2 hat sie 1857 gesehen.

Ich fand diese interessante Amelide in Gesellschaft ron Ophiodromus flexuosus Dolle Chiuje sehr hänfig in den Ambularralfurchen von Astropecten auruntiacus, bispinosus, plutyacunthus und pentuctunthus bei Triest. Die Elytren sind hald vollkommen farblos, bald unr mit distalem schwärzlichem samme, haben also weniger Pigment eingelagert als die neapolitanischen Individuen.

\section{Sthenelais fuliginosa.}

(Taf. 1, Fig. ‥)

Claparéde, Annèl du golfe de Naples, a. a. O. Bd. XIX. 1868, pag.414, Pl. IV, Fig. ?.

Die Form, welche ich hieher ziehe, zeigt in derFärbung der Elytren und in dem Ban der Ruder einige Abweichung von der Cla p a rè d'schen Beschreilung. Fïr die Aufstellung einer eigenen Art wiirde ich mich aber erst dann entscheiden, wenn ich mit Hilfe eines reicheren Materiales ans der Adria - mir standen nur 2 Exemplare von $4 \mathrm{Cm}$. Länge und $4 \mathrm{Mm}$. Breite zur Verfïgung - und von Original-Exemplaren aus Neapel die Beständigkeit dieser Art oder die unbestreitbare Richtigkeit der Diagnose und Zeichnnng Claparède's zweifellos nachweisen könnte.

Die Elytren (Fig. 2 A) zeigen die Gestalt. Welche Clap. (l. c. Fig. 2 II) wiedergibt, ebenso fehlen die Tuberkel ant der ganzen Fläche und die Randpapillen nicht; die Anflagerung des Pigmentes ist aber eine andere. Während Claparèdle eine längst des äusseren und hinteren kandes lanfende medial sich verschmälernde schwarze Binde und in einiger Entfernung des innern Winkels derElytren einen dunklen Fleck zeichnet, bedeeken bei der vorliegenden Form dicke russartige Massen in verschiedener Mächtigkeit die freien Flächen. So erscheint die Oberfläche des von dicht gedrängten Elytren bedeckten Körpers vollkomuen sehwarz, rauh, gekörnt. Nur an dem einen der beiden Exemplare war das letzte lintere Viertel des Leibes mit schwach schwarz gesprenkelten Elytren besetzt. Aber anch diesen fehlte die eigenthünliche oben erwähnte Zeichmmng. Die

2 Bidrag til Kundsk. ow Middelhav. Littoral-Fauna Christiania 1857 , pg. 104 . 
Rutler (Fig. 2) sind etwas abweichend ron claparède's Angaben und Zeichnmmg (l. ( . Fig. 2 A) gebant, aber man wird die grösste Ähnlichkeit zugeben. Ebenso ist zu enrägen, dass die Ruler hei der Gattung Stheneluis uach den Arter sehr verschieden sind, so dass, 1 m zu einer Arten-Trennmug berechtigt z.n werlen, ganz andere Gegensiitze nöthig sind. Die Kieme ( b v) steht nicht in der Ebene des Ruders, sondern iiber demselben. Auf dem dorsalen Rande des Ruders finden sirls niclut 2 , soudem 3 Flimmerkissen (f). Es liegt nimlich gerade in dem Winkel, den das Ruder mit dem Körperande macht, ein drittes selief "uach rorne gestelltes. Von den 2 anderen lateralen ist das iunsserste kleiner als lats medial gelegene, also ungekelırt wie in Claparède's Zeichnung. Die Elytre (e) bedeckt die Kieme ron oben mul reicht wohl bis iiher das änssere Flimmerkissen, nicht aber iiber das obere Borstenliindel, kam also von demselben nicht, wie r'lap. angibt, emporgehoben werken.

Der untere Ast des Ruders ist zwar lïnger als der obere, aber bei Weitem nirht in dem Masse wie in Clap. Zeichlnung. Der obere Ast besteht ans einem hinteren, lingeren, mentbranartigen, und einem vorleren rompaten Lappen. Ich fand nicht allein an diesem letzteren Papillen, sondem anch an dem hinteren, und zwar 4 an rorteren und :3 oder 4 lingere an den hinteren Lappen. Zwischen diesen beiden Lappen entspringt die Hauptmasse der Borsten des oberen Biindels, nur eine geringe Zahl gleirhbesehatfener aber riel feinerer Borsten von der hinteren Fläche des hinteren Lappens. Der untere Ast besitzt einen mehr uinder conischen Mitteltheil $(m)$, der ror seinem Ende eine stumpfe Papille trägt. Er wird rom 3 dimmen Lappen unfasst, einem vorderen und 2 hinteren. Der rordere $(v)$ ist an seinem (omvexen äusseren Rande ausgezackt (10-11 Zähne) und geht nach oben nicht iber die Acirula; ron den beiden hinteren iiberragt der obere den Mitteltheil und steht so als stumpfer Fortsatz anch ron rorne sichtbar ror. Der untere rerschmilat mit lem vorigen in der Mitte ler hinteren Fläche des Ruders und krimmmt sieh

Die Borsten des Rinders stimmen rollkommen mit jenen der St. fuliginusa ron Neapel. Die des oberen Biindels sind ron 
ähnlich russartigen Auflagerungen wie auf den Elytren hie und da gesprenkelt.

Der Kopflappen und das erste Ruderpaar wurden von $\mathrm{Cl}$ a p arè de nicht speciell geschildert, weil sic eben bis anf die Lage der Angen nicht besonders charakteristisch sind. Übereinstimmend liegen anch bei meinen Exemplaren die 4 Angen nahe dem Vorderrande des Kopflappens, hart an der Basis der schuppenartigen, winklig nach aussen gebogenen paarigen Fïhler, beide Augenpaare dicht aneinander gedlängt. Erwähnen will ich noch, dass Palpen zuriickgelegt fast das 7. Ruderpaar erreichen und an die ihrem Ursprunge mit einer Scheide versehen sind.

Ich fand meine 2 Exemplare an sandigen, steinigen, während der Ebbe entblössten Stellen der Südostkiiste der Bai von Ing gia.

\section{Eulalia (Eumida) prollida.}

Claparède, Anilél. dı golfe de Naples, a. a. 0. Tome XlX, 1868, pag. 556, pl. XVl, fig. 6.

Ein kleines Exemplar von 8 Mm. Länge mit 35 Segmenten. Der Riissel war nicht in eine Schlinge gelegt, sondern nur sanft grebogen. Er reichte bis zum 14. Segment. Hier stand am Mageneingang ein Kranz von circa 22 Papillen. Der Magen endete mit dem 21. Segmente, war somit 8 Segmente lang. Der auf ihn folgende Darmabschnitt stieg als ein diunnes, ein Viertel der Magenbreite betragendes Rohr nach abwärts bis in das 24. Segment, bog dann tm und ging breiter werdend bis in den Hinterrand des 20. Segmentes zuriick, wo er wieder umbiegend nach hinten zog. Mit dem 24. Segmente traten die ersten Darmtaschen auf. Die Doppelschlinge nahm also das 21, 22., 23. Segment ein und reichte zum Theil mit einer Krimmumg in das 20. und 24. Im Übrigen stimmte alles zu Claparède's Beschreibung.

Nordkiiste der Bai von Muggia mit Algen. 


\section{Eulatia viren.}

Ehlers, Die Borstenwiirmer. Leipzig 1s6t-6s, pag. 159, Tat. VII, Fig. 1-5.

Ist mit der folgenden sehr häufig. Sie erreicht eine Länge von 23. Mm. mit 134 Segmenten. Das Basalstiick des rentralen Cirrus des 2. Segmentes schliesst eine oder zwei Aciculen ein.

\section{Eutalia (Pterocirrus) macroceros.}

Phyllodoce (Eulalia) macroceros. Grube, Beschreib. nener oder wenig bekannter Annel. Archiv f. Naturgesch. Bl. XXVI, 1860, pag. 82, Tab. 3, Fig. 4. Ansflug nach Triest. Berlin 1861, pag. 141, Taf. III, Fig. $t$.

Eulatin volucris. Ehlers, Die Borstenwiirmer, pag. 165, Taf. VII, Fig. $6-10$.

Ehlers entuahm die Unterschiede seiner Eululin rolucris ron der Phyllod. (Eululia) macroceros Grube, den oben citirten Figuren Grube's, die nach Weingeist - Exemplaren gemacht wurden. Die andere Gestalt des Kopflappens, der Angen, der Riicken- und Banchcirren bestimmten ihn zur Aufstellung einer nenen Art. Hiezu kam noch die von Grube im Texte angegebene in der Zeichnung nicht ersichtliche Zweitheilung der Segmente. ( "segmentis linea transversu subdirisis"). Allem dem muisste man nach Vergleich der beiderseitigen Figmren noch die viel grössere Länge der Fiihler - sie sind $1^{1}{ }_{2}$ mal so lang als der Koptlappen - bei E. mucroceros beifiigen.

Vergleichende Tutersuchungen an zahlreichen lebenden sowie in Glyeerin oder Alkohol conservirten Exemplaren haben mich belehrt, dass alle oben angefiilıten nuterseheidenden Merkmale der E. macroceros anf Rechumg der Conservirungs-Fliissigkeit kommen. Der Kopflappen ist contraetil und sehrumpft auch an den unter dem Deckgglase getödteten und in Glycerin-Chromsäure eingeschlossenen Thieren, wenn anch in geringerem Grade, als an jenen, die im Weingeiste abstarben. So werden die Fiiller $11 / 2$ mal länger als der Kopflappen. Die Riicken- und Banchcirren sind ron Grube in hall, schiefer Lage gezeichnet. Ich habe sie an Weingeist-Exemplaren sellst so gesehen, wie sie 
Grube Fig. 4 " darstellt, während sie mir im Leben die ron Ehler's wiedergegebene Gestalt zeigen. Die Angen werden nach dem Tude in Folge Diffusion des Pigmentes grösser; nierenförmig sah ich sie nie. In Betreff der Zweitheilung der Segmente heschränken sich meine Benbachtungen nur anf die conservirten Exemplare. An diesen siehtman, wieder andeutlichsten an eontrahirten Weingeist-Exemplaren, eine zarte pigmentlose Querlinie oder Furche die Segmente in eine kiirzere vordere und eine längere hintere Hälfte theilen. Diese Qnerlinie zeigt den durehscheinenden Glanz der Beriihrungslinie der Segmente. Manchmal bauchten sich diese Linien nach hinten aus. Der daranf folgende Theil des Segmentes ist ron vorne nach hinten gewölbter als der ror ihm liegende. Schon an den in Glycerin conservirten Exemplaren ist die Furchung der Segmente weniger deutlich; an den lebenden ist sie mir mol Ehlers entgangen. Die E. rolucris wird also dem Gesagten zu Folge der älteren E. macroceros Grube weichen miissen.

Als Ergänzung zur genanen Beschreibung, die Elrlers gegeben, fitge ich noch Folgendes hinzu: Die linearen Angenflecken hinter den rundlichen Angen sind, wie Elıle rs rermuthete, nicht constant. Das brame Yigment des Körpers concentrirt sich öfter in der ersten Hälfte der Banchfläche an der Ursprungsstelle der Ruder zu kleinen Flecken. Wimperbiischel stehen nicht nur an der Seite der Segmente in den Zwischenräumen zweier Ruder, sondern anch mehr dorsal an der Basis des Riickencirrus. Das Basalstiick des rentralen Cirrus des 2. Segmentes birgt in sich eine Acicula. In einzelnen Fällen, beikleinen Individuen, sind die hiickeneirren etwas kiirzer als sie Ehlers angibt. Das Gleiche gilt ron dem dorsalen Fiihlereirns des 2. Segmentes. Die Lage der Riisselröhre und des Magrens fand ich bei einem Exemplare von 50 Segmenten und 8 Hn. Länge etwas abweichend. Die Riissehröhre war ǧerade, nicht in Windungen ge. legt. Sie reichte bis zum 13. Segment, wo der Magen mit seiner charakteristischen Gestalt und den starken Längstalten begann. Dieser nahm wie gewöhnlich die 4 folgenden Segmente ein. Exemplare ron 8 Mm. Länge waren geschlechtsreif. Die dunkelblangriinen Eier erfüllten den ganzen Leib rom 5. Segmente an und nur die letzten 7 Segmente blieben frei. 
E. mucroceros wiirde nach der blattförmigen Gestalt des rentralen Cirrus des 2. Segmentes in der Untergattung Pterocirrus Clap. zil stehen kommen.

Sehr häufig unter den Nulliporen und Bryozoën.Überziigen grösserer Algenstämme.

\section{Carobia hugens.}

Phyllodoce lugens. Ehle rs , Die Borstenwïrmer, 1864, pag. 145, Taf. VI, Fig. 15-21.

Carobia lugens. Qu a tre f., Hist. nat. des Annél. T. II, pag. 145 (1865).

Diese ron Ehlers bei Martinsica (Adria) entdeckte kleine Annelide gehört zu den gewöhnliclisten Erscheinungen auf den Algengründen der Bucht von Muggia. Qu a tre fages erhob (l. c.) die Phyllodoce lugens Ehlers zu einer eigenen Gattung Curobir ohme aber zur Charakteristik andere Merkmale der genauen Beschreibung von Ehlers zu entnehmen als das Vorkommen von 6 Fiihlercirren (Tentakel Quatref.) anf dem ersten Segmente. In demsellsen Jahre errichtete ebenfalls nur auf den Befund von 6 Fiihlereirren auf dem ersten Segmente Malmgren für eime Phyllodocide aus Spitzbergen die nene Gattung Anaïtis. In diese Gattung reilite C la p a r è de (Annél. du golfe de Naples) 1868 und 1870 vier nene Phyllodociden aus Neapel ein, modificirte aber den Gattungsbegriff von M almogen derart, dass man wohl belaupten kann, es sei eben nur der Name geblieben. Es ist stets misslich und die Gefahr einer Verwirrung mit sich bringend, einen ron einem anderen Autor aufgestellten diurftigen Gattungscharakter ohne Priffung der Originalexemplare, welehe der urspriinglichen Beschreibung zu Grunde liegen, blos nach Beobachtung scheinbar ähnlicher Formen von ganz anderen Localitäten zn erweitern. In vorliegendem Falle hätte Claparède, dem Rechte der Priorität überdies folgend, fuir seine Arten den Gattungsnamen Carobin acceptiren und diese und nicht die Anuitis erwei. tern missen, weil sich in der ausfiihrlichen Beschreibung der I'h. lugens, welche der Gattung C'arobiu, wie erwähnt, zu Grunde liegt, die Hanptmerkmale wiederfinden, die Clap. bei seinen Anaït is hervorgehoben. Ieh ziehe also die Anaïtis cephalotes $\mathrm{Cl}$ a p,, lineatu Cla p., peremptoriu Cla p. und pusilla Cla p. zur Gattung Carobin und versuche in Rüicksicht daranf den Gattungscharakter "Carolia" folgendermassen festzustellen : 


\section{Carobia ${ }^{1}$ Q uat tref.}

Erstes und zweites Segment meist zu einem, 3 Paar Fiihlercirren ind ein Borstenbiindel tragenden scheinbar ersten Segmente rerschmolzen. Das näehstfolgende eigentlich dritte Segment jederseits mit einem Fiihlercirrus, einem blattartigen Bancheirrus und cinem mehr oder weniger ausgebildeten Ruder. Riiekeneirreu blattartig.

Von der Gattung Phyllodoce unterscheidet sich demmach Carobia dureh die Vertheilung der vier Pare Fïhlercirren auf 3 und nicht 2 Segmente. (Cla p. nimmt an, dass 2 Paare auf dem 1., je ein Paar auf' dem 2. und 3. Segmente stehen.) Wo das erste nnd zweite Segment versehmelzen, liefert das Borstenbiindel an diesem scheinbar ersten und einfachen Segmente das Kriterium; denn bei Phyllodoce und allen anderen in diese Gruppe gehörigen Formen treten die Borsten immer erst an dem 2. Segmente auf.

Die Gattung Ancït is Malngre 11 mag vorläufig neben $C_{n-}$ robia stehen bleiben.

Die Dimensionen der Carobia lugens sind bedeutender als sie Ehlers angibt. Ich fand unyollständige Exemplare von $10 \mathrm{Mm}$. nit 57 Segmenten. Als Ergänzung der Färbung habe ich zu erwähnen, dass man bei Untersuchung mit der Lupe in der Nittellinie zwei schwärzliehe Längslinien erbliekt, zwischen welehen ebenfalls bräunliches Pigment abgelagert ist. In den Seitentheilen der Segmente befinden sich Anhäufungen braunen Pigmentes, die durch ein ïberdie Breite der Segmente lanfendes band rerbunden werden, so dass mit den Längslinien eine kreuzartige Zeichnung auf dem Riieken der.Segmente zu stande kommt. Der Kopflappen ist nicht so sehr oval, als viehmehr abgerundet sechscekig. Die grösste Breite befindet sich in der Höhe der Augen (Mitte der hinteren Hälfte des Kopflappens). Von hier läuft der Seitenrand sanft ausgebogen nach vorne. Der abgerundete Vorderrand ist schmaler als der Hinterrand und trägt die 4 Fühler, von welchen aber stets die oberen etwas lïnger waren als die unteren, nicht

' Die Carobia patagonica $\mathrm{Kin}$ berg, Amnulata nova, Öfvers af Kongl Vetensk. Akarl. Forhandling. 1865, Stockholm 1866, pag. 242, gehört jeden+ falls einer anderen Gattung an 
umgekehrt, wie Ehlers g'esehen. Zu beiden Seiten des Kopflappens, an der Grenze desselben mit dem ersten Segmente, bemerkte ich die kleinen Höcker, die anch bei anderen Phyllorlociden vorkommen. Die Gestalt der Fiihlercirren entspricht der Beschreibung und Zeichnung ron Ehlers, bis auf das Paar grösserer dorsal gelegenen Fiihlercirren. Ich fand diese am lebenden Thiere stets flaschenförmig, anfangs ziemlich gleichbreit, in dem letzten Fiunftel in den engen Hals iibergehend. Die Riickencirren mit ausgezacktem Rande (E hle rs, Taf. VI, Fig. 18 /) salı ich nie. Die Aftercirren waren blattförmig, fast zweimal so lang als breit, nicht allmälig sich verjingend, sondern erst vordem Ende in eine kurze stumpfe Spitze ausgezogen. Zwischen diesen beiden grossen Cirren steht am hinteren Rande des Analsegmentes ein kleiner cylindrischer stumpfer Fortsatz.

\section{Podare agilis.}

Ehlers, Die Borstenwürmer, pag. 197, 'Taf. VIII, Fig. 9-11.

Hania agilis. Q 1 a trefa ges, Hist. nat, des Annél. T. II, pag. 104.

Ehlers fuihrte bei dieser Art nur einen Fiihlercirrus jederseits am 3. Segmente an und Qu atrefages errichtete daraufhin die Gattung Mania. Wie ich an zahlreichen Exemplaren beobachten komnte, besitzt auch sie 2 Fiillercirren jederseits am 3 . Segmente. Die Gattung II nniu entfällt somit. Offenbar hatte Ehlers ein verstiimmeltes Exemplar vor sich. Ich selbst fand ganz intacte Individuen relativ nicht häufig und hielt ich diese in kleinen Glasgefässen, so erlitten sie in kurzer Zeit den Verlust eines oder des anderen Anhanges. Bis auf das Aftersegment stimmten im Übrigen meine Exemplare rollkommen mit der Beschreibung ron Ehlers. Dieses hatte 2 anffallend lange schlanke Cirren an der Endfläche, zeigte mir aber nie die 2 seitlichen Cirren jederseits; ein mehr oder minder ausgebildetes Ruder mit Borsten, Riicken-mul Bauchcirrus muss wohl als dem vorhergehenden Segmente angehörend aufgefasst werden. Manchmal war dieses Ruder auf einen liuren Stumpe mit Borsten reducirt ohne Cirren, oder es fehlte bei rollkommener Ausbildung doch der Bauchcirrus. 


\section{Ophiodromus flexuosus.}

Nereis flexuosu. Delle Chiaje, Mem. sulla storia e notom. degli anim, senza vert. Napoli 1823-29. Vol. II, pay. 368,400 et 425 , tab. X1X, fig. 8 .

Oxymlromus fasciulus. Grube, Beschreib. neuer oder wenig bek. Annel Arehiv f. Naturgeseh. Bd. XXI, 1855, pag. 98, Taf. IV, Fig. 1, 2.

Stephania flexuosu. Clapar ède, Aunèl. ehét. du golfe de Naples. Supplément Mém. I. l. Sociét. de Pliys, et d'Hist. nat. de Genève, Tome XX, 1870, pag. 482, Pl. XII, Fig. 1.

? Ophiodromus vitutus. S a r s, Forhandl. i Videnskab.-Selskab. i Clıristiania, Aar 1861. Christiania 1862, pag. 87.

Die ron Cla pa r è d 1870 rehabilitirte Nereis flexuos D e ll e Chiaje fand ich bei Triest mit Acholoë ustericola in den Ambulaeralfurehen nicht des Astropecten aurantiacus allein, sondern anch der anderen dort vorkommenden Arten dieser Gattung (A. bispinosus, platyacanthus, penturonthus) ziemlich häufig. Meine Exemplare erreichten nicht die von ( l a p. angegebene Länge ron 38 Mm. mit ō 5 Segmenten. Die grössten waren $23 \mathrm{Mm}$., hatten aber nichtsdestoweniger 55 Segmente, andere bei ciner Länge von 15 Mm. 38 Segmente. Die Lage der weissen Querbinden ist ganz inconstant. Am häufigsten traf ich sie an 9., 13., 18., 26. Segmente. Der Kopflappen war mehr trapezförmig, mit abgerundeten Ecken, aber geraden Seiten, die Palpen zeigten mir für gewöhnlich nicht das anffallende Missrerhältniss zwischen Basalund Enrlglierle. Letzteres war immer länger als der Träger und nicht so zart wie inder Zeichmung Cl a parè de's ersichtlich. Nur bei starker Compression oder bei Extraversion des Riissels mahm der Kopflappen eine quer orale Gestalt an und die Palpen erschienen in ilurem basalen Antheile breiter, wiahrend das Endglied sich verkiiryte. Das Buccalsegment ist rou oben nicht sichtbar, so dass das auf den Kopflappen folgende Segment 4 Paar Fühlercirren zu tragen scheint. Erst bei einer Untersuchung von der Banchfliche werden die thatsächlichen Verhältnisse klar. Das Bnecalsegment sowie die beiden folgenden tragen jedes ein Paar Fiihlereirren jederseits. Die Cirren sind nicht glatt, sondem zeigen Andentungen einer Gliederung. Die zweiästigen Ruder bieten nichts besonders Auffallendes, es sei demn, dass die zungenförmigen Fortsätze beider Äste kiirzer waren als in Cla p arède's 
Zeichnung und dass die Aciculen meiner Exemplare selbst bei sehr starker Vergrössermug nur Spuren einer Granulirung zeigten.

Es besteht kein Zweifel, dass diese Art nach Delle Chiaje von Grube nen beschrieben wurle unter dem Namen Oxydromus fusciutus. In der Charakteristik der neuen Gattung Oxydromus und der betreffenden Species ist die Angabe irrthimlieh, dass die Ruder einästig sind, und in der Zeichnung (Taf. IV, Fig. 1) sieht man nur ein Paar Fühlercirren jederseits am sogenannten Bucealsegment, wälıend im Texte steht „utrinquequatuor" Den unteren Fiiller fasst Grube nicht als Palpen auf. Grube fand die ersten Exemplare in Schlamm bei Triest und Villafranca, später ebenfalls in den Ambulacralfurchen ron Astropecten aurantiucus (Insel Lussin 1864, pag. 82). Die Gattung Ophiodromus, welche Sars 1862 für eine nordische Art ans dem Grunde errichtete, weil die Ruder zweiäistig waren, bei Oxydromus aber einästig angegeben wurden, fällt also vollkommen mit Oxydromus iiberein. Ja die Beschreibung des Opliodromus vittutus S a r s macht die Identität dieser Art mit dem Oxydromus fusciutus $\mathrm{G} r u b \mathrm{e}=$ Nereisflexuosu Delle Chiaje sehr wahrscheinlich. Man miisste also die Gattung O.xyılromus Grube's mit der kleinen Änderung in Bezug auf Ruder und Palpen richtigstellen und die Gattung Ophiodiomus streichen, wie dies in allen Fällen mit der Gattung Stephoniu Clap. zu gesehehen hat; dem Claparède hat sowohl den Oxydromus Grube als den Ophiodromus S a rs iibersehen. Allein da Grube ${ }^{1}$ selbst seine Gattung O.xydromus durch Einfiigung zweier Arten von wesentlich verschiedenem Ban (jederseits ein Paar Fïhlercirren an den 4 ersten Segmenten, zweiästige Ruder) modifieirte und Ehlers dureh den Widerspruch in Texte und in der Zeichnung des Oxyd. fusciatus unsicher gemacht in seiner Zusammenstellung der Gattungen der Fanilie der Hesioniden ${ }^{2}$ die Charaktere der ron Grube nacliträglich eingeschobenen Arten als Gattungseharakter von Oxydromus annahm, so will ich, um die Verwirrung nieht zu steigern, den Namen Oxydromus fuir die Nereis flex'nosu fallen lassen und die mit einer rollkommen

I Grnbe, Annulata. Oerstediana Virlenskabelige Meddelelser for Aaret 1857, Kjönbenhaven pag. 172.

${ }^{2}$ E h l e r s, die Borstenwiimer, 1564, pag. 187. 
pricisen Diagnose versehene Gattung Ophiudromus Si a r's annehmen. Die beiden amerikanischen Formen O.rydromus flaccidus Gr. Oersd. und Orydromus longisetis Gr. Oersal, mögen ilure Namen weiterfiilnen.

Oxydromus pullidus Claparède, Glanures zooton. parmi les Amnél. de Port Vendres, Mém. de la Sociét. de Plıys. et d'Hist. uat. de Genève B. XVII, 1S6t, pag. 521, pl. IV, Fig. 1, ist eine Podarke.

\section{Paedopleylax clariger.}

Cla p a rè de.Annél. du golfe de Naples (IIém. d. Li Sociẻt. de Phys. et d'Hist. nat. de Genéve Tome XIX 1868) pag. 521, pl. XIII, Fig. 2.

Das einzige Exemplar war ein W eibehen, zihlte 24. Segmente und hatte eine Länge von 21/2 $\mathrm{Mm}$.

\section{Sphaerosyllis hystrix.}

(l aparède, Beobachtungen ïber Anatom. und Entwieklungsgeseh. wirbelloser Thiere. Leipzig 1863, pag. 45, Taf. XIII, Fig. 36, 37; Glannres zootom. parmi les Annél. Mém. de la Socièt. de Phys. et d'Hist. nat. de Genère Tome XVII 1864, pag. 546, Pl. VI, Fig. 1.

Individuen ron $1 \frac{1}{2}-5$ Mm. Länge bei einer Zahl ron 23-37 Segmenten. Der Drisenmagen lag bei den kleineren Thieren im 5. и. 6., bei den andern im 6. и. 7. Segmente.

\section{Grubea pusilla.}

Claparède, Glanures zootom. parmi les Annél. a. a. 0. pag. 549 pl. VI, Fig. 3. (Sphaerosyllis pusilla.)

Ich fuihre als Ergïinzung zu Claparède's Beschreibungo den Befund an einem bei Zanle erbenteten Exemplare an.

Es war 2 Mm. lang und hatte 28 segmente. Der Körper war farblos durchsichtig; der Darm mit gelblich-granlichen Massen erfiillt. In der Leibeshöhle röthliche Eier. Die etwas bräunliche Schlundröhre hatte im hinteren Drittel ein pigmentloses Querband, war 3 Segmente lang und nahm die hintere Hälfte des 2., das 3., 4., und einen Theil des 5. Segmentes ein. Der Eingang in dieselbe war mit einem glänzenden aus melreren Stiicken zusammengesetzten Chitinringe verselıen. Die 
Bewaffnnng bestand ans einem Zahue. Der röthliche Driisenmagen begam in der zweiten Hälfte des 5 . Segmentes mud reichte bis in das 7.; hatte somit die Lïinge von 2 Segmenten. Man konnte 10 dentliche Reihen von Driisen erkenuen. Kurz hinter dem Driisemmagen machte der Darm 2 seitliche taschenförmige Ausbuchtungen, die nach rorue gerichtet sind. Die Ruder haben meist 6 zusammengesetzte Borsten, deren messerförmiges Endstick eine einfache leicht gekriimmte Spitze besitzt. 1, 2 oder 3 sind stets länger als die iibrigen, was nicht nur anf Rechnung eines längeren Stabes, sondern anch eines doppelt so langen, wenn anch schmäleren Endstickes zu setzen ist. Die charakteristischen, am Ende und an der Basis gleichbreiten fast Parallelopipede darstellenden Riickencirren enthielten die von Clapar è $d$ e beschriebenen zwei spindelförmigen Körper von ${ }^{2} / 3$ Länge les gan längeren Cirren einen einfachen papillenartigen nicht gegalselten mittleren.

\section{Gruber dolichoporda n. sp.}

Taf. 4 , Fig. 1.

Ein einziges eiertragendes Weibchen lag vor. Der Körper 2 .Im. lang, mit den Rndern fast $0 \cdot 3 \mathrm{Mm}$. breit, ans 28 Segmenten zusammengesetzt, farblos, nur auf der Riickenfläche in den hinteren Ecken aller Segmente mit Ansnahme der 4 letzteu braune Pigmentflecken, die durch ein zartes Querband von gleicher Farbe rerbunden werden.

Der Kopflappen (Fig. 1 k) zweimal so breit als lang, zien!ich halboval mit geradem Hinterrande.

Die Palpen (p) sind unbedentend länger als der Kopflappen. Thre dorsalen Flichen verwachsen mit einander mul nur eine mediane Linie zeigt die Beriilırungsstelle an, wählrend die ventralen Flächen getrennt bleiben mol nach hinten divergirend bis unter das vordereAngenpa r reichen. Der-Vorderrand der coalescirten Palpen ist seicht ansgeschnitten. Die 2 grösseren vorderen A ngen mit nach vorue und anssen gerichteten lichtbrechenden Körpern liegen beiläufig in der halben Höhe des Kopflappens unweit ron dem Seitenrande, die 2 linteren kleineren mit nach 
hinten und aussen gerichteten lichtbrennenten Körpern in einer Hïhe mit dem Ursprunge des muparen Stirnfiihlers, nacl imen und unten rlervorleren Angen. Ansserdem 2 kleine Angenflecke dicht an Vorderrande des Kopflappens an dem medialen Rande der parigen Stirnfiilıler.

Stirnfiihler und Cirren sind nugegliedert, fast giatt. Der

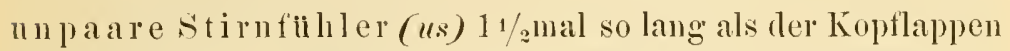
und die Palpen zusammen, aber kiirzer als die Riickencirren des zweiten Segmentes, in der hinteren Hälfte schwaehkolbig, ،lann in ein feines abgermudetes Endle ansgezogen. Die p a a r i ge n (ps) etwas liinger als cler halbe mupare, gerlungener.

Das Buccalsegment (b) ist von oben vollkommen sielitbar, etwas länger als das zweite Segment. Es ist elvenso breit als der Hinterrand des Kopflappens und trägt zwei Paar F ii hl le rc ir ren. Der Dorsale (df') etwas länger als die seitlichen Stirnfiihler, aber kiirzer als der nittlere, iibrigens von der Gestalt dieses. Der ventrale (vf) Fihlercirus kaum halb solang als der dorsale mit kurzer, schlanker Spitze.

Die Segmente erreichen an Ende des ersten Viertels (7. Segment) die grösste Breite $(0.18 \mathrm{Mm}$.). Hier sind sie viermal so breit als lang $(0.045$ Mm.) Hinter ier Mitte des Körpers (18 Segm.) schon werden die Segmente schmäler (0.138 Mm.), aber höher (0.06 $\mathrm{Mm}$.), so class sie mur cirea $2 \mathrm{mal}$ so breit als lang sind. Da aber an dieser Stelle die Ruder fast doppelt so lang sind als vorne, so erscheint der Körper an sich ziemlich gleichbreit und nu' ganz g'eg'en das Ende versehmälert. In dem rorleren Drittel des Leibes springen die Räinder rler segmente weniger vor, als dies weiter nach riickwärts der Fall ist, wo sie sich zu dentlichen 'Träg'ern der Cirren entwickeln.

Die Ruder (Fig. 1, A) sind rom 9. Segmente an sehr lang. Während sie noch am 7. Segmente nur 0.048 Mm. lang sind, werden sie schon am nemnten 0.081 Mn. nud weiter 0.093 Mm. also doppelt so lang. Vorne $-3 / 2$ mal kiirzer als das Segment, sind sie nach ribkwärts fast so lang als die Segmentgrenze. An jerlem Ruder lassen sich deutlich :3 Lippen muterscheiden. Die hintere (hl) ist die längste nnd geht in einen mach riickwärts gekrimmten, stumpfen: papillenartigen Fortsatz ans; 
damn folgen in der Länge die mittlere $(\mathrm{ml})$ und endlich die vordere ( $(v)$, beide mit kurzen Knöpfehen endend.

Die R i ck en eirre n (re) gleichen den Stirnfiihlern und dorsalen Fihlercirren. Sie sind wenigstens doppelt so lang als die Ruder, meist länger; auch fast dureh aus viel länger als die Segmente breit. Der Riickencirus des 2. Segmentes ist fast doppelt so lang als der des 3., der iiberhaupt unter Allen der kiirzeste ist. Yom 10. Segment an nehmen die Cirren an Lä̈nge zu. Ein Alterniren längerer und kiirzerer Cirren kommt in kaum bemerkenswerther Weise zum Ausdrucke.

Ob die starke Entwicklung der Ruder und Cirren in den 2 hinteren Dritteln des Leibes mit der Brutpflege, welche diese Art wie andere Syllideen iibernimmt, zusammenhängt, kann ieh nieht entscheiden, da eben nur ein eiertragendes Weibehen zur Beobachtung liam und z. B. bei Syllides pulliger Krohn gerade die nicht eiertragenden Weibchen längere Cirren besitzen.

Vom 9. Segmente bis incl. 17. liegen in den Zwischenräumen von zwei aufeinanderfolgenden Rudern (Fig. 1, B), an diese selbst und die Riiekeneirren geheftet, runde Eier von 0.06 Mm. Durehmesser, meist nur eines jederseits oder auch 2, wo dann eine Versehiebung des einen Eies anf die Riickenfläche des Ruders stattfand. Die Eier waren mit körnigen Dottermassen erfiillt.

In jedem Ruder von dem 7 . Segmente angefangen eine breite, spitze und eine kaum so breite feine deicul a, die aus dem Ruder herausdringt mol mit leicht gebogenem spitzen Ende soweit wie die Stäbe der Borsten hervorragt. In den fünf rorhergehenden Rudern bemerkte ich die zweite Form der Aeienlen nicht. Die Borsten (Fig. 1, $C$ ), 8 in einem Biindel, das so lange als das Ruder ist, haben ein zartes, messerförmiges Endstiick, das an der Spitze fein zweizähnig ist. Gewöhnlich sondern sie sich in 2 Gruppen, welche ihre glatten. hier nicht mit Haaren besetzten schneidenden Fläehen einauder zukehren.

Die Baucheiren (Fig. 1 Abc) sind ziemlieh gleich breit, etwas schmäler als die Riickeneirren, kiirzer als die Ruler, am Ende alggerundet.

Das Afte e s e g m ent, quaciratisch, abgerundet, etwaskiirzer als das vorliergehende, mit kurzen Riickencirren ausgestattet. Es 
trägt 2 Cirren, die etwas länger sind als Aftersegment und das vorhergehende zusammengenommen und einen kurzen mittleren Cirrus.

Die Schlundröhre (Fig. 1, s) beginnt im 2. Segmente und reicht bis zum 6. Oberhalb des vorderen Drittels liegt der eonische Zahn (z), im hinteren Drittel ein pigmentloses Querband. Papillen um den Eingang habe ich nicht beobachtet, ebensowenig ist mir erinnerlich, einen aus mehreren Stiicken zusammengesetzten chitinösen Ring wie bei anderen Grubea-Arten gesehen zu haben. Der Driisenmagen ( $m$ ) ist 3 Segmente lang; er nimmt das 6. 7. 8. ein. Er ist $0.39 \mathrm{Mm}$. breit, seine Wandung $0.03 \mathrm{Mm}$. dick und zeigt 19 Driisenreihen.

Der Gruber dolichopodn steht die Grubea (Sphaerosyllis olim) tenuicirratu Clapar ède' nahe. Abgesehen davon, dass die Palpen bei letzterer Art länger zu sein seheinen, liegt ein wesentlieher Untersehied in den viel kiirzeren Riickencirren und Rudern, in einem kiirzeren Drïsenmagen und einem anders geformten, Lanzenspitzen ähnlichen Zahne.

Allerdings bildet $\mathrm{Cl}$ a p a rè dle nur ein männliches Thier ab, und mir lag nur ein Weibehen vor; aber er sagt im Texte, dass die weiblichen Thiere bis auf das Fehlen der Capillarborsten den männlichen gleichen. Von der Eigenthimliehkeit, die Eier mit sich hermutragen, erwähnt Claparède niehts. Später (Annél. du golfe de Naples a. i. O. T. XIX, pag. 517 note) fïhrt Claparède die G. temicirrata auch für Neapel an und bemerkt, dass sie dort 32 Segmente gehabt und dass der Unterschied zwisehen dorsalen und ventralen Cirren weniger auffallend gewesen sei, als in der Form von Port St. Vendres; ein Unstand, der wohl ein Zusammenfassen meiner Art mit der derartig erweiterten $G_{\text {r. }}$ tenuicirruta anssehliesst. Eine zweite Art ron Neapel Grubea limbatu Cl a parè de hat das Buccalsegment von oben nieht siehtbar mil den Riiekencirrus des 2 . Segmentes so lange als jenen des dritten.

1 Glanures zootom. parmi les Annél. a. a. 0. T. XVII, 186t, pag. 547, Tat. 6. Fig. 2. 


\section{Syllis lussinensis.}

Taf. III, Fig. 1.

Grube, Beschreibung nener oder wenig bekanmer Alineliden. Archiv f. Naturg. 29. Bd. 1863, pag. 46, Tat. 1Y, Fig. 9.

? Syllis prolifera Kroln $(18.52)=$ Syllis Armandi ('la par ède, Glamures zootom. a. a. T. Bu. XVII 186t, pag. 530, pl. V, Fig. 1.

Ich halte eine in der Bai ron Inggia ziemlich häufige Syllis für die ebenfalls in der Adria gefundene $S$. lussinensis Grub e, mag immerhin ein flichtiger V'ergleich meiner Beschreibung. und Abbildungen mit jenen Grube's dieses Vorgehen nicht besonders empfehlen. Man muss eben dem Umstande Reehnung. tragen, dass Weingeist-Exemplare, nach einem solchen machte Grube seine Diagnose und Fignren, stets veränderte Bilder geben. Scheinbar ticfere Widerspriiche versuche ich weiter unten aufzuklären.

Der folgenden Charakteristik und den betreffenden Figinen liegt ein bestimmtes Individum zu Grunde, das ich darum gewählt, weil es gesehleehtsreif und in der Bildung des Stolo begriffen war. Doch fiige ich zum Schlusse die Resultate der Untersuchung an 5 anderen Exemplaren bei, 1 m die Dehnbarkeit gewisser Merkmale zn zeigen.

Der Körper $17 \mathrm{Mm}$. lang, mit den Rudern fast $1 \mathrm{Mm}$., mit den Riiekeneirren 2.5 Mnı. breit, sammt dem Stolo aus 6로. Segmenten zusaninengesetzt. Der Körper bräunlich-violet (Eisenviolet). Das Pıgment ist theils körniç, so an der Basis aller Riiekeneirren und am vorderen Rande der 7 ersten Segmente eine Querbinde bildend, theils in circa 0.015 Mn. grossensternförmigen Zellen abgelagert, die planlos in ziemlich grossen Zwisehenräumen anftreten. Der Darm sehimmerte brïunlieh-griun durch die Haut. Das hintere Leibesende war sehmutzig gelbgrïn. An den stimfühlern, Fiihler- mn Rïickencirren fielen sehon dem unbewaffneten Auge schwïrliche zerstrente Punkte auf.

Der kiopflappen (Fig. 1 k) deutlich sechseckig. $1 \frac{1 / 2}{2}$ mal so breit als lang. Der Hintermand ron dem winklig rorspringenden Vorderande des Buccalsegmentes (b) rerdeckt. 4 rothbranne Angen. Die vorderen grösseren in der Höhe der seitliehen Ecken des Kopflappens, ein wenig entfernt vom Rande. Die hinteren kleineren mach unten und imnen der vorderen, in 
einer Linie nit dem Ursprunge des mpaaren stirnfiihlers (us). Die vorderen Augen besassen dentlich hervortretende lichtbrechende Körper, in den hinteren kamen solche erst nach angewandtem Drucke zum Vorschein.

Die Palpen (p) ragen soweit ror, als der Kopflappen lang" ist. Sie sind an der Basis nur anf eine ganz kntze streeke in der Mittellinie aneinander geheftet, weichen daun mit ihren concaren imern ausgehöhlten Rande anseinander; aber ihre stunufen Enden nälıeru sich wieder, so dass die Palpen mit den Armen einer Zange recht gut vergliehen werden kümnen. An der Basis sind sie fast so breit, als der innere Rand hoch ist; gegen die abgermulete Spitze werden sie allmälig sehmäler.

Der un pare Stirnfiiller (us) ist $2{ }_{1}$, mal so laug als der Kopflappen und die Palpen zusammen, 28gliedrig. Die parrigen (ps) sind etwas länger als Kopflappeu und Palpeu. 16 grliedrig.

Die Segmente sind ror der Leibes-Yitte $2_{1}, 3$-3mal breiter als lang, dann werden sie aber läuger, so dass sie eirca 2mal so breit als lang sind. Das B necalsegment (b) halb so lang als das folgende mit winklig vorspringenden Torderrande und seitlich in uach vorne gerichtete cylindrische Fortsätze ausgezogen, auf welchen die Fiihlercirren stehen. Von diesen ist der dorsale (df) kürzer als der unpare Stirnfühler und der Riickencirrus des 2 . Segmentes, 2 -g gliedrig; der ventrale ( if') 15gliedrig. Stirufiblhler nud Cirren sind sehr deutlich gegliedert, die Glieder quadratisch steife Härchen an ihrem Vorderrande tragend. Die zerstrenten seluwarzen Flecken auf den Gliedlem sind im auffallenden Liehte kreideweiss. Sie scheinen dureh Ablag'erung mnorganiseher (kalkiger) Substanzen bedingt zu sein. Auffallend war, dass diese Flecken den kurzen Riickencirren fehlten. Das zweite seguent hatte wie alle folgenden mit Ausnahme des Aftersegmentes ein Rulerpaar. Sein Riickencirrus (rc) ist 35ggliedrig, weiter herrorragend als der unpaare Stimfiiller, iuberhaupt der längste Anhang des ganzen Körpers (der der linken Seite war merklich kiirzer). Hierauf folgten Cirren mit 18, 25, 27 und 17 Gliedern an 3. 4. 5. und 6. Segmente: dann inmer längere und kiirzere alternirend, erstere selten 30 Glieder erreichend, letztere mit 17. Die kurzen Riickencirreu 
so lange oder etwas länger als die Segmente breit sind, die langen $\mathrm{mm}$ die Hälfte oder nicht ganz $\mathrm{m}$ das Doppelte länger.

Die Ruder (Fig. 1 A) sind 41/2 - 5mal in der Segment-Breite enthalten. Sie haben eine gut entwickelte Mittellippe $(\mathrm{ml})$ und wie gewöhnlich eine kiïrzere Hinterlippe $(h l)$. Die Ränder der Vorder- (vl) und Hinterlippe fallen ziemlich steil naeh innen ab, so dass die Ruder im Profil dreieckig erscheinen. 3 Aciculen. Zwei breite zngespitzte mud eine schmälere nach vorne gelegene mit sehwach fusstörmig verbreitertem(Fig. 1 B) Ende. Die eine spitze Acicula ragt häufig ans dem Ruder herans. Zahl und Länge der Borsten (Fig. 1, B) in einem Ruder sehr ungleich: 6. 8. 9. 12. ete. Das Maximum war 16. Die Differenz der Länge liegt nicht nur in einer Verkïrzung des Stabes bei einem Theile der Borsten, sondern auch des messerförmigen Endes. Dieses ist 0.03 bei den einen, 0.05 bei anderen, zweizihhng an der Spitze und relativ grob gebärtet an der Schneide. Die kurzen Borsten sind in allen Theilen kräftiger. An den Borsten der hinteren Segmenten nimmt die Länge des Endstiiekes ab.

Die Bancheirren (Fig. 1, $A$ bc) sind ungegliedert, lanzettlich so lang oder ummerklich länger als die Ruder.

Das A fte rs e g'ment trug zwei $0 \cdot 4 \mathrm{Mm}$. lange Cirren, welche den 5 letzten Segmenten des Stolo an Länge gleichkommen uncl mehr als zweimal so lang waren als der ummittelbar vorangehende unvollständig entwickelte Riickencirrus.

Der von 10 Papillen umstellte und mit einem Zahne (z) bewaffnete Eingang in die Schl undröhre lag im 3. Segmente, und diese endete im 6., war somit 4 Segmentelang. Der Drii s enma ge n nahm das 7., 8., 9. Segment ein. Breite 0.05 Mm., Dicke der Wände 0.012 $\mathrm{Mm}$., cirea 30 Driisenreihen. Der Übergangstheil des Darmes trug jederseits eine T-förmige Anlıangsdriise, die im 10., 11. und 12. Segmente zu liegen kam.

Mit dem 48. Segment begann die Kopfbildung des sich ablösenden Gesehleehtsthieres. Doch reichten die schmutzig gelbgrünen, polygonalen 0.066 Mm. grossen Eier theilweise noch in das 46. Segment. Vor der Stelle, wo der Riickencirrus des 48. Segmentes aufsitzt, stehen 2 Augenpaare dicht aneinander gredrängt und vor diesen je ein kleines kurzes mngegliedertes Fühlerchen. Das 49. Segment bis incl. 60. trugen aus einem 
Hörker anf der oberen Fläche des Rulers hervortretende lange Capillar-Borsten. Im 60. Segmente lagen aurh die letzten Eier. Das 61. Segment hatte zwar noch ein vollständiges Ruderparar, aber keine Capillar-Borsten. Hieraut folgte das Aftersegment. Der stolo $4.5 \mathrm{Mm}$. lang, $11 \frac{1}{2}$ mal so breit als die rorangehenden segmente.

Die Modificationen, die sich ergeben, sowie mehrere Exemplare in den Kreis der Untersuchnng gezogen werlen, sind folgende: Individuen von $6 \mathrm{Mm}$. Länge hatten 57 oder 62 Segmente, ein anderes ron 15 Mm. Länge zeigte 65. Das Pigment kamn in etwas veränderter Weise abgelagert sein oder nur spärlich anftreten. So befand sich in einem Falle auf den ersten 12 Segmenten eine nicht scharf eontourirte brame Querlinie, die ron der Basis des einen Riickencirus zur anderen ging. Damn löste sich dieses Band in zwei anf; rom 30. Segmente aber bis ans Ende fand sich nur eine Querlinie an der hinteren Segmentgrenze. Zı den + Angen treten häufig auf ilem Kopflappen zerstreut liegende t ugenflecken hinzu.

Die Gliederzahl der Stimfiihler, Fiihler- und Riickeneirren kamı zunehmen (unparer Stimfinhler 30; parriger bis 20; dorsaler Fuihlerrirus bis 30; Riickencirrus des 2. Segmentes bis 46 ; Riickencirren iiberhanpt bis 36). Anch kleine Schwankungen in dem Verhïltnisse der einzelnen Anhïnge zn einander treten anf. Die parrigen Stimfïhler, ler Riickencirrus des ‥ Segmentes werden länger als Fig. 1 zeigt. s'o sah ich den unpaaren Stirnfühler nur 110 1/s länger als die paarigen. Die Zahl der Borsten bleibt in einzelnen Individuen stets gering. Acienlen habe ich wiederholt nur zwei gesehen, eine spitze und eine mit verbreiterten Ende. Die C'irren des Aftersegmentes sind so lang als die.5 orler 6 letzten Segmente. Die Schlundröhre reiehte rom 2. bis 7 . orler 3. bis 9. oder :3. bis 10. Segmente. Der Driisenmagen nahm wie oben die folgenten drei Segmente ein: $7-10$, 9-12, 10-13.

Es sind num zwei Angaben in der Diagnose, die (rrube von seiner $S$. lussinensis gibt, welche man in der rorangehenden schilderung rergebens suchen wird, nämlich: Tentucula toros fromtales lange excedentiu, impar 2+1,2 longitudiue enrum requans parilus. $1 / s$ longins mul(impar) rirris tent acularillus

(v. Marenzeller.) 
minus prominens. Was den ersten Punkt anbelangt, so lehrt ein Blick auf Grube's Figur, dass es heissen soll: 3) $1 / 2$ mal so lang als die Palpen oder $2{ }_{1}$ mal so lang als Palpen und Kopflappen zusammengenommen, und dieses ist gerade das Verhältuiss, das auch ich gefunden. In Betreff des zweiten Punktes, dass der unpaare Stirnfiihler weniger vorrage als der dorsale Fiihlereirrus, bin ieh der Ansicht, dass es gar nicht der dorsale Fiihlercirrus sei, den Grube hier in Betracht gezogen, vielmehr der Riickeneirrus des 2. Segmentes. Die Abbildung correspondirt allerdings mit dem Texte. aber es muss auffallen. dass das 2. Segment ganz ohne Cirrus gezeichnet ist. Nach Gr ube miisste der dorsale Fiihlercirus ohne Zweifel der lingste Anlang des ganzen Körpers sein; nach meinen Exemplaren wäre es der Rückencirrus des 2. Segmentes. Letzteres Verhältniss trifft man noeh bei vielen anderen Syllis-Arten, ersteres wäre etwas ganz Ausserorlentliches. Ich stehe darum nicht an, diese Erscheinung in rorstehender Weise des Auffallenden zu entkleiden. Dass die Zahl der Glieder der Riiekencirren mit 46 und 25 angegeben ist, während sie sich nach meinen Beobachtungen mit Tebergehung des Rïckencirrus des 2. Segmentes niedriger stellt, ist bei der relativen Geringfiigigkeit dieses Merkmales und der von mir constatirten Schwankungen kaun besonders hervorznheben. Die iibrigen Merkmale sind aber ganz wohl in Einklang: zul bringen.

Ich muss endlich auf die grosse Verwandtsehaft der Syllis Armandi Claparède mit der $S$. lussinensis hinweisen. Entschieden fuir die Zusammenziehung will ich mich aber erst nach emeuter Untersuchung reicheren Materiales entscheiden. Stellt sich die Identität als richtig heraus, dann wird auch der Name $S$. lussinensis fallen und dafuir der ältere $S$. molifern Krohn eintreten, da ja K rohn (Arehiv f. Naturg. Bd. 35 1869, pag. 197 Note) die $S$. Armandi fuir seine $S$. prolifera (Archiv f. Naturg. Bd. 18, 185:, pag. 68) erklärte. Syllis Armandi Clapa rède prolifura $\mathrm{Krohn}$ hat nit unserer Art gemein die Grösse und Zahl der Segmente, Form des Kopflappens und der Palpen, Länge und Gliederzahl der Stirnfiibler und des dorsalen Fühlercirrus, relative Länge des Ruickeneirrus des 2. Segmentes, die Dimensionen der Schlundröhre und des Drüsenmagens. 
Dagegen ist der ventrale Fiihlereirrts merklieh länger, die Gliedel\%ahl der Rückencirren wird beträchtlich höher angegeben (55-60), die Form der Borsten ist etwas abweichend und die Ruder sollen zwei geknöpfte Aciculen besitzen. Clapar ède beobachtete die Bildung des Stolo meist in 45 . Segmente; in den e:nzigen Falle der mir unterkam, war es das 48.

\section{Syllis vittutr.}

Taf. III. Fig. 2.)

Grube, Aetinien, Eehinodermen u. Würmer der Adria u. des Mittelm. Königsberg 1840, pag. 97.

sinllis aurita Claparede. Glanures zootom. i. a. O. T. XVII, 1864, pay. 539, pl. V, Fig. 5, 11. Annél. ehétop. dı golfe de Naples a. a. 0. T. XIX, pag. 509, I'l. XIV, Fig. 5.

Die kure und ron keiner Abbildung begleitete Beschreibung der $\boldsymbol{S}$. vittata Grube sowie ein anderes Colorit veranlassten Cl a parè d e zur Aufstellung seiner $S$. unitu als eigene Art. Ich fand sehr häıffig im Hafen von Triest eime Syllis, welche ich mit um so grösserer Sicherheit auf die $S$. vittatı zuriickfiilıren komte, als Grube diese anch von einer in der Nähe gelegenen Localität (Zaule) und ron Cherso angiebt. 1 Indem ich aber Grube's Beschreibung mit Wort und Bild ergänze, wird die Uebereinstimmung der $S$. auritu ('la p. mit $S$. vitutu Grube bis auf kleine, nicht wesentliche Unterschiede dentlich. Eine Nachuntersuchung der $S$. auritu diufte anch diese beseitigen. Ich begegnete nie so grossen Exemplaren als Grube und Claparide. Die grössten waren 22 und 19 Mm. lang, ohne Ruder $1 \mathrm{Mm}$, breit und hatten 86 und 74 Segmente. Die Zeichnung der Thiere wird durch ein braunrothes (dunkeleisenvioletes) Pigment erzengt. C'laparède gibt Violet als Farbe an, Grube schlechtweg Braun

Der Kopllappen (Fig. ㄴ $k$ ) ist algerundet, sechseckig, in das Buccalsegment (b) etwas eingesenkt. Die Palpen (p) sind sehr breit, divergent, länger als der Kopflappen, an ihrem Rande und an der Riuckentläehe pigmentirt. Von ilırer Basis zieht sich zur Ansatzstelle des nnparen Stimfühlers (us) ein keilförmiger Pigmentfleck. Der Hinterrand des Kopflappens

${ }^{1}$ Grube, Ausflug naeh Triest. Berlin 1861. pag. 127. 
ist mit einer bogenförmigen Zeichnnng, die sich aneh an den Seitenrand hinzieht, geziert. 4 im Trapeze stehende Angen. Der unpare Stirnfihler (us) ist nur um weniges länger als die parigen $(p)$ s). Ieh zählte :32 Glieder bei jenem, 28 bei diesen. stimfiihler, Fiihlereirren nud Riickencirren sind reieher oderspärlieher pigmentirt und nit zarten Börstehen am distalen Ende her Glieder versehen. Die Glieder werden gegen die Basis zu immer schmäler. Im Contraetionszustande erseheint diese etwas hulbös. Der unpare Stirnfiihler (us) entspringt mitten am Kopflappen. Die paarigen stehen $(p s)$ an Vorderrande. Clap a red e zeichnet die paarigen Stirnfiihler in gleicher Höhe mit dem unparen, also aneh anf der Fläche des Kopflappens, erwähnt aber von dieser Stellung niehts im Texte. Das Bueealsegment (b) ist von oben sehr gut siehtbar, mit einem convexen Vorsprunge in der Mitte des vorderen Randes, Vorder- und Hinterrand mit einer Binde. Von den beiden Füllerpirreur jederseits ragt der dorsale ( $l f$ ) iiber die iibrigen Auhänge des Kopfes, aber nur unbedeutend vor. Er hat :30 dentliche Crlieder und mehrere sehr schmale an der Basis. Der R iiekencirrus $(r$ c) des 2. Segmentes ist zwar absolut länger als der dorsale Fiihlereirrus, ragt aber nicht, wie aneh $\mathrm{Cl}$ aparède angibt, weiter ror als dieser. Die Ruiekenciren hahen 3:2, :37 Glieder, dazwisehen solehe mit 26 oder weniger Gliedern. Längere und kilizere ('irren alteruiren namentlich im vorderen Theile des Körpers deutlich. Die letzten 10-15 segmente wurden bei allen von mir untersuchten Exemplaren sehr schmal, und die Gliederzahl der Riickencirren sank bis anf 7 , die letrten 2 oder ;) waren ganz ungegliedert. Das breit abgerundete A ftersegment trägt 2 lange gegliederte (irren (ungefähr von der Länge der letzten 10 Segmente) und einen medialen kurzen. Die Anordnung der Binden anf den Segmenten ist wie Grube und ('laparide dieselbe sehildern: eine breite mediale und eine schmälere an der vorderen und hinteren Grenze jedes Segmentes. Diese Zeiehnung wird nach hinten immer undentheler und verschwindet endlich im letzten Viertel gänzlich. Die líuder (Fig. :2 1) mit wenig entwickelter Mittellippe ( $m l)$ und ziemlich grleich langer und starker Vorder- (lll) mui Hinterlippe (hl). Die Vorderlippe fibllt sehief nach unten ab, letztere ist germudet und 
Tagt weiter als jene vor. Im Ruder liegen 4 Acic ule n, :3 starke am Ende schief abgesehnittene und eine schwach - knopfförmige und 17-20 Borsten. In einzelnen Rudern sah ich 5 Acienlen. Claparède zeiehnet nur zwei (Glanures zoot. pl. $V$, fig. 5 a) Die Borsten (Fig. 2 B) mit kräftigem, an der Spitze gebogeuem einfachen Endstiicke, das an der Schneide einen diehten Besatz feiner Haare aufweist. Die Ba u eh cirren (Fig. $2 A, b c$ ) unge gliedert, mit breiter Basis entspringend, an Ende abgerundet, kuirzer als das Ruder. Die Sehlundröhre (s) reicht rom 4. bis 13 . der Driisenmagen (m) vom 13 . bis 19 . Segmente, bei $S$. uuritu erstere vom 5 . bis 14, letztere vom 14 . bis 20 , somit das ganz gleiche Verhältniss. Der starke Zahn (Fig. $2 C^{\prime}$ ) ist im Profil gesehen etwas weniger gebogen als der von Claparède gezeiehnete (1. c. Taf. V, Fig. 5 \%).

Syllis vittutu ist ans dem Mittelmeere von Palermo, Zanle, Cherso (Grube), Port St. Vendres, Neapel (Claparède) bekannt. Ich selbst fand sie anf dem Holzwerke der Bäder im Hafen von Triest häufig; nie aber bei Zaule.

\section{Syllis macrocola ${ }^{1} \mathrm{n}$. $\mathrm{sp}$.}

(Tit. III, Fig. 3).

Von dieser neuen Art kam nur ein einziges geschleehtsreifes Weibchen zur Beobachtung.

Der Körper ziemlich gleich breit, gegen den Kopf und After hin ummerklich verschmälert, im hinteren Drittel in Folge Anhäufung der Geschlechtsproducte etwas rerbreitert, $18 \mathrm{Mm}$. lang, $0.5 \mathrm{Mm}$. breit aus 77 Segmenten zusammengesetzt. Farbe zart rosenröthlieh, gelblieh; vorne sehimmerte der braune Darminhalt durch, vom 52. Segmente an gaben die rosemrothen Eier eine intensivere Färbung.

Der Koptlappen (Fig. $3 k$ ) abgerundet, pentagonal, $1^{1}{ }_{2}$ mal so breit als lang. Der Vorderrand stark vorspringend, der Hinterrand etwas concar. 4 dunkelrothe Augen mit liehtbreehenden

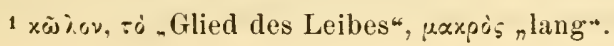


Körpern. Die vorderen grösseren anssen ron der Basis der paarigen Stirnfiihler, hart an Vorderrande des Kopflappens, die hinteren kleineren nach imuen der vorderen, in gleicher Höhe mit dem im C'entrum stehenden unparen Stirnfïhler. Ausserdem 2 Augenflecken in unsymmetrischer. Stellung nach innen und oben der vorderen Augen. Die Palpen (p) ragen soweit vor, als der Kopflappen lang ist. Sie verwaehsen im unteren Drittel des innern Randes der dorsalen Flächen, während die ventralen frei bleiben, weichen aber damn mit ihren eoncaren imnern Rändern auseinanter. Ihre grösste Breite ist nur um wenig geringer als die Höhe ihres innern Randes. Das Ende ist breit abgerundet.

Die 3 Stirnfïhler sind scharf gegliedert, im lebenden Thiere schon dentlieh, wenn auch nieht auffallend rosenkranzförmig. Der un pare ( $u s$ ) ist kaum nennenswerth länger als Kopflappen und Palpen zusammen, 1 -gliedrig, etwas kiurzer als der dorsale Fiihlercirus, ragt aber fast ebenso weit vor als dieser. Die paarigen $(p s)$ sind etwas ktirzer als der mpare, 8 gliedrig.

Das Buecalsegmen $\dagger$ (b) ist so lang und so breit als das zweite Segment. Der vordere Rand wölbt sich vor, um sich in den Aussehnitt in Hinterrande des Kopflappens hineinzulegen. Auf Vorsprïngen der Seitemränder stehen die Fïhlercirren.

Der dorsale $(d f)$ ist $11 \mathrm{gliedrig}$, der ventrale ( $v f)$, kürzere igliedrig. Der Charakter der Gliederung wie bei den Stimfithlern. In der Haut der Rïckenfläehe der Segmente beobachtete ich nachträglich an den in Glycerin-Chromsämre eingeschlossenen Thiere bei stärkerer Vergrösserung eine feine Querstreifung derart, dass dunkle Linien mit hellen abweehseln. Die ersten 20 s e gmente rirca sind weniger lang als die folgenden, $1 / 3$ so lang als breit. Die iibrigen bis anf die ganz letzten fast halb so lang als breit. Demnach stehen die Riiekencirren im Vordertheile des Leibes gedrängter als hinten, wo sie in grossen Zwischenräumen aufeinander folgen. Die Seitemränder der Segmente springen als Träger der Riiekencirren stark vor, so dass die Grenzen zweier Segmente um 1/4 kiirzer ist als der grösste Querschnitt des Segmentes selbst.

Die R u d e r, cirea $0.07 \mathrm{Mm}$. lang, haben eine schwache Mittellippe und abgerundete Vorder- und Hinterlippe. Letztere ist 
etwas kïrzer als erstere. Sic sind beiläufig bmal kiirzer als die segmente breit. 2 am Ende schief abgestutzte Aciculen. 5-6 Borsten (Fig. 3 A) in einem Bïndel. Das Endstiick ist 2zälnig und am sclmeidenden Rande gebärtet; 1,2 oder 3 Borsten in einem Biindel sind ?mal so lang als die anderen.

Die Riickencirren ( $r$ c) sind sehrkurz, an der Basis verbreitert, das Endglied abgerundet, conisch. Auch sie sind etwas moniliform, doch verflachen die Glieder der hinteren. Von allen ist der des 2. Segmentes der längste, auch absolut länger als die Stirnfülller und Fühlereirren. Er hatte 17 Glieder. Hierauf folgen kiirzere und längere abwechselnd; der Unterschied in der Länge ist aber verschwindend, es handelt sich höchstens $11 \mathrm{~m}$ die Läinge eines oder zweier Glieder. Der Riickencirrus des 3. Segmentes hatte auf beiden Seiten nur 8, der des 5. zwölf, alle äbrigen aber weniger: bis zum 60 . Segmente 10,9 , 8 , dann 7 und 6 Glieder. Die Cirren sind schon vom 8. Segmente an kiirzer als die Segmente breit. Der drittletzte Riickencirrus hatte 5 , der folgende 3 Glieder, der letzte war nur ein kurzes Stiimpfehen.

Die Ba uchcirren ungegliedert kürzer oder höchstens so lang als die Ruder.

Das Aftersegment (Fig. 3 B) ist schmäler als das vorhergehende, das einen rudimentären Rïckencirus und knopfförmigen Baucheirrus trägt. Es ist mit 2 seitlichen 11 gliedrigen ('irren ( $a c$ ), die so lang sind als die 4 letzten Segmente zusammengenommen, und einem kurzen, auf breiter runder Basis stehenden mittleren Cirrus versehen.

Die Mundöffnung liegt im Vorderrande des ersten Segmentes. Die mit einem Kranze von 11 weichen Papillen und einem Zahne (z) ausgezeichuete S chl undröhre (s) beginnt im 3. Segment und reicht bis in den Anfang des 9. Der Drii senmagen (m) nimmt nicht ganz das 9., dann das 10., 11. und fast vollständig das 12. Segment ein. Breite 0.24 Mm. Dicke der Wand $0.08 \mathrm{Mm}$. 31 Reihen von Driisen.

Vom 52. Segmente an erfïllten die Leibeshöhle rosenrothe Eier, welche cine leichte Ausdehnung des Körpers in den folgenden 18 segmenten hervorriefen. 
Ahnliehe Formen ans der Adria sind: S. hyalina Grube und $S$. pellucida Ehlers. Erstere ist dureh eine wie es scheint andre Gestalt der Palpen, dureh die dieht gedrängten kurzen Segmente, andere Dinensionen der Sehlundröhre und des Magens (9 Segmente), letztere dureh die andere Form des Kopflappens, lange Riickeneirren, die unbewafthete Sehlundröhre und den viel lïngeren Driisenmagen zu unterseheiden.

\section{Trypanosyllis ${ }^{1}$ «ebra.}

(Taf. V, Fig. I).

Grube, Besclireibung newer oder wenig bekannter Ameliden. Arehiv f. Naturg., Bd. 26, 1860, pag. 86, Taf. III. Fig. 7; Ausflug nach 'Iriest. Berlin 1861, pag. 143, Taf. III, Fig. 7.

Die ron Claparède ansgesproehene Vermuthung, die Syllis zebra sei eine Trypanosyllis, ${ }^{2}$ kann ich vollauf bestätigen. Der Haupteharakter letzter Gattung wurde von Claparede in dem Trepankronen ähnlichen Kranze ron Zähnen g’elegt, die den Eingang in die Sehlundröhre ungeben. Grube gab iiber den Verdanmostractus niehts an und daher die Unsicherheit von Clapar ède. Ieh habe Syllis zelrre in einem nicht vollständigen Exemplare bei S. Serrola (Bai von Muggia) gefunden und konnte die Sehlundröhre untersuchen. Der Eingang liegt im 7. Segmente Ein chitinöser, wellig gebogener Saum nimmt 12 Zähne aut.' 10 hievon sind untereinander gleich gebaut, breit, dreieckig, eigentlich eine Pyramide mit dreiseitiger Basis darstellend; zwei in der Vittellinie iiber einander liegente, sieh theilweise deckende Zähne sind sehlanker, länger, mehr coniseh. 10 weiche Papillen liegen vor der Zahnkrone. Die Schlundröhre reicht bis zum 17. Segmente. Der Driisenmagen nimmt das 17. bis inel. 31., also 15 segmente ein. Da aber diese sehr kurz sind, so ist auch seine Länge keineswegs bedeutend. Breite $0 \cdot 6 \mathrm{Mm}$., Dicke der Wand

1 Clap arède, Glanures zoot. parmi les Annél. a. a. O. Taf. XVII, 1864, pag. 558 .

2 C' I p arède, Ameil. du golfe de Naples, a. a. O. T'af. XIX, 1868, pag. 513, note. 
$0.2 \mathrm{Mm}$. Ieh zählte 123 Segmente an dem unrollständigen 17 Mm. langen und nicht ganz $2 \mathrm{Mm}$. breiten Individuun. Die Besehreibnng Grube's passte in allen Punkten. Die Unterscheidung der Tryp. sebr" von der ähulich gezeichneten Syllis vittat" Grube oder etwa noch $S$. gracilis Grube ist sehr leicht. Autfallend ist bei unserer Art der Wechsel kurzer und fast doplelt so langer Riiekencirren, der an meinen Exemplaren wenigstens, regelmässig zu nemnen war. Borsten waren meist melu wie 8 in einem Bündel, durch zwei starke Endzähne ausgezeichnet. Die Tryp. Krohui Claparèd e (Glanmres zootom. 1864, Fig. 558) ist sehr nahe verwandt, wemn nicht identiseh mit der $T$ : zebru. Sie hat nur weniger Segmente und die Glietlerzall der Stirntiihler. Fiihlercirren und Riückencirren ist geringer. Die Zalnkkrone nit 10 Zähnen.

\section{Odontosyllis i) vivescells $11 . \mathrm{sp}$.}

(T'at. IT, Fig. 2.)

Körper 12-16 Mm. lang, $1 \mathrm{Mm}$. breit, gegen den Kopf und das hintere Leibesende unbedentend rersehmälert, ans 47-87 Segmenten bestehend. Farbe gelblich-griin.

Der Kopflappen (Fig. 2, $k$ ) rundlieh oral, $1{ }_{+}$smal so lang als breit (die Länge in der Medianlinie gemessen), vorne schwach rorgewölbt, am Hinterrande winklig. eingebuchtet. 4 eisenviolete Angen in der vordern Hälfte des Kopflappens. Die 2 vorderen mit liehtbrechenden Körpern stehen nahe an dem Vorderrande und haben die Gestalt von abgestmmptten Dreieeken. Die 2 hinteren mehr rundlichen Augen liegen dicht an den ersten, aber etwas nach innen.

Die Palpen (p) sind sehr kurz; sie ragen nur in der Ausdehnnng eines Drittels der ganzen Länge des Kopflappens vor. Ihre inneren geraden Ränder liegen nahe an einander, bleiben aber vollkonmen getrenut; der äussere Band fällt in einem fla-

1) Cla pare de, Beobachtungen iiber Anat. u. Entw, wirbellos. Thiere Leipzig 1863 , pag. 47. 
chen Bogen ab. Am abgerundeten Vorderrande stehen einige steife Borsten. Die Stirnfühler, Fïhler irren und Riickencirren sind alle ungegliedert, etwas gefaltet und mit kurzen Härchen beset\%.t.

Der unpare Stirnfihler ( $u s$ ), in gleicher Höhe mit dem vorleren Augenpare entspringend, ist fast 3mal so lang als Kopflappen und Palpen zusammen. Die paarigen $(p s)$ sind cirea halb so lang als der unpaare.

Das Buccalsegment ist ron oben nur seitlich sichtbar; der dorsale Fiihlereirus ( $d f$ ) unbedentend kiirzer als der unpaare Stirnfühler, der ventrale $(v f)$ etwas länger als die paarigen.

Das zweite Segment trägt das charakteristische Merknal der Gattung, einen abgerundeten mit Cilien besetzten Lappen (Fig. 2 a), der sich iiber den Kopflappen bis an die Basis des unpaaren Stirnfiihlers legt. Er ist diinn und durehsichtig, an der Basis so breit als der Kopflappen in der Medianlinie lang ist. Das 2. Segment ist noch durch einen sehr langen Ruickencirrus ausgezeichnet. Er ist $11 / 2$ nal so lang als der unpaare Stimfuhhler und 3mal so lang als der Riickencirrus des 3 . Segmentes, iiberhaupt der längste Anhang des ganzen Körpers. Die Segmente folgen ziemlich gedrängt auf einander; sic sind in der Leibesmitte $41 / 2$ mal so breit als lang. Die Seitemrainder springen als Träger der Cirren zumal in der vorleren Leibeshillte wenig vor.

Die Ruder (Fig. 2 A), 0.15 Mm. lang, mit grösserer, nach unten abgerundeter Vorderlippe $(v l)$. Die Hinterlippe $(h l)$ ist zwar ebenso lang, aber weniger hoch, von aussen nach imnen unten abgestutzt. 2 Aciculen (Fig. $2 B$ ). Die melır nach vorne gelegene Acicula ist schmäichtiger und endet mit einem gebogenen Knöpfehen, die hintere ist 3 mal stärker und hat ein verbreitertes fussförmiges Ende. Die Borsten (Fig. 2 C), 15-20 in einem Bündel, mit sehr kurzem (0.012 Mm.); einfach hakenförmigem Endgliede. Die Rii ckencirren sind rom 3. Segmente an höchstens so lang als der Körper breit. Längere und kürzere alterniren. Letztere sind mitunter laalb so lang als die Segmente breit sind. 
Die Bauchcirren (Fig. ․ $A b c$ ) ungegliedert, sehr breit, kürzer als die Ruder, mit stumpfspitzigem Ende.

Das Aftersegment conisch mit abgermudetem Ende und ('oncaven Seiten, in der Mittellinie nicht ganz so lang als die letzten 2 Segmente. Es trïigt 2 Cirren von der Länge des Aftersegmentes mit dem vorhergehenden zusammengenommen. Das vorletzte und drittletzte Segment ist durch mnverhältnissmässig lange Riickencirren ansgezeichmet.

Der Mund liegt in dem anf der Banchftiche volkommen sichtbaren ersten Segmente mol fülırt in die Riisselröhre, lie bis in das 6. Segment reicht. In dessen hinterer Hälfte beginnt die Schlnndröhre. Der chitinöse Rand des Einganges in die Schlundröhre (Fig. 2 D) trägt an seiner unteren Seite 6 mit der Spitze nach hinten gerichtete Zähne (z); die 4 mittleren sind grösser, die 2 äussersten kleiner. Jeder der conischen platten Zähne ist an seiner hinteren Hälfte vor der Spitze von der Seite nach oben wie hohl geschliffen, so dass er an dieser Stelle gewissermassen vierschneidig wird. Dorsal ist die Schlundröhre tief eingeschnitten - ihr Rand liegt hier mehr nach hinten als anf der ventralen Fläche. Unmittelbar, wo die Umbiegung des Randes von unten nach oben stattfindet, liegt jederseits eine Chitinplatte $(a)$ derart schief gestellt, dass beide nach hinten convergiren. Sie lraben einen gerarlen Anssenrand, einen coneaven bogenförmigen Imnenrand; das vordere, respective äusscre und das lintere, respective innere Ende der Platte ist etwas spitz. Dieser Apparat in der Schlundröhre wird ron dem mit einer diünnen Chitin-Membran ausgekleideten lintern Ende der Rüsselrölıre ( $\beta$ ) wie eine Art Kappe umgreben. Sie legt sich dorsal in den erwähnten Ausschnitt der Schlundröhre mol ist hier ebenfalls eingeschnitten, einen nach vorne offenen Winkel darstellend. Der vordere Rand liegt ventral etwas oberhalb der Zahnreihe in der Schlundröhre, der Hinterrand nicht ganz in gleicher Höhe mit deren dorsalem Rande, sondern etwas nach hinten. Die Schlundröhre reicht von der hinteren Hälfte des 6. Segmentes bis zum 10. Vom 10. bis 16. liegt der Driis e nmagen. Er nimmt somit 6 Segmente ein. Breite 0.55 Mm., Wandlicke $0 \cdot 18 \mathrm{Mm}$. Beiläufig 80 Driisenreihen.

2 Exemplare bei Zaule mit Algen. 


\section{Pterosyllis ${ }^{1}$ lincata.}

('Taf. V, Fig. 2.)

Amblyosyllis lineata G rub e, Beschreib. nener oder wenig bekannter Anutliden. Arehiv fïr Naturgesch. Bd. 29, 1863, pag. 48, 'Taf'. V. Fig. 1; Insel Lussin, Breslau 1864, pag. 84.

„Les Amblyosyllis ressemblent de tous joints à des Pterosyllis dépourues d'ailerons occipitaux et de lobes frontaux", sagt Clapar è 1 e, Glanmres zootom. etc. a. a. 0. p. 562. Damit hatte er nur die Amb. lineatu im Ange, welche Grube bei Lussin piccolo in der Adria aufgefunden. Ieh trat dreimal in der Bai von Muggia anf heraufgeholten Steinen hermnkriechend eine Syllidee, die ich mit um so grösserer Sicherheit nit $A$. lineata identifieiren komte, weil sie derselben Fauna angehörte. Segmentzahl und Grösse, Habitus stimmten vollkommen, aber ich fand anch die ganze Reihe der Charaktere, welche meine Thiere zu eines Pterosyllis maehten: Wimperlappen am Kopfe, Palpen, und der Zahnkranz in der Schlundröhre. Vor der Alternative stehend, im strengen Festhalten an dem Umfang der Grube'schen Diagnose eine nene Art anfzustellen oder jene zn ergänzen, wählte ich, in der festen Überzengung, dass wir Beide dieselben Thiere vor uns gehabt, das Letztere und beschwere zum mindesten die Literatur nicht mit einem neuen Namen.

Alle 3 Individuen hatten 16 Segmente und waren $5-7 \mathrm{Mm}$. lang.

Die Grundfarbe des Körpers ist ein lichtes Braun, daraut tritt eine dumkelbrame Zeichmmg auf. Am Kopflappen, hinter den Augen, eine schmale halbmondförmige Linie, hinter iln ein ganz kurzer der Länge nach gestellter Strich; am hintern Rand des Buccalsegmentes ein Querstreif. Das 2. Segment vorne mit einem in die Breite gezogenen geschlossenen Ringe, hinten eine etwas längere Querlinie. An den folgenden 6 Segmenten kam num 3 iiber ihre Breite lanfende Linien unterscheiden und ror der ersten noch lateral jederseits eine schmale Querlinie. Treten

1 Prerosyllis C:laparde. Beobachtungen iiber Anatomie und Eutw eklungsgesch. wirbelloser Thiere a. d. Küiste der Normandic. Leipzig 1863. j) $\mathrm{ig} .46$. 
letztere mit den Enden der folgenden Querlinie in Verbindung, so hat es den Anschein, als läge im Anfange des Segmentes ein nach vorne offener Querring. Viel häufiger vereinigen sich die 2 hinteren Linien lateral, so dass ein geschlossener Ring anftritt. Auf den hinteren Segmenten :indert sich die Zeichnnmg insoforne, als die rorlern seitlichen Linien verschwinten und die erste Querlinie schmäler wird; die zwei hintern Linien bleiben bis ans Ende; nur das Aftersegment ist stets nugefäibt. Die eben geschilderten Verhiiltnisse sind muter allen Umständen nur deutlieh auf den is ersten Segmenten, weiter nach hinten nur damn, wenn der Darm entleert ist und keine Geschlechtsproducte entwickelt sind. Ist der Leib mit blangrinen Eiern erfiillt, so dominirt natiirlich diese Farbe und die Linien sind ant' dem opaken Körjer nicht sichtbar. Stirnfïhler, Fiihler- mol Riuckenciren fand ich, allein nicht immer, zierlich von in regelmässigen Abständen stehenden braunen Fleckehen gezeiølmet.

!)er Ko pflappen (Fig. $2 \mathrm{k}$ ) ist etwas mehr als $1{ }^{1} / 2$ mal so hreit als lang, abgerundet-hexagonal, stark gewölbt. Die zwei A ug en pa are liegen dicht anfeinander. Das rordere ist grösser und wird, weil tiefer liegend, nur bei veränderter Einstellung sichtbar. Hinter den Angen, lart an iler vorderen Grenze des lunccalsegmentes, stehen die 2 fliigelartigen an ihrer ganzen Oberfläche mit Cilien bedeckten $\mathrm{W}$ imperlappen (Fig. $2 . x$ ), welehe die Länge des Kopflappens, die Breite der Fiihlercirren besitzen, aber ungegliedert sind. Ein terminaler bramer Fleck zeichnet sie ans.

Yon oben habe inh weder bei dieser norh der folgenden Art. während des Lebens Palpen bemerkt. Sie sind nämlich beweglich und entgehen dem Beobachter lam, wem sie nach hinten umgeschlagen und nicht gerate rorgestreekt sind. Legt man die Thiere anf den Riicken, so sieht man hinter den Angen zwei conische Lappen (Fig. $2 A$ l), die dem Buccalsegment (b) anfliegen. In der Mittellinie beriilıren sie sich nur mit ebenso kurzen als schmalen medianwärts gericliteten Npangen. Nur die Basis wird darlurch verbreitert, die Palpe selbst, die nie iiber den Seitenraul des Koptlappens rorragt, bleibt schmäiler als dessen Hälfte. Nit einer Narlel kam man die Palpen nach vorne umlegen und findet damn, dass sie bei unserer Art nur mberlentend den 
Vorderrand des Koptlappens überragen. Unmittelbar hinter ihrer Ansatzstelle in der Mittellinie liegt die Mundöffnung im Anfange des Buccalsegmentes (Fig. ㄴ A o). Die 3 stirnfii hler sind gegliedert.

Das buccalsegment ist, von ohengesehen, ec. ${ }_{3}^{3}$ solang als dals folgende. Der dorsale Fühlercirrus ist länger als die parrigen Stirnfiihler. Die 5 ersten Segmente nehmen an Länge und Breite successive zu und sind ce. 3mal so breit als lang, die Seitenränder springen einfach abgerundet vor. Das 6. Segment, das den Driisemmagen birgt, ist deformirt, fast quadratisch. Die folgenden Segmente sind so gebildet. dass sie in ihrem rordern Drittel so breit als lang sind, dann aber plötzlich sich ausburhten und zweimal so breit als rorne werden. Das 2. bis inel. 14. Segment tragen Rnder. Das vorletzte (15.) Segment ist nur nach hinten etwas verbreitert, sonst rechteckig und trïgt einen dorsalen und rentralen Cirrus, beide gleich gestaltet, aber der erstere so lang als sein Segment und das vorhergehende, der rentrale $2 \frac{1}{2}$ mal kiirzer. Das kurze Aftersegment, gleich breit und lang, hinten abgerundet. Es hat ein einziges Paal Cirren, die so lang sind als dieses Segment mit dem vorhergehenden, aber kiirzer als die dorsalen Cirren des letzteren.

Die R nder (Fig. '2 B) mit in einen fingerförmigen Furtsatz ansgehender Vorderlippe $(\cdot /)$, kürzerer stmmpf endender Hinterlippe $(\mathrm{hl})$ und einer gut entwickelten Mittellippe $(\mathrm{ml})$. Acicnlen spitz, 3-4, in der hintern Lippe endend. Das Borstenlündel horizontal ansgebreitet. Die Borsten (Fig. 2 C) sehr zalılreich, mit 2zähnigem, messerförmigem Endstiicke, migleich an Länge, die längsten doppelt so lang als das Ruder.

Dic Bauchcirren (Fig. $2 \boldsymbol{B} b \boldsymbol{c}$ ) breit, blattförmig, etwas länger als das Ruder.

Riissel- und Sehlundröhre sind nur wenigg gefaltet und gewunden. Fin Kranz von 12 gedrängt stehenden Zähnen (Fig. 2 D) umgibt den Eingang in die Schlundröhre. Der rechteckige Drüsen. magen nimmt das b. Segment ein.

Blangrine Eier erfïllten bei einem Individuum die Leibeshöhle rom 7. segmente an.

Alles, was ich in vorliegender Schildermng ibergangen, ist in Einklange mit der Diagnose Grub e's. Ausser den Eröänzungen 
ist dieselbe somit in folgenden Punkten richtig zu stellen: Das Buccalsegment ist nicht "kanm zu unterscheiden " rix distinyurndum; in der Zeichuung 1. c. Taf. 5, Fig. 1 ibrigens ganzdentlich); die Stimfiihler sind nicht mngegliedert (teutacula fromtalin hum urticulatu); die dorsalen Fiihlercirren ragen nicht blos so weit vor als die paarigen Stirnfühler, sondern sind länger. Die Banchcirren sind nieht schmal wie die Figuren Grube's zeigen, ein fadenförmiges Gebilde unterhalb des Riickencirrus (l. (. Fig.1b) existirt nicht; die Borsten sind nicht einziilhnig wie in der Fig. $1 c$.

Wiinschenswerth wäre die Nachnntersnchung der Nicotin (Pterosyllis) lineolatu Costa (Annuario del mus. zoolog. della r. univ. di Napoli 1862, Napoli 1864 , pag. 160, Taf. III, Fig. 1-4), die zahlreiehe Beziehungen zu vorliegender Art hat. Indem ich die Gaitung Amblyosyllis derartig erweiterte, dass sie mit der Pterosyllis zusammenfällt, sollte diese der ersteren weichen, weil sie die jiungere ist; aber ich halte es fiir vortheilhafter, die Gattung Amblyosyllis ${ }^{1}$ mit ihrem urspringlichen Charakter, den Grube nachträglich mit der Einstellung der A.lineatu selbst anders anffiasste, anf die A. rhombenta ${ }^{2} \mathrm{Gr}$. Oerstd. beschränkt zu lassen.

\section{Pterosyllis plectorhynch ${ }^{3}$ 11. s]).}

(Taf. T, Fig. 3.

Körper des einzigen Exemplares (Fig. 3), dessen jch habhaft wurde, $14 \mathrm{Mm}$. lang, vorne $0.8 \mathrm{Mm}$., in der Mitte $2.5 \mathrm{Mm}$. breit (ohne Ruder), aus 16 Segmenten bestehend. Im ersten Viertel ist der Leib schmal, damn nimmt er plötzlich in Folge Anhänfung der Geschlechtsproducte an Breite zu und ist in der Mitte dreimal so breit als vorne, $1 \mathrm{~m}$ sich wieder almälig gegen das Ende zu versehmäehtigen. Die 6 ersten Segmente waren durchscheinend, grauliehgriinlich gefärbt, dagegen die iibrigen mudurehsichtig;, dottergelb. Am Kopflappen und dem Buccalsegment fiel mir keine besondere Zeichnung auf. Die iibrigen Segmente bis auf das Aftersegment trugen ovale, in der Mitte etwas eingeschniirte eisenviolete Flecken, die bis auf einen nicht sehr breiten Rand das

1 Gr u b e, Annulata Oerstediana. Videnskab. Meddelelser. Aaret 1857, Kjöbenhavn, pag. 185.

2 Ebenda.

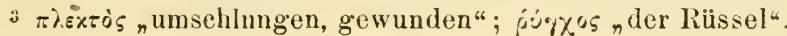


ganze Segment eimnehmen. Yom 7. Segmente an zeigten sie gan\% deutlich die Gestalt ausgespannter Fledermausfligel, lagen hart an Vorderrande des Segmentes, waren etwas schmäler und halb so lang als diese. Eine kleine mediane Stelle im Vorderrande dieser Flecken blieb pigmentlos und hier schimmerte die gelbe Farbe des Körpers dureh. Stirnfühler und Cirren nicht getöirbt.

Der Kopflappen (Fig. :3 k) algerundet-hexagonal, stark

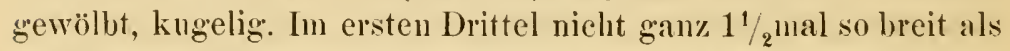
lang, der Hinterrand schmäler. Die fliige lartigen W i n p e r l a p p e e (.v) stehen etwas hinter den Augen ror dem Rande des Buccalsegmentes mil sind etwas mehr als ${ }^{1}{ }_{2}$ mal so lang als der Kopflappen, breiter als der dorsale Fihlereirus, aber nicht so breit als der Riickencirrus des 2. Segmentes, ungegliedert, mit Cilien bedeckt. 4 eiscnviolette Angen. Das vordere Augenpaar steht weiter auscinander und wegen der gewölbten Gestalt des Kopflappens tiefer als das hintere, dicht auf ihm liegende.

Palpen (Fig. $3 A p)$ wie bei $P$. linertu beweglich, aber es liegt die Anheftungsstelle viel weiter nach rorne, etwas hinter der vortern Grenze der Angen. Die Palpen werden daher anfugerichtet beträchtlich iiber den Kopflappen vorragen.

Von den:3 Stirnfiihlern war der nupare (us) nur mubedeutend länger als der Kopflappen. Natiurlich laisst sich nicht sagen, ob dies normal orler nur Folge einer Verstiummlung. Die paarigen ( $p$ s), welehe rom Vorlerrande des Kopflappens entspringen, während der mpaare mehr nach hinten steht, sind unmerklieh länger $(2 \cdot 17 \mathrm{Mm}$.) als der dorsale Fiihlereirus (2.07 Mm.). stirufühler, Fỉhler- und Riickeneirren sind ziemlich regelmässig und rollkommen gegliedert und mit abstehenden steifen Haaren besetz. Die Glieder mit Körnern erfïllt. Da ron dem 7. an die Segmente durch dic angehäuften Eier aufgetrieben waren, so diirften meine Angaben iiber ihre Gestalt kanm anf rolle Richtigkeit Anspruch haben.

Das Bucralsegulent (b) ist ron oben unr in einer sehr kuren Ansilehumg sichtbar, kamm 1,4 so lang als das folgende. Es trigt 2 Paar Fiihle reiren. Der dorsale (df) war $2.07 \mathrm{Mm}$. lang; der ventrale (rf) rechts und links nur ce. $1^{1}{ }_{2}$ mal so lang als der Kopflappen. Diese Kiirze ist derartig auffallend, dass man zur V'ermuthumg grelangt, auch sie seien nur Rudimente. Fie Enden 
waren aber wie bei dem nnparen Stimfihhler vollkommen abgerundet. Die folgenden 4 Segmente wachsen an Grösse und sind $21 / 2^{-}$bis $3 \mathrm{mal}$ so breit als lang. Ihre Gestalt ist fast die eines gestreckten Achiteckes mit abgerundeten Erken. Es springt eben der Vorderrand der Segmente etwas vor. Das 6. Segment ist dureh den Driisenmagen deformirt, etwas breiter als lang. Von hier an werden die Seg'nente selı viel breiter. Das 7 . war $1 \frac{1}{2} \mathrm{mal}$, das 8. zweimal so breit als das 5., das 9. noch etwas breiter. Bis zum 14. nimmt dam die Breite wieder ab. Dieses ist so breit als das 7., das 15. nicht ganz so breit als das 2., nud das Aftersegment so breit als dieses. Die Ecken, welche man an den 5 ersten Segmenten sehen kounte, sind dureh Auftreibung verstriehen. Das 15. Segment ist ammähernd rechteckig, vorne so breit als lang, hinten etwas breiter.

Alle Segmente mit Ausualme des 1., 15 und 16. tragen Ruder von derselben Form wie bei der $\boldsymbol{P}$. lineuta, nur in allen Dimensionen grösser. Die Vorderlippe ebenfalls nit einem stark entwickelten fingerförmigen Fortsatze. Aciculen spitz 5-6. B o rsten (Fig. 3 B) selı zahlreich (iiber 30 in einem Bindel) mit zweizähnigem Endstiicke. Das Borstenbiunlel ist gleichfalls ziemlich horizontal ausgebreitet und enthält Borsten von sehrverschiedener Länge. Ich habe eine der längsten bei dieser und der vorigen Art (Fig 2 (') abgebilulet, um die Grössenunterschiede zu zeigen.

Die Riickencirren sind gegliedert und ron excessiver Länge. So ist del des 2. Segmentes $9 \mathrm{Mm}$. lang, die andern variiren zwisehen $4 \cdot 5-7 \mathrm{Mm}$.

Die Ba uchoirren blattartig, lanzettlich, die Ruder dentlich iiberragend.

Das Aftersegment (Fig. :3 C) ist ein abgerundeter ('onus, so lang als breit. Seine zwei Cirren (ac) waren nicht ganz halb so lang als die Riiekencirren des vorhergehenden Segmentes. Dieses (15.) trug jederseits einen liiickeнеirrıs von 7 Mn. Länge und einen gleichgebildeten, nur etwas sehwär-heren ventralen, der unmerklich länger wal als das Segment (cc. 1 Mm.). Die Riisselund Schlundriohre sind ansserordentlich lang. Schon die erstere ist gefaltet und gewunden und die letztere so vielfach ineinander geschlungen, dass es fast mumöglich scheint, diesen Knäuel zu (v. Marenzeller.) 
entwirren. Der Eingang in die Sehhundröhre (Fig. 3 D) ist mit 6 durch Zwischenräume von cinander getrennten Gruppen von je drei Zähnen bewehrt.

Der Dritsenmagen nimnit das 6. Segment ein. Gelbgefärbte Eier erfiillten rom 7. bis incl. 14. Segment den Leib, verbreiterten denselben und machten ihn undurehsiehtig.

$P$. plectorhynchu ist durch die ausserordentlich langen Riickencirren und dureh die eigenthimliche Gruppirung der Zähne in der Schlundröhre von den 6 anderen bisher beschriebenen Arten wesentlich verschieden. Auch wird sie in der Grösse nur von der Gattiola spectabilis Johnston erreicht.

Gefunden bei Servola (Bai von Muggia) in einer Tiefe von 8 Fuss.

\section{Procerdeat ${ }^{1}$ lumurians n. sp).}

(Taf. VI, Fig. 1 und Taf. VII, Fig. 1.)

Körper 14-21 Mm. lang, 0.4 Mm. breit bei 78-100 Segmenten. Vorne unmerklich, nach hinten allmälig verschmälert. Gewölnhlich sieht man mit freiem Auge oder bei schwaeher Lupenver. grösserung den Leib schmutzig-griinlich, von lichten Binden gekreuzt, gegen das Ende aber farblos. Bei etwas stärkerer Vergrösserung bemerkt man jedoch, dass diese Färbung von griinlichen Contentis des Darmes herrihit und dass die lichten Querbinden den Einschnirungsstellen des Darmes entsprechen. Die eigentliche Farbe ist röthlichgelb, stellenweise gelblich-bräınlich, zumal in der hinteren Leibeshälfte; auch die Spitzen der Stimfüihler, Fiihlercirren und der Riickencirren des zweiten Segmentes enthalten denselben Farbstoff.

Der Kopflappen (Taf. VI, Fig. $1 k$ ) rundlich, so lang als der Hinterrand breit ist, der Querdurehmesser der Mitte etwas grösser. Der Vorderrand etwas abgeflacht, die Seitenränder nicht rein convex, sondern in der Mitte leicht geknickt. Die hintere Hälfte ist gewölbt und füllt plötzlich gegen das dünnere Vorderende ab. 4 Augen. Die vorderen grösseren, mit nach vorn und aussen gerichteten lichtbrechenden Körpern versehenen rundlichen Augen stehen im hintern Drittel des Kopflappens vom Aussenrande abgeriickt, hinter dem Ursprunge der paarigen Stirnfülıler. Die

1 Ehlers, Die Borstenwürmer, p. 256. 
hinteren kleineren laben nach hinten und anssen gerichtete lichtbreehende Körper, liegen dieht an den vorderen, aber etwas mehr nach innen, und sind von dem Hinterrande des Kopflappens weniger entferut als von dem Aussemrande. Ausser den 4 Augen sah ich noeh in einem Falle 5 zerstreute Augenflecken. Die Farbe der Augen im durehfallenden Lichte ist rothbraun.

Palpen fehlen. Die Configuration der ventralen Fläche des Kopflappens wird bei der Schilderung des Verdaumgstraetes erörtert werden.

Von den 3 Stirnfihlern ist der unpare ( 1 s) nieht allein der breiteste, sondern auch weitaus der längste Anlang des ganzen Körpers. Er ist weiter nach hinten geriekt als die parrigen $(p s)$ und entspringt in gleicher Höhe mit den vordern Augenpaare. Mehr als dreimal so lang wie die parigen Stirnfuihler $\left(2 \cdot 4: 0 \cdot 7 \mathrm{Mm}\right.$.) und mehr als $1 \frac{1}{2}$ mal so lang als der Riickeneirus des 2.Segmentes $(2 \cdot 4: 1 \cdot 5 \mathrm{Mm}$.) wiirde er zurickgelegt bis in das 20. Segment reichen. Die pa arigen Stirufïhler $(p s)$ entspringen annähernd in der Mitte des Koptlappens, weiter naeh rome als der unpare. Sie sind sebmäler als dieser, länger als der dorsale Fiihlercirus ( $d f$ ), halb so lang als der Riiekencirrus des 2. Segmentes. Stirnfiihler wie Fühlereirren und Riickencirren sind ungeglielert, an der Peripherie sehwaeh gefaltet oder gerunzelt und sehr reichlich mit steifen Haaren besetzt.

In der Haut des Riickens aller Segmente bemerkt man sehon bei schwacher Vergrösserung rundliche, rundlieh-eckige glänzende Körperchen in 2-3 bis zmm Seitenrand ziehenden Querreihen. (In der Zeiehunng sind diese Gebilde weggelassen.)

Die Segmente sind durehsehnittlich $21 / 2^{11}$ al so breit als lang, ihre Seitenränder nicht auffallend vorspringend. Das ruderlose B u e cals e gment (b) ist von oben vollkonmen sichtbar, etwas kürzer als das folgende, breiter als der Ilinterrand des Kopflappens. Der iiber diesen auf beiden Seiten vorragende Theil ist schief nach aussen abgestutzt und träigt $2 \mathrm{~F}$ ii hlercirren jederseits, von welehen der dorsale (df) $2 \frac{1}{2}$ mal so lang ist als der ventrale $(v f)$ und zweimal kiirzer als der Riickeneirrus $(r c)$ des 2 . Segmentes; der ventrale wird von den paarigen Stirnfiihlern unberlentend an Lïnge übertroffen. Das zweite Segment hat wie 
alle folgenden init Ausnalıme des Aftersegmentes ein Ruderpaar. Es trägt einen Riickencirrus, der an Länge nur dem mpaaren Stimfiihler nachgibt; er ist $5 \frac{1}{2^{m a l}}$ so lang als der Riickencirrus des :). Segmentes. Der Rülckencirrus des 3. Segmentes ist doppelt so lang als der des t. Die Cirren sind etwas spindelförmig, das Ende bleibt immer stumpt, die steifen Haare ilurer Oberfäche bilden nicht selten terminale Biischel. Vom 4. Seg. mente an sind die Riickencirren, längere mul etwas kiimer alternirend, 21/2-3mal in der Breite des Segmentes enthalten; nur gegen das Eude des Körpers erreichen sie eine grössere Läinge, und da gleichzeitigdie Segmente schmäler werlen, ändert sieh das Verluältniss: die Cirren sind fast so lang als die Segmente breit sint.

Die Ruder (Taf. VI, Fig. 1, d) sind fast so breit als lang, ron oben gesehen abgerundet quadratisch, mit etwas schnälerer Vorderlippe $(v l)$ und breiterer Hinterlippe $(h l)$, zwischen welchen beiden das in verticaler Ebene ansgebreitete Borstenbindel anstritt. In der Seitenlage bemerkt man, dass die Hinterlippe von oben nadh nuten kiirzer ist als die vordere. Die Ruder sind t-5mal kiirzer als die Segmente breit simul, und erreichen circa die halbe Cirruslänge. Eine orler zwei Acirulen. 6-8 Borsten, die oberen lïnger als die nnteren. Das Bïndel ragt beilänfig so weit vor als die Ruder lang sind. Die Borsten ('Taf. VI, Fig. 1, B) sind zus:mmengesetzt mit sehr kurzem, nur $0.006 \mathrm{Mm}$. langem, hreitem, zweizihnigem Endstïcke. Manchmal sicht man noch einen dritten Zahn. Das verbreiterte Ende des Stabes zeigt einen rauhen Vorderrand und kleine Zähnchen an seiner der schmeidenden Flïche des Endstiickes entsprechenden Seite. Zu dieser Form tritt noch ror der Nitte des Körpers eine zweite hinzn, die einen viel schmäleren Stah hesitzt mul statt des eben erwähnten Endstiickes einen kurzen, gertenförmigen, leicht gebogenen Anhang trägt. Ich sah immer nur in einem Biindel eine einzige dlerartige zu oberst liegende Borste.

Bat uch cioren fehlen.

Das Afters e g me ent (Taf. VI, Fig. 1, C) ctwas länger als das vorhergehende, stumpfronisch mit ansgermudeten Seitenrindern nnd steifen Haaren am Hinterende. Es trägt 2 Cirren ( $a$ c), die in rler oberen Hälfte ler Seitenränder ihren I'rsprmmg nehmen 
mud den ó letzten Segmenten an Länge gleichkommen. Das vorzund drittletzte Segment haben kiirzere Cirren als ihre Vorgäinger, die mit anffallend langen versehen sind.

Die L'mgebung der Mundöffnumg (Taf. VI, Fig. 1, I) o) wird von dem Vordermande des Buccalsegmentes und dem Itintermande des kopflappens gebildet. Das Buccalsegment (b) ist auf der Banchfiache länger als auf der Riickenfläche. Diese Vergrösserung geschieht dadurch, dass sich in der Mitte ein Aufsatz entwickelt von der Breite des Kopflappens und sich aut diesen bis zur Höhe des Hinterrandes des vorderen Augenpaares hinaufschiebt.

Laterale Einsehnitte tremen diesen Theil von den anf der Banchfläche gut zur Einsieht kommenden Trägern der Fiihlereirren an den Seitemrändern des Segmentes. Die Unterfläehe des Kopflappens ist dureh eine mediane Furche in ¿ Hälften getheilt, aber diese weichen naeh hinten anseinander und stellen im Vereine mit dem ansgeschnittenen Vorderrande des Buccalsegmentes eine rantenförmige Öffnung - die Mundöffnung dar. Der Hinterrand des Kopflappens liegt anf der Bauchfläche, genan in einer Linie, die man zwischen rorderem und hinterem Angenpaare ziehen wiirde. Die Riisselröhre (r) erstreckt sieh bis zur Mitte des dritten Segmentes, da sie noch den Anfang der Schlundröhre in der Länge von 1 1 $/ 2$ Segmenten als Scheide umgibt. Die Sehlundröhre (s) beginnt im 3. Segmente und endet im 6 ., ist aber länger als 4 Segmente. Sie bildet nïmlieh eine noeh etwas hinter den Anfang des Driisenmagens reichende Sehlinge.

Der Eingang in die Sehlnndröhre wird von einem ehitinösen Sanme umgeben, der in 10 flache, aber nieht ganz stumpfe Zacken ausgeht. Hinter diesem erenulirten Samme steht ein Kranz von cirea 20 dreikantigen spitzen Zühnen von etwas ungleicher Grösse ('Taf. VII, Fig. 1). Ein dichter Beleg longiludinaler Muskelfasern umhiillt die Sehlundröhre in ihrer ersten Hälfte, während die zweite nackt bleibt.

An dem von der Riisselröhre eingeseheideten Theile ist die Museulatur weniger entwiekelt und erseheint auf den ersten Bliek ringförınig und nicht longitudinal angeordnet. Die ringfömnigen Fasern gehören aber nicht der Schlundröhre, sondern der Rüssel rölıre an, wie man sich nach Entfernung der letzteren iiberzeugen 
kann. Cla parède unterseheidet an der Schlundröhre von Autolytus hesperidum und Proceraeu aurentiacu (Annél. chétop. du golfe de Niples. Mém. d. l. Société de Plysiq. et d'Hist. nat. de Genève 1868, pag. 528 und 531, pl. XIV., fig. 1, et pl. XV, fig. 1) 3 Regionen: die erste mit Ring-, die zweite mit Lüngsfasern und die dritte ganz ohne Muskelfasern. Da ich beide Arten nicht kemne, bin ich nicht in der Lage zu entscheiden, ob hier eine Täusehung vorliege. Der Drüsenmagen ( $m$ ) nimmt 3. Segmente ein, llas 7., 8., 9. Breite 0.3 Mm., Dicke der Wand (1).09 $\mathrm{Mm}$. Ich zählte cirea (60) Driisenreihen.

Häufig mit Algen an der Siidkiiste der Bai von Muggia.

\section{Proceruea brachyeephala n. sp.}

(Taf. VI, Fig. 2 und Taf. VII, Fig. 2.)

- Körper kur\%, gedrungen, breit im Verhältniss zur Länge. 4.5 und $6 \mathrm{Mm}$. lang $0.3,0.4 \mathrm{Mm}$. breit bei 54 und 60 Segmenten. Nach vorne und hinten in nieht auffallender Weise verschmälert. Färbung älnnlich der vorigen, griunlich bei gefiilltem Darmeanale, in Wirklicllkeit blass orangeroth. Doeh enthält nur die vordere Körperhälfte dieses Pigment reichlicher, wo es Flecken an der Basis der Cirren und ein medianes Längsband bildet.

Der Ko plfla p pe n (Taf. VI, Fig. $2 k$ ), breiter als lang, am Hinterrande schmäler als in der. Mitte, vollkommen abgerundet. Er jst bis auf beiläufig das vorderste Viertel seiner ganzen Länge nach stark gewölbt - ein Bogen dureh die Ursprungsstellen der beiden unpaaren Stirnfiilhler gezogen, bildet die Demareationslinie ler Rest, eine schmale vordere Zone, ist dïm, flach. Der gewölbte Theil fällt ziemlich schroff gegen den planen ab. 4 Augen. Das vordere, etwas grössere Angenpaar steht wenig hinter der Mitte des Kopflappens, das hintere kleinere ziemlieh dicht daran, aber nach innen. Beide sind ron dem Seiten- und Hinterrande des Kopflappens merklich entfernt. Die Stellung der liehtbrerhenden Körper in den beiden Augenpaaren ist dieselbe, wie in der vorigen Art. Auch hier treten vereinzelte Augenflecken an versehiedenen Stellen des Kopflappens auf. Palpen fehlen. Der Kopflappen zeigt anf der Banchfliche dieselbe Bildung wie 
bei $P$. luxurians; allein er ist ebenso lang als am Ritcken oder mit anderen Worten: das Bucealsegment ist nicht länger anf der ventralen Seite als auf der dorsalen.

Von den drei Stirnfiihlern ist der unpare ( $u s)$ mur Im 1/s länger als die paarigen ( $p s$ ) und kaum merklich kiirzer als der Riickencirrus des 2. Segmentes. Er nimmt seinen Irsprung hinter den parigen und steht in der Mitte des Kopflappens in einer Linie mit dem vorderen Augenpare. Zuriickgelegt, reicht er bis in das 6 . Segment. Die pa a ri ge n Stimfühler $(p s)$ sind fast so lang wie der dorsale Fihlercirrus ( $d f$ ). Ihre Stellung wurde bereits friiher präcisirt. Stirnfïhler, Fuillereirren und Riickencirren sind ungegliedert, viel weniger germnzelt als bei der vorigen Art. Ich hatte in meiner Original-Skizze keine Härchen angezeigt und an den conservirten Exemplaren kann ich keine mehr erkennen, wiewohl dies bei P. Iuxurinns ohne-sichwierigkeit gelingt. Es diìften also die Härchen zarter urd spärlicher sein als bei jener. Charakteristiseh für Stimfühler und Cirren ist ihre plumpe, gegen das abgerundete Ende sich kaum verschmälernde Gestalt.

In der Haut des Ritckens aller Segur e nt e liegen wieder die runden, rundlich-ovalen glänzenden Körperchen (Taf. VI, Fig. 2, A). Sie sind meist in einem ziemlich regelmäissigen, in der Mitte verbreiterten Querbande, das an seinen Enden in 2 nach hinten gebogene dicke Haken ansgeht, angeordnet. Dahinter folgt noeh ein kurzes Streifehen. Die Segmente sind $31 / 2$ mal breiter als lang und haben selır stark vorspringende Ränder, die sich zu conischen Trägern der Cirren entwickeln.

Das Bucealsegment (b) fast um die Hälfte kiirzer als das folgende, breiter als der Hinterrand des Kopflappens. Es trägf $2 \mathrm{~F}$ ii hlercirren jederseits; der dorsale Fiihlercirrus ( $d f^{\prime}$ ) nur unbedentend länger als die parigen Stirnfiihler, der ventrale ( $\left.v f^{\prime}\right)$ um $1 / 3$ kiirzer.

Von dem zweiten Segmente an haben alle bis auf das Aftersegment Ruder mit Riickencirren. Der Riickencirrus $(r c)$ des 2. Segmentes ist etwas lainger als der mittlere Stirnfühler iiberlıaupt der längste Anhang des gauzen Körpers; der des 3. Segmentes ist kürzer als die Hälfte des vorigen; der des 
4. Segmentes halb so lang als der des dritten. Die iibrigen sind in nieht anffallender Weise abwechselnd länger und kïrzer. Die xiemlich gleieh breiten Riiekencirren sind cirea $2{ }^{1}$ „mal kürer als die Segmente breit.

Die Ruder (Taf. VII, Fig. 2), im Wesen gleich gebaut mit jenen der vorigen Art, aber etwas länger und breiter, sind circa 3mal in der Breite eines Segmentes enthalten und reichen gewölnulich bis an die laalbe Länge ihres Cirrus. 2 Aciculen. 8 Borsten (Taf. VII, Fig. 2, A) loch auch 6 und 10 in einem Ruder. Länge des Borstenbündels, Lage und Art der Borsten wie bei der vorigen. Das Endstiek ist kaum nemnenswerth kiirzer, der unter dessen Spitze befindliche Zahn etwas länger; das Ende des Stabes weniger rauh; die zweite Form der Borsten etwas sehmäehtiger.

B a ne he irren fehlen.

Das Aftersegment mit 2 Cirren, die so lang als die letzten 5 Segmente sint.

Die Mundöffinung ebenfalls von dem eingeschnittenen Vorderrande des Bucealsegmentes und den auseinanderreichenden Hälften des Kopflappens gebildet. Die Rüsselröhre (r) reicht nach hinten noch bis in den Anfang des 5. Segmentes; die Scheide, mit welcher sie die Schlmudröhre umgibt, ist 2 Segmente lang.

Die Schlundröhre (s) beginnt im 3. Segmente und endet im 7. Sie legt sich in ihrer hinteren Hälfte einfach zusammen, bildet keine geschlossene Schlinge. Der crenulirte Eingang (Taf. VII, Fig. 2, B) hat sehr flache Zacken. Hinter diesen steht ein Kranz von 30 conischen Zälhnen - grössere und kleinere, meist so abwechselnd, dass 2 oder 3 kleinere zwisehen 2 grossen zu stehen kommen. Die einzelnen Zälne sind an ihrer Basis kaum schart getremnt. Die Verhältnisse der Musculatnr, welche die Schlundröhre umgibt, sind wie bei $P$. luxurians. Der röthlieh violete Driis en magen $(m)$ nimmt das 8., 9., 10, 11. Segment ein. Breite $0.27 \mathrm{Mm}$., Dicke der Wand 0.07 Mnı, Drilsenreihen circa 40.

Mit der vorigen. 


\section{Eumice Claparedii.}

Qu a trefages, Hist. nat. đ. Annelés, T. II, Paris 1865, pag. 65:. (Eumice Harassii auct. sed non A ud. et M. Edw.)

Nachdem Quatrefages (l. c.) zuerst die Verschiedenheit einer von Claparede ${ }^{2}$ als Eunice Hurussii beschriebenen Form von der eigentlichen E. Harassii A nd. et M. Edw. nachgewiesen unl dieselbe als eine eigene Art: $\boldsymbol{E}$. Clupuredii bezeichnet latte, spraeh sich $\mathrm{Cl}$ a $\mathrm{p}$ a rè de für die Identität seiner E. Hurassii, riehtig E. Claparedii, mit den unter ersterem Namen ron $(\mathrm{r}$ ube 2 und Ehlersabesehriebenen Formen aus und setzte die Synonymie in diesem Simne fest." In demselben Jahre berichtigte Grubes selbst seine frühere Bestimmung, erklärte jedoeh seine aus der Adria stammende $\boldsymbol{E}$. Hurassii für die E. torquat" Quatrefages. ${ }^{6}$ Er hält anch später r daran fest, olune die Clapra rèd e'schen Auseinandersetzungen zu erwälnen.

Die im Mittelmeere, auch in ler Adria, sehr häufig vorkom. mende Eunice, welche den Arbeiten Grube's und Ehlers' das Material lieferte, wird somit von Claparède als $E$. Clapuredii, von (Krube als $\boldsymbol{E}$. torquutu anfgefasst. Es bandelt sich aber hier viel weniger um eine von neuem rerwirte Nomenelatur, als um die Frage, ob die Eunice des Mittelmeeres identisch sei mit der der französischen Westkiiste. Quatrefages und auch Claparède halten erstere für eine eigene Art: $\boldsymbol{E}$. Chaparedii; Grub e

1 Glanures zootom. parmi 1. Annelid. de Port Vendres. Mém. d. l. Sue. d. Phys. et d'Hist. nat. de Genève, 'Tome XVII, 1864, p. 118, pl. II, fig. 5.

2 Zur Anatomie und Physiologie der Kiemenwïrmer. Königsberg 1838 p. 35.

3 Die Borstenwiirmer. Leipzig 1868. p. 312.

* Anuél. dn Golfe de Niples. Supplément. Mém. d. I. soe. d. Phys. et d'Hist. nat. de Genève, T'ome XX. see. partie 1870, paig. 395, note.

5 Bemerkmugen iiber Ameliden des Pariser-Mnseum. Arehiv f. Nalurg. 36 Bd. 1870. p. 293.

6 Hist. nat. d. Amnẻl. B. I, p. 312.

7 Mittheilg. iiber S. Malo ete. Abhandig. der schles. Gesellsch. f. vaterl. Cultur 1869/72. Breslau 1872. pag. 90, Note. 
für dieselbe: E. torquatu. Von keiner Seite ist aber das pro und contra zu motiviren versucht worden; es sei denn, dass man fiir Quatref ages seine bekannte Voreingenommenheit gegen das Zusammenzielien von atlantischen und mediterraneen Amnelidenformen anfïhren wollte. Quatrefages, Clapar ède, Grube haben nur gezeigt, dass die E. Ilarassii A ud. et M. Ed w. ganz etwas anderes sei als das, was man seit 30 Jahren dafiir gehalten. Die Basis der Beurtheilung ist für jeden spaiteren Beobaehter in einer zu ernewernden Intersuchmo der $\boldsymbol{E}$. torqunta Quatretages - die Eunice des Mittelmeeres ist dureh die elassisehe Arbeit von Ehlers mehr als geniigend bekannt - oder in einem Vergleiche der respectiven Beschreibmngen liegen geblieben.

Da mir keine Exemplare der E. torquutu der westfranzösischen Kiiste zur Verfiigung stehen, muss ich mich einzig an die Angaben von Quatrefages halten, die von Grube nur dahin ergänzt wurden, dass die Zahl der Kiementäden auf 14 steige. Wenn ich daraus aueh nicht den Schlıss ziehe, dass Ergänzungen iiberhanpt nieht zu machen seien, wird anderseits sielierlich den Widerspriichen zwisehen der Beschreibung der $E$. torquatu und der Eunice des Mittelmeeres niclits an Schärfe benommen. Die Formen bleiben unvernittelt und selbst die Ammahme von Varietäten hleibt Vermuthung..

Der Vergleich ergibt:

1. Die Segmentzahl ist bei $\boldsymbol{E}, t o r q u a t a \mathrm{im}$ Verhältnisse zur Länge geringer als bei der Mittelmeer-Form, die Segmente an sich miissen länger sein.

E. torquatu 2:0 Mm. lang, 140-160 Segmente (nach Q natrefages). Limice des Mittelmeeres 160 mnd $120 \mathrm{Mm}$. lang, 195 und 180 Segmente (nach $\mathrm{E} h \mathrm{ler} s$ ).

Darnach wiirden die Segmente bei E. torquatu fast $11 \mathrm{~m}$ das Doppelte länger sein.

2. Das Buccalsegment (nach Quatrefages eigentlich 1. und 2. Segment) wird bei $\boldsymbol{E}$. torquutu so lang als die 5 folgenden Segmente angegeben; bei der andern ist es so lang oder nur unbedentend länger als die 2 folgenden Segmente.

3. DerZahn (mâchoires inférieures $Q$ u a tref.) der E. torquatu hat an seiner Basis 2-3 kleine, weiter vorne 4-5 grosse Z $Z$ äh he; die Sïgeplatten (denticules Quatref) sind 
selır gross und nach hinten verlängert. Bei der Eunice von Ehlers zeigt der linke $/ 4$ ahn 5 , der re ehte 6 gleich grosse starke Sïgezähne; die Sägeplatten sind weder besonders gross noeh nach hinten verlaingert zu nemen.

4. Der Unterkiefer (Iabre Q natref.) der E. torquata ist mässig. ansgesehweift und zeigt an seinem Vorderrande 4-6 ziemlieh ausgeprägte wellige Vorspriinge; bei der andern

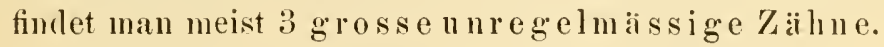

5. Die Kiemen beginnen bei beiden am 5. Segmente; denn das 3. Segment, für welche Quatref. bei $E$. corquata las erste Auftreten der Kiemen angibt, ist das fünfte, wenn man abweiehend von Quatref. sein Buecalsegment als 2 Segmente ansieht und mit einrechnet. Die Zahl der Kiemenfäden ist bei E. torquatu 6-- 8 nach Quatref., bis 14 naeh Grube; bei der Eunice des Mittelmeeres 12 oder 13.

Mögen nun in der Folge Amuäherungen zwischen den beiden Formen anfgedeekt werden, dermalen halte ich eine Zusammenziehung für noel nicht gehörig begriindet. Ich sehliesse mich daher Quatrefages und Claparède an und sehe in der verkannten Eumice Harassii des Mittehmeeres die Eunice Cluparedii Quatrefages und nicht die $E$. torqualu $Q u a t r e f a g e s$. Erstere wäre somit anf das Mittelmeer beschränkt, letztere anf den atlantisehen Ocean (Westkiiste Frankreichs). Die echte Eunice Harassii And. et M. Edw. ist beiden Meeren gemein, da dieselbe von Prof. Reichert bei Camnes (Grube Mitheil. iiber S. Nalo etc.) und von mir 1872 in der Bai von Muggia bei Triest in einem Exemplaregefunden wurde.

\section{Marphysa Bellii.}

(Marpliysa Quatrefages.)

Eunice Bellii A u don in et Milne Edwards, Classific. d. Annèl. Annal. d. sciene. nat. I śér., T. 27, pI. 11 , fig. $1-4,8.9$, et 'T. 28 , pag. 223 (18.33).

Marphysa Belli Quatref a ges, Ilist. d. Annèl. 'T'. 1, pag. 333.

Marphysa Bellii, an den englisehen Kiisten und der französischen Westküste einheimisch, kommt auch bei Triest vor. Ich fand sie während der Ebbe unter Steinen der Siidkiiste der Bai von Muggia. Das grösste Exemplar war $70 \mathrm{Mm}$. lang, an der 
breitesten Stelle etwan mehr als 2 Mm. breit und besass 200 segmente. A ud. und M. Ldw. geben die Länge mit kaum melur als $2 "$, die Breite mit ec. 2 Linien, die Segmentzahl mit 84-100 an. Q uatrefages erwälut ein Individnum von 22 Centim. (!) Läinge mit ,beilïutig“ “ 150 Segmenten (!). Die Kiemen traten mit dem 12. rulertragenden Segmente (dem 14: im Ganzen), ganz. wie die französischen Autoren angeben, auf und nahmen 17, 19 anch 21 Segmente ein. (15, 17, 19 Aud. et M. Edw.; nie unter 20-25 Quatrefages). Die Kiemen hatten 10, 14, 17 Fäilen, auffallend mehr als die 'Thiere aus dem atlantischen Heere $(8-10$ A ull. et M. Edw.; 6-8 Quatrefages). Anderweitige Unterschiede fielen mir nicht anf und Originalexemplare der Eunice Bellii standen nicht zur Verfiigung. Ich fiigre eine Beschreibung des Kieferapparates bei. Alle Theile des Oberkiefers sind braun gefärbt, nur die Reibplättchen etwas blässer. Die Träger sind sehlank, gut riermal so langa als breit, die Zangen stark gewölbt. Die Schneide des linken Zalmes mit $\boldsymbol{\tau}$, die des rechten mit \& Sägezähnen, die von vorne nach hinten etwas an Grösse abnehmen und die Hälfte des inneren Zahmrandes besetzen. In der linken Kieferhälfte eine unpaare Zahmplatte nit 7xïlnigem liande. Inmittelbar vor den paarigen Sïgeplatten und nicht mit ihnen fest verbunden (Kali-P'räparat) liegen 2 tiefbramne halbkreisförmige diinne Platten. Die linke Sägeplatte mit 6 , die rechte mit 9 Zialunehen. Jederseits ein kleines Reibplïttehen. Der Lnterkiefer ist kalum merklich länger als Zange und Träger zusammen. Er ist braun bis ant die durehaus weissliehe gehöhlte Endplatte, die sich lateral in einen zahnähnlichen Fortsatz auszieht. Nach Qu atrefages wären die Kiefertheile kaum gefürbt und die Sägeplatten (denticules) ungezähnt.

Erwälnen will ich noch, dass in die Riickencirren wie bei Murphysa sauguinea ein Bindel feiner Borsten eindringt.

\section{Nereis (Hediste) dirersicolor.}

(Taf. VII, Fig. 3)

U. F. Mülle r, Prodromus zoolog. dan. 1776, pag. 21 i

Ehlers, Die Borstenwürmer 1868, pag. 554.

Die aus der Ost- und Nordsee, von den Kiisten Englands und der Westkiste Frankreichs bekannte „buute Nereide“ 
O. F. Miiller's wurde ron mir anch bei Triest aufgefunden, und ich will durch eine kurze Zusammenfassung der wesentlichen Punkte nachweisen, dass die abriatischen Thiere im Ganzen und Grossen wenig von ihren nordischen Briidern abweichen. Dass die $N$. diversicolor iberlanpt gewisse Wandlungen durehmaeht, lehrt die von Elılers zusammengestellte Synonymie, an der ich in vollem I'mfange festhalte. Die Inconstanz der Art scheint neben Anderem in der weehselnden Zahl der Kieferäihne und Paragnathen nnd ler nugleiehen länge der oberen Fiihlercirren des hintern Paares zn liegen. Meine 12 Individuen waren 25-85 Mm. lang 1 ud hatten 66 -. 92. Segmente. Darunter waren Exemplare von 3:3 Mm. Lainge nit 80 Segmenten; $43 \mathrm{Mm}$. mit $75 \mathrm{Segm.;} 60 \mathrm{Mm}$. mit $82 \mathrm{Segm.;} \mathrm{und} 80 \mathrm{Mm}$. mit 85 Segm. L'eber die Färbung in Leben habe ich mir leider keine Aufzeichnungen gemacht; die in Weingeist conservirten Thiere sind unbestimmt bräunlich, ins Grangelbliche gehend; die Ruder lichter als der eigentliche Körper. Immer ist dessen Vordertheil an Rïcken dunkler gefärlıt. bräunlich mit einem stich ins Grinliche nud hier wieder den als weisse Linie ant der ganzen Länge des Rüickens durehschimmernlen Riickengefässe z!1nächst dunkler als seitlich. So grewinnt es bei manchen Exemplaren das Ansehen, als liefen 2 branne Streifen iiber die Dorsalseite der Segmente hin. Der Gesammthabitus stimmt mit der Beschreibung ron Ehlers. Das erste ruderlose Segment ist gewöhnlich nicht so lang als die beiden folgenden zusammen. Von den Fiihlereirren reichen die oberen des hintern Paares bald bis zum Anfang des t., odler, mul das ist das Häufigste, bis in das D. Segment. In einem Falle war das erste Segment so lang als die beiden folgenden und der obere Fiihlereirus reichte bis zmm 7. Segment - die Segmente waren eben sehr kur. Bei der N. diversicolor der Norlsee etr. seheint das erste Segment etwas kiirzer zu sein und die Fihhler(irren werden in das 3 . oller 万. Segment reichend angegeben.

Der Riissel a zeigt nach den einzehnen Exemplaren manche Variationen, insbesonders in der Disposition der Kiefer-

1 Die 'Terminologie nach Kinberg. Siehe Ehlers I. c. pilg. 445. 
spitzen am dorsalen Theile des oralen und maxillaren Abschnittes. Die mediale Gruppe des ersteren (V) fehlt immer bei Nereis diversicolor. Die lateralen (VI) bestehen aus $3-8$ Kieferspitzen; an hänfigsten sind 4 oder 6 . Die Zahl ist rechts nnd links ungleich. In dem Mittelfelde (I) des maxillaren Absehnittes ist meist eine einzige Spitze vorhanden, doeh kïnnen anch 2, 3 oder 4 hinteremander anftreten. Die seitlichen Gruppen (II) bestehen meist aus gekrimuten Doppelreihen von Spitzen, die ihre Concavität uach vorne und aussen kehren. Auf der Ventralseite zeigt der orale Abschnitt eine Binde mregelmässig angeordneter Kieferspitzen, an der man annähernd 2 Systeme hintereinander liegender Linien unterseheiden kann (VIII VII VIII). Lateral reicht diese Binde nie iiber eine Linie hinaus, welche man sich in Verlängermng des Riiekens der Kiefer nach hinten gezogen denkt. Der maxillare Antheil der ventralen Seite lässt im Mittelfelde (III) ein Band ron Kieferspitzen unterscheiden, das aus mehreren (3 oder 4 ) hintereinander liegenden Reihen besteht, oder die Spitzen sind untereinander geworfen, die Anordnung ist undeutlieb. Es kummt aueh vor, dass das Band sieh in $6-7$ sehärfer getrenute Gruppen auflöst, von denen jede $3-4$ hintereinanderliegende Spitzen enthiilt. Allerdings schiebt sich auch dann hie und da ein einzelnes Spitzelıen zwischen die Gruppen und miter diesen hat die eine oder die andere un ein Spitzchen mehr. Die lateralen Felder (IV) des rentralen maxillaren Absehnittes werden von einer gekriimmten Gruppe von Kieferspitzen eingenommen, welche ihre Coneavität der Mittellinie zukehrt und bald aus Doppelreihen bald in einem unregelmässigen Hanfell von Kieferspitzchen lesteht.

Die Kiefer haben $6-8$ Zähne; die Spitze seharf mit einem schneidenden Rande, auf dem 2 Zähne Platz hätten. Die Ruder und Borsten zeigen mir keine bemerkenswerthen Differenzen mit den Bildern von Ehlers und Malmgren; Exemplare aus dem andern Faunengebiete konnte ieh nicht vergleichen. Ich habe Tat. VII, Fig. 3 ein Ruder (das60ste) abgebildet um die Übereinstimmung zu zeigen. Nereis falsa Quatrefages 1 aus dem

1 Hist. d. Annél. T. I, pag. 505. N. falsa Quatrefages ist div N. purallelogramma (') a p a ède (Annél. chétop. du golfe de Naples. Mém. 
Mittelmeere hat mit der $\Lambda$. diversicolor die gleiche Disposition der Kieferspitzen; ist aber an einer andern Ruder-Form und dem viel längeren Riickencirrus sehr leicht zu erkennen. Bei der $N$. diversicolor ist der Riickencirrus nur an den ganz letzten s'egmenten so lang oder etwas länger als das obere Züngelchen, sonst bedentend kiirzer.

d. I. Soc. l. Phys. et d'Hist. nat. de Genève, 'T'ome XIX, pag. 477, pl. XI, fig. 7, pl. X. fig. 2). Grube hat (Actin. Echinod. 11. Würmer d. adriat. u. Nittelmeeres. Königsberg 1840, pag. 73) eine Nerris ron Neapel mit den Originalexemplaren jener Nereis, die Rath $\mathrm{k}$ e (Zur Fauna der Krym. Mém. prés. à l'Aeadémie imp. d. Seiences de St.-Pétersbourg III, 1837, pag. 412, pl. 7, fig. 1 u. 4-8) als Nereis pulsatoria Mont. (?) angefuihrt, vergliehen, identisch betundeu und ebentalls Nereis pulsatoria Mont. benamnt. Die Besehreibung $\mathrm{R}$ at hke's ist aber so abweichend vou der $\boldsymbol{N}$. pulsatoria Mont. die A u dou in u. M.E dwards (Amales d. seiene. nat. t. XXIX 1833, pag. 216 et t. XXVII, 1832, pl. XIII, fig. 8-13) gegeben, dass Qu a t l e fa ges die Nereis von Rathke als eigene Art: $\boldsymbol{N}$. falsa linstellte (1865). Claparède land bei Neapel die Nereis, welche Grube, Rathke folgend, pulsatoria genannt hatte, erkanute gleiehfalls den Irrthum und gab ihr den neuen Namen: N. parallelogramma (1868). Dieser Name muss als der jüngere gestriehen werden. Die Nereis pulsatoria M o n t. et L e a c h (Lycor is pulsatoria S a vigny, Syst des Ann. 1820, pag. 33) ist mukenntliel. Die Original-Exemplare sind verloren. Es bliebe eigentlich nur eine $N$. pulsatorin A ud. u. M. Edw. wenn nieht Quatrefages l. c. pag. 503 eine $\boldsymbol{N}$. pulsatoria besehriebe, von der er vermuthet, dass sie sieh der $N$. pulsatorin Mont. (S a v.) nähere, und ausdriieklieh angibt, sie weiehe von der $N$. pulsatoria A ı d. a. M. Edw. wesentlich ab. Aueh führt er in der Synonymie seiner pulsatoria gar nieht die $N$. pulsatoria Aud. u. M. Edw. an. G i' u b e (Bemerkungen ïber Anneliden d. Pariser-Museum, Arehir f. Naturg. 36. B. 1870, pag. 309) spriebt sich ebenfalls für die Selbststïndigkeit der N. pulsatoria A ud. u. M. E dw. aus und ist nieht abgeneigt die $N$. pulsatoria Quatrefages für die $N$. zonata II grn. zu halten. Jedenfalls kaun nur eine einzige $N$. pulsatoria berüeksiehtigt werden und dis ist die von $\mathbf{A} u \mathrm{~d}$. u. M. E d w.

Ieh habe das auseinındergesetzt, weil Grube (Insel Lussin, Breslan 1864, pag. 81) eine N. pulsatoria Mont. von Crivizza (Westkiiste von Lussin) anfiihrt, die er, weil schleeht erhalten, nur an den Kieferspitzehen des ausgestreekten Pharynx erkannte. Naeh dem Gesagten kann das eine Nerers falsa Quatrefages, eine $N$. pulsutoria Aud. u. M. Edw., ja selbst eine $N$. diversicolor gewesen sein. 
Iclı fand die $\boldsymbol{N}$. diversiculor an mehreren Stellen der Bai von Muggia; anch in Abzugsgräben der ehemaligen Salinen bei Zaule in stark versiisstem Wasser.

\section{Armemalia oligops n. sp.}

('T'uf'. VII, Fig. 4.)

Meine Besehreibung ist mangelhaft, weil ieh nur eines einzigen Exemplares habhaft wurde und dieses noch während der Untersuchung durch einen mgliieklichen Zufall zu Grunde ging. Ich glaubte jerloch die Veröffentliehung der bis zum Augenblicke der Zerstörnng gemachten Notizen und Zeichnungen nicht vorznenthalten, da unsere Kemntnisse iiber diese merkwiirdige, Polyopthalmus zunächst verwandte, Gattung noch sehr gering sind, und ieh die wesentlichen Merkmale alle in den Bereich meiner Untersuchungen latte ziehen können.

Das Thier war $3 \mathrm{Mm}$. lang, etwa $0 \cdot 2 \mathrm{Mm}$. breit nugefärbt, dem freien Ange scheinbar ungegliedert, nematudenartig. An dem Vorderende des conischen Kopflappens ('Taf. VII, Fig. 4) stand ein kurzer, an der Basis eingesehniirter, stumpfer, beweglieher Fortsatz. 3 Angenflerke lagen in einer Linie beilänfig in der Mitte des Kopfes, mmittelbar anf dem Gehime. Hinter die sen waren zu Seiten des Kopfes zum Theil entfaltete Wimperfalten $(x)$, eine jederseits, bemerkbar. Der Körper war aus 26 Segmenten und einem, 7 knrze fingerartige Anluänge tragenden Aftersegmente zusammengesetz. Jedes dieser 26 Segmente (Taf. VII, Fig. 4 4) trug ein Paar fast rechteckiger Ruder, deren vorderer und hinterer Rand gerade, der Aussenrand etwas gewölbt war. Die Ruder waren beiläutig ' 4 so lang als die Segmente breit, mit einem Biisehel kurzer Capillarborsten und narh innen von diesem mit einem zweiten doppelt so langen ansgeriistet. Vom 2. Segmente an bis inclusive 21. erscheinen medial oberhalb Iles hinteren Randes des liuders cirrusartige Gebilde, die an ilırer Oberfläche mit Cilien bedeckt sind, und der ganzen Länge narh einen centralen, von einer periferen \%ellenlage hegrenzten Hohlraum zeigen. Ich habe niehtbeohachtet, ob sie Blut fiihren. Derartige Cirren oder Kiemen sind im Gamzen 20 Paare. Das erste Segment und die 5 letzten hatte deren keine. Von 7 . Segmente an traten ummittelbar oberhalb des Ursprunges der Ruder 
augenartige Pigmentflecken auf: Augenflecken. Das letzte Paar stand am 17. Segmente, so dass deren also 11 Paare waren. Liehtbrechende Körper habe ich nicht notirt. Vom 4. bis 24. Segmente erfullten rosenrothe granliche Eier mit grossen Keimbläschen und Keimflecken die Leibeshöhle und comprimirten deı Darm.

Mit der von d e Fili pl p i gegebenen Diagnose seiner Gattung Armandia: "privo di fossete vibranti ecfaliehe" stcht allerdings meine Art in Widerspruch, da Wimperlappen vorhanden sind. Doch können diese Organe Filipp i entgangen sein. Die iibrigen Merkmale: Estremità anteriore del eorpo eon un prolungamento proboseidiforme. Cirri laterali, ed alle base di questi due tubercoli setigeri passen vollkommen. Die einzig angeführte Art charakterisirt de Filippi wie folgt: La specie uniea sinora, che io chiamero A. cirrlosa, potrà essere caratterizzata dal numero lei cirri ehe è di 24 in serie, d'ambo i lati. Ad ogni eirro eorrispondono due macehiette pigmentali nere. Letztere Stelle ist einigermassen dunkel. Wörtlich würde es heissen: Jedem Cirrus entspreehen 2 sehwarze Pigmentflecken. Damn miissten 96 solehe Flecken sein. Es ist aber wahrseheinlich, dassde Fil ipp imeinte, jedem Paare von Cirren entsprechen 2 Pigmentflecken, so dass dann 48 vorhanden wären. Nach de Filippi hat meines Wissens Gruber allein eine Armandiu zur Bcobachtung bekommen und zwar ebenfalls ans der Adria, ans Portorè. Sein Exemplar war $7 \mathrm{Mm}$. lang, $1 \mathrm{Mm}$. breit mul hatte 26 fiufringlige Segmente. Das Aftersegment mit wenigstens 8 ziemlich ovalen Papillen. Cirren an allen Segmenten mit Ausuahme des 1. und der 3 letzten, somit 22 Paare. Augenflecken begannen am 8. und hörten am 21. auf, also 14 Paare (nicht 15, wie Grube angibt). Am Kopfe sah Grube an dem Weingeist-Exemplare nur 2 Augenpunkte und 2 zur Seite hervorragende saekförmige Gebilde, die er fiir Wimperorgane ansprechen zu kömnen glaubt. Grube zieht diese

1 F. de Fili p p i, Armandia, nuovo genere di Anellidi nel Mediterraneo Archiv, per la zoolog. l. Anat. ela Fisiolog. 1861, fascic. II. Vol. I. Genova. p. 215 , Tab. XIV, Fig. 7.

2 Familie der Opheliaceen pag. 60 und 66. 46. Jahresb. d. schles. Ges. f. vat. Cultur 1868, Breslan 1869.

(v. Marenzeller.) 
Form zur A. cirrosı de Filippi. A. cirrosa hätte somit einmal (nach de Filippi) 3 Augen am Kopfe, 24 Paar Cirren, 24 (oder 48) Paare Augenflecken und das andere Mal (nach Grube) 2 Augen am Kopfe, 22 Paar Cirren und 14 Paar Augenflecken. Meine vollkommen gesehlechtsreife Form ron Triest hat 3 Augen am Kopfe, 20 Paar Cirren, 11 Paar Augenflecken. Ob nun alle drei zusammengehören, wage ich nach dem bisherigen Materiale nicht zu entseheiden. Ich ziehe es vor, die $A$. cirrosı Fili p pi intact zu erhalten und stelle meine Armandiu ron Triest als eigene Art hin, nur die Frage offen lassend, ob nicht die ron Grube bei Portorè gefundene Art mit meiner zusammenfalle.

Zwischen Nulliporen und Algen bei Zaule.

\section{Lagis (Pectimaria) Koreni}

Fig. VII. Fig. 5 .

I a lmgren, Nordiska Hafs-Annulater. Öfversigt. af kongl. Vetensk Akad. Forhandl. 1865, Stockholm 1866, pag. 360, et Annulata polychaeta, ibid. 1867, pag. 213, tab. XIV, Fig. 74.

I arenzeller, E. v., Ueber Lagis (Pectinaria) Koreni aus dem Nittelmeere nnd die Hakenborsten der Amphicteneen. Verhandlg. d. k. k. zoolog. bot. Ges. in Wien, Bd. 241874 , pag. 217.

Ich gebe die Abbildung einer Hakenborste, im Profil ( $\alpha$ ) und in verticaler Stellung $(\beta)$. Man sieht die groben Kammzähne in 2fachen Längsreihen und die undentliche Doppelreihe der feinen Zähnchen, die nur ${ }^{1}$; cc. der ganzen Länge der Hakenborste ausmacht. Der Meisselzaln $\left({ }^{*}\right)$, das hintere Ende der Hakenborste, erscheint in Obensicht als Halbkreis.

Gefunden bei Zaule während der Ebbe an Stellen, die geewöhnlich 3-4' unter' Wasser. Eine nähere Beschreibung dieser Pectinarie und der Nachweis, dass sie die Pectinaria Malmgreni Grube, $=P$. neipolitana $\mathrm{Clapar}$ àde ist, sowiedass diese mit der Lagis Koreni Mgru. aus der Nordsee zusammenfällt, wurde von mir a. a. 0 . durehgefithrt.

\section{Melimun alviatica.}

Taf. VII, Fig. 6.

Die Thiere massen ohne Kiemen und Fiihler 15-30 Mm. in der Länge, 2-2.5 Mm. in der Breite. Der Körper graubräun- 
lich mit einem Stich in's Fleischfarbne, vorne jederseits mit einem blutrothen Flecke an den Seitentheilen; der Riicken in seinem ersten Viertel undeutlich weiss gesprenkelt. Die weisslichen Kiemen mit brammem Mittelstreif. Die Tentakel farblos.

Der Kopflappen (Fig. $6 k$ ) quer getheilt. Der vordere Antheil dreilappig mit vorspringendem mittlerem Lappen. Der hintere Antheil schmal, halbringförmig, links und rechts ron feinen bramen Punkten getiipfelt.

Das Buccalsegment (Fig. 6 b) erstreckt sich dorsal bis zur Ursprungsstelle der Kiemen und ist annïherd so lang als der Kopflappen. Sein vorderer Rand ist der ganzen Länge nach in ähnlicher Weise mit feinen braunen Punkten gezeichnet wie der hintere Theil des Kopflappens. Ventral schiebt er sich als conischer Zapfen nahe bis an das vordere Ende des Kopflappens.

Die 4 folgenden Segmente bilden eine Art Kragen, die soge. nannte Nackenfalte (Fig. 6rx), der halbringförmig, mit freiem Rande das Buccalsegment umfasst und dann, in gleicher Ebene leiläufig mit dem Kopflappen, rechts und links einen Winkel bildend in etwas geschwungener Linie auf den Riicken zieht, wo er etwas unter und hinter dem Kiemenbiischel an den Seitentheilen des Körper's mit runder Ecke endet. An diesen Stellen liegen die erwähnten blutrothen Flecken, die blässer werdend nahe dem Rande des Kragens nach abwärts ziehen.

Zwischen den beiden dorsalen End en des Kragens erscheint ein häutiger Lappen (Fig. $6 y$ ), dessen freier Rand schwach ausgerandet ist. Man kam daran bei den einzelnen Exemplaren t-8 vollkommen abgerundete Zacken erkennen. An unausgewachsenen Thieren sind sie undentlich oder gar nicht vorhan(len. Der vordere Rand dieses Kammes liegt in gleicher Höhe mit dem 4. Segmente, sein hinteres Ende ist an der Grenze des o. Ind 6. Segmentes angewachsen.

Etwas ror diesem Kamme, ummittelbar an dem hintern Ende der dorsalen Hülfte des Buccalsegmentes, entspringen die $8 \mathrm{Kiemen}$ (Fig. 6 br). Sie sind in einem Hufeisen angeordnet, dessen Convexität nach oben gerichtet ist und zwar derart, lass rechts und links je eine Gruppe ron 3 nur an der Basis untereinander rerwachsenen Fïden steht, welche Gruppen sich in der Mittellinie beriihren, und vor diesen eine dritte, nur aus 2 Faden 
bestehende. Die Kiemenfäden sind flach, glatt mit braunem Mittelstreif, rerhältnissmässig breit an der Basis und gehen erst in ihrer oberen Hälfte in eine verjiingte Spitze ans. Sie reichen zuriikgelegt bis in das 12 Segment.

Hinter der seitlichen Gruppe der Kiemenfäden, zwischen dieser und dem dorsalen Kamme, ragt jederseits aus einerkleinen runtlichen Erhabenheit ein nach linten gekrimmter starker Haken (Fig. 6 h und Fig. 6 A) hervor. Einmal waren links 2 solche Haken.

Die Tentakeln (Fig. $6 t$ ) kamen mir nur an einem einzigen Exemplare zur Ansicht, als 4 glatte, etwas convexe weissliche Faden, die aus der Mundöffnung hervorragten. Sie waren um die Hälfte schmäler als ein einzelner Kiemenfaden und theils kiirzer, theils unbedeutend länger. Die Thieren hatte 78-91 Segmente. Die 3 ersten Segmente besitzen Bündel ungesäumter Capillarborsten (Fig. 6 B), die einfach in gleichen Zwischenräumen in dem Rande des Kragens stecken, der Buccalsegment und Kiemen umfasst. In dem dorsalen Ende des Kragens steckt das 4. Borstenbündel, gleichfalls olne Andentung eines Borstenhöckers oder Ruders aber mit gesäumten Capillarborsten. Die folgenden 14 Segmente (5 bis incl. 18) tragen Capillarborsten, die ans einem Ruder hervorragen und Flösschen mit Hakenborsten, wälnend die iibrigen (60-73) Segmente mit Ausnahme des Aftersegmentes nur Flösschen mit Hakenborsten zeigen.

Die Ruder sind cylindrische Fortsätze, die durch einen verticalen, jedoch nicht bis zur unteren Fläche durchdringenden Einschnitt gespalten sind. So entstehen eine schmälere, zugleich etwas kiirzere vordere und eine breitere etwas längere hintere Lippe, zwischen welchen das aus cc. 14 Borsten (Fig. 6 C) bestehende Biindel austrittt. Die Borsten sind einfach, mit ziemlich hanchigem Saume und von ungleicher Länge.

Die ersten 18 Segmente machen beiläufig ein Viertel der ganzen Körperlänge aus. Vom 19. Segment an steht ober den Flösschen nur ein winziger Höcker als Andeutung des fehlenden Rnders. Die Flösschen bilden rom 26. Segment cirea an eine kurze ventrale Spitze.

Die Hakenborsten (Fig. 6, D) haben ansser dem abgerundeten Hinterrande 5 grosse und einen kleinen Kammzahn. 
Nur die äussersten in einer Reilıe traf ich כzähnig. Zumeist liegen $36-47$ Hakenborsten in einem Flösschen mit Ansnahme der ersten und letzten, so beispielsweise im ersten 22.

Das Aftersegment ist abgerundet, die etwas dreieckige Afteröffinung steht dorsal.

Die Röhren der Thiere waren durchsehnittlich $70 \mathrm{Mm}$. lang, $3 \mathrm{Nm}$. breit, grau, lederartig;, spärlich mit Sandkörnern und Iuschelfragmenten besetzt.

Wenn man vorliegende Sehilderung mit jener der Sulbellides cristatu S a r's M.', die M a $1 \mathrm{~m} g \mathrm{~g}^{\prime}$ e $\mathrm{n}^{2}$ mit Recht zu einer eigenen Gattung (Melinna) erhob, vergleicht, wird man einerseits alle Eigenthiimlichkeiten dieser Art wiederfinden, anderseits die Auffassung der adriatischen Melinna als Art für sich gerechtfertigt halten. Es liegen die Unterschiede zwischen diesen beiden Arten in der grossen Zahl der Segmente der adriatischen Form bei geringerer Kö̈rpergrösse, in der grösseren Kürze der Kiemen, in einer veränderten Beschaffenheit des häutigen Kammes am Riicken, in der etwas abweichenden Gestalt der Borsten, in der geringeren Zahl der Hakenborsten in einem Flössehen, in den 6zähmigen Hakenborsten (M. cristutu hat 4zähnige) und endlich in der abweichenden Färbung. Die zweite der bisher bekannten Arten Melima palmata ${ }^{3}$, von $\mathrm{G} \mathrm{r}^{\circ} \mathrm{u}$ b e bei St. Malo in einem einzigen Exemplare anfgefunden und nur kurz charakterisirt, steht der H. adriatica sehr nahe; doch hat sie in grösserer Ansdehnung, zum Theil bis anf ein Drittel ihrer ganzen Länge, verwachsene Kiemenfäden, nur 4 gleichgrosse Kammzähne an den Hakenborsten und eine andere Färbung. Die Entscheidung; ob sie mit der adriatischen Art identisch muss späteren Untersuchungen vorbehalten hleiben.

Mit der M. adriatica ist ein Repräsentant der bisher aus dem Mittelmeer nicht bekannten Gattung Melinna gegeben. Ich fand sie bei Zanle im lettigen Grunde in einer Tiefe von $t^{\prime}$.

1 Fauna littoralis Norvegiae. Seconde Livraison Bergen, 1865, pag. 19 Pl. 2, Fig. 1-7.

2 Nordiska Hafs Amunlater. Öfversigt af kongl. Vetensk. Akad. Förhand. 1865, Stoekholm 1866, pag. 371, Tab. XX. Fig. 50.

3 Grub e, 47. Jahresber. der sehles. Ges. f. vaterl. C'ultur. 1864 Breslan 1870, pag. 68 und Bemerkungen iber die Amphicteneen unil Amphareteen ebenda 1870 , Breslan 1871, pag. 82 . 


\section{Verzeichniss}

\section{der in Betracht gezogenen Gattungen und Arten.}

(Die Synonyme sind durchschossen gedruckt.)

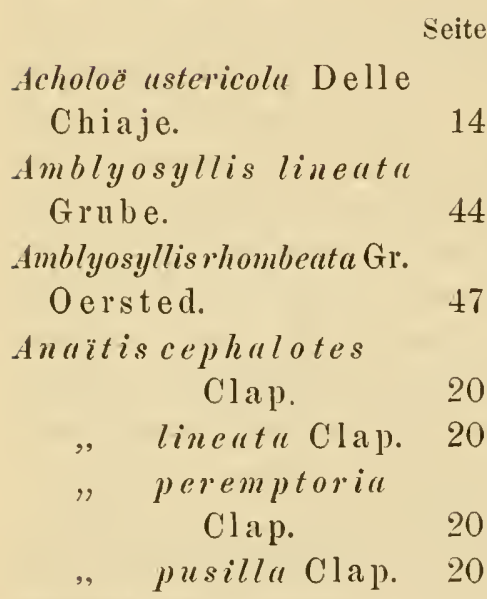
Armandiucirrosu Filippi. 65 , oligops $n . s p$. Autolytus hesperidum

Clap. Carobia cephalotes Clap. 20 " linerta Clap. 20 " lugens Ehlers. 20

, patugonicu

K in b $g$.

.. peremptoria Clap. 20

, pusilla Clap.

0

Eulatia macroceros Gr u be. 18 , pallida Clap.

"volucris Ehlers. 18

Eumida Mgru.

Eunice Claparedii

$$
\text { Quatref. }
$$

,Harassii Aud. et M. E d w.

„ torquutu Quatref. 57 Guttiolu spectubilis Jo hnston.

Grubea dolichopoda n. sp. 26 " limbata Clap. $\quad 29$ " pusilla Clap. 25 " tenuicirrutu $\mathrm{Clap} .29$ Hediste $\mathrm{Mg} \mathrm{gr}^{\mathrm{n}}$. $\quad 60$ Lagis Koreni M grn. $\quad 66$ Lycoris pulsutoriu Sav. $\quad 63$ Mania Quatref. 22 Mania "gilis Ehlers. 22 Marphysu Bellii A ud. et M. E d w. 
Zur Kenntniss der adriatischen Anneliden.

Seite

Marphysa sanguinea

Mo nt.

60

Melima adriatica n. sp.

cristatu S a r's.

66

69

palmata Grube. 69

Nereis diversicolor O. F.

M iill.

60

falsu Quatref.

", flexuosu Delle

Chiaje.

, parallelogram-

ma Clap.

. pulsutoria

Nont.

pulsatoria A ud. et

Edw.

, pulsutoria (?)

Rathke.

"pulsatoria

Grube.

, pulsatoria Qua-

$\mathrm{t}$ ref.

, squamosa Delle

Chiaje.

, zonata $\mathrm{Mg} \mathrm{rn}$.

Nirotia lineolatu Costa. 47

Odontosyllis virescensu.sp.

Ophiodromus flexuosus

Delle Chiaje. 23 vittatus $\mathrm{S}$ ars. 23

Oxydromus flaccidus

Gr. $\ddot{0} \mathrm{rsd}$.

fasciatus

Grube.

longisetis

Gr. Örs d.
62

23

62

63

63

63

63

63

14

63

Pterocirrus Clap.

Phyllodoce lugens

Ehlers.

Podarke agilis Ehlers. 22

" pallida Clap. 25

Polynoë astericola

Delle Chiaje. 14

" crassipulpa n. sp. 6

", Jolnstoui n. sp. 14

, Lamprophthalma

n. $s p$.

2

malleatn

Grube.

14

reticulut $\mathrm{Cl}$ a p. $\quad 6$

, scolopendiina

Sar.

" scolopendrina

Johnston.

14

, variegata

Gribe.

13

Pterosyllis lineata Grube. 44

, plectorhyncha

$$
\text { n. } s p \text {. }
$$

47

Procernea aurantiaca

Clap.

brachycephala

$$
\text { n. } \mathrm{sp} \text {. }
$$

25

luxuriuns n. sp. 50 
v. Marenzeller.

\begin{tabular}{|c|c|c|c|}
\hline & beit & & eit \\
\hline Sabellides cristata & & Syllis gracilis Grube. & \\
\hline Sars. M. & 69 & ,, hyalina Grube. & \\
\hline Sphaerosyllis hystrixC la p. & 25 & Inssinensis Grube. & \\
\hline Stephania Clap. & 24 & macrocolu $n . s p$ & \\
\hline Stephaniaflex nosa & & pellucida Ehlers. & \\
\hline Delle Chiaje & 23 & prolifera I & \\
\hline Sthenelais fuliginosaCl a p. & 15 & vittata Grube. & \\
\hline Syllides pulliger Krohn. & 28 & $z e b r a \mathrm{Grube}$. & \\
\hline yllis Armandi Clap. & 30 & Trypanosyllis Krohni C l a & \\
\hline , aurita Clap. & 35 & C $C$ & \\
\hline
\end{tabular}




\section{Erklärung der Abbildungen.}

k. Kopflappen.

p. Palpen.

u s. Unpaarer Stirnfïhler.

$p s$. Paarige Stirnfiihler.

b. Buccalsegment.

d $f$. Dorsaler Fühlercirrus.

$v f$. Ventraler Fühlercirrus.

$r c$. Riickeneirrus.

$b$ c. Baucheirrus. $v$ l. Vorderlippe des Ruders.

m l. Mittellippe, ,

$h$ l. Hinterlippe $\pi$,

a c. Aftercirrus.

$r$ Rüisselröhre.

s. Schlundröhre.

z. Zahn der Sehlundröhre.

m. Drïsenmagen.

Tafel I.

Fig. 1. Polynoë lamprophthalma u. sp. Von oben 70/1.

" $1 \mathrm{~A}$ " $\quad$ Hinterfläche des Ruders in Seitenlage 70/1, $\propto$ oberer Ast des Ruders.

$\Rightarrow 1 B \quad$.. $\quad$ Borsten 500/1.

" 1 C $"$ Elytre $50 / 1$.

Fig. 2. Sthenelais fuliginosa Clap. Vorderfläche des Ruders in Seitenlage 30/1. b r. Kieme; e. Elytra; $f$. Flimmerkissen; $m$. Mitteltheil des unteren Astes; $v$. Vorderlappen; $b c$. Banchcirrus.

$\rightarrow 2 A \quad \Rightarrow \quad$ Elytre $20 / 1$.

\section{Tafel II.}

Fig. 1. Polynoë crassipalpa n. sp. Von oben 70/1.

" $1 \mathrm{~A}, \quad$,

Hinterfläche des Ruders in Seitenlage 30/1. $\alpha$ oberer Ast des Ruders; -papillenartiger Fortsatz; $f$. die tiefe Furche der Ventralflïche. 
v. Marenzeller.

Fig. 1 B Polynoë crassipalpa n. sp. Borsten 500/1. $\alpha$ Borsten des oberen Ruder-Astes, $\beta, \gamma$, $\delta$ Borsten des unteren Astes.

ก $1 C \quad$. Elytre, $50 \%$.

r. $1 \mathrm{D} \quad$. $\quad$ Aftersegment von der Bauchfläche.

, $1 E \quad$, $\quad$ Ein Kiefer, $70 / 1$.

\section{Tafel III.}

Fig. 1. Syllis lussincnsis Grube. Von oben, 70/1.

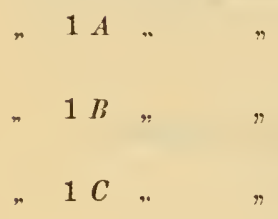

Vorderfäche eines Ruders in Seitenlage, 130/1.

A cicula mit schwach fussförmigem Ende $500 / 1$.

Eine kürzere und eine längere Borste, 5001.

Fig. 2. Syllis vittata Grube. Von oben, 251 .

" $2 A \quad$. "

r $2 B$, .

Hinterfläche eines Ruders in Seitenlage, 70/1.

$" 2 C, " \quad$

Eine Borste, 500/1.

Zahın der Schlundröhre, 70/1.

Fig. 3. Syllis macrocola $n$. sp. Von oben, 70/1.

" $3 A$ " ,

Eine Borste, 500/1.

" $3 \mathrm{~B}, \quad$ Aftersegment mit den 2 vorhergehenden Segmenten, 70/1.

\section{Tafel IV.}

Fig. 1. Grubea dolichoporla n. sp. Yon oben, 160/1.

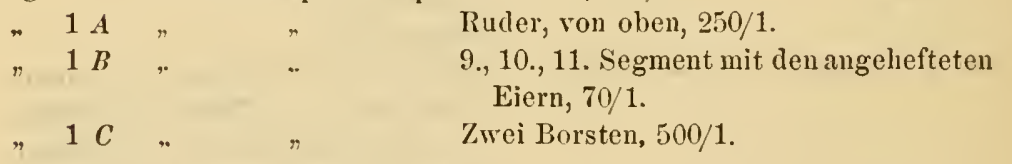

Fig. 2. Odontosyllis virescens $n . s p$. Yon oben. $x$ der Wimperlappen am

त $2 A \quad$ - $\quad$.

, $2 B \quad, \quad$,

" $2 C \quad$ r

" $2 D \quad$.
2. Segmente, $70 / 1$.

Hinterflïche eines Ruders in Seitenlage, $90 / 1$.

Die beiden Formen der Aciculen, 250/1. Eine Borste, 500/1.

Eingang in die Schlundröhre. $z$ die 6 Zähne, $\alpha$. die seitlichen Chitinplatten. 3. der mit einer Chitinmembran ausgekleidete kappenartige lintere Theil der Rüsselröhre, $70 / 1$. 


\section{Tafel $\boldsymbol{V}$.}

Fig. 1. Trypanosyllis selora Grube. Zahnkrone im Eingange der Schlundröhre, $250 / 1$.

Fig. 2. Pterosyllis lineata G $\mathrm{r} u$ be. Kopflappen und Buecalsegment von oben. $x$ die flïgelartigen Wimperlappen, $70 / 1$.

r $2 A \quad, \quad$,

Kopflappen ron unten. $p$ die nach hinten umgesehlagenen Palpen. $b$. Bucealsegment. o Nund, 70/1.

" $2 \mathrm{~B}$ Pterosyllis lineata $\mathrm{Grub}$. Rnder ron oben, 70/1.

$\begin{array}{llll} & 2 C & & \\ & 2 & D & \end{array} \quad$,

Eine der längsten Borsten, 250/1.

Der mit 12 Zïhnen bewaffnete Eingang in die Schlundröhre, $500 / 1$.

Fig. 3. Pterosyllis plectorhyncha n. sp. Natiirliche Grösse.

" 3 " " Von oben, 35/1.

" $3 A \quad "$

Kopflappen von unten. $p$ die nach hinten nmgeschlagenen Palpen, b. Bueealsegment, o Mund, 70/1.

\begin{tabular}{|c|c|}
\hline$n \quad 3 B$ & , \\
\hline $\rightarrow 3 C$ & , \\
\hline $3 D$ & " \\
\hline
\end{tabular}
Eine der längsten Borsten, 250/1.

Aftersegment und vorletztes Segment. $a$ c Aftercirren, 8/1.

Der mit 6 Gruppen zu je 3 Zälunen bewaffnete Eingang in die Schlundröhre. Halbe Obensicht, $500 / 1$.

\section{Tafel VI.}

Fig. 1. Proceraea lnxurians n. sp. Von oben, $70 / 1$.

$\begin{array}{llllll}n & 1 & A & & & \\ & & 1 & B & & \\ " & 1 & C & " & \\ & 1 & D & & \end{array}$

Vorderfäehe eines Ruders in Seitenlage $90 / 1$.

Die beiden Formen der Borsten, 500/1. Aftersegment mit den beiden vorhergehenden Segmenten, 70/1.

Kopflappen von unten. $o$ Mundöffnung $70 / 1$.

Fig. 2. Proceraea brachyceplata n. $s p$. Von oben, $70 / 1$.

n $2 \mathrm{~A}$. $\quad$,

Gruppirung der glänzenden Körperchen in der Iaut des Rüekens.

\section{Tafel VII.}

Fig. 1. Proceraea luxurians n. sp. Zilhnkrone am Eingange der Sehlundröhre 250/1. "2 Zïhne isolirt. 500/1.

Fig. 2. Proecraea brachycephalu u. sp. Hinterfläehe eines Ruders in Seitenlage. $115 / 1$. 
v. II a renzell er.

Fig. 2 A Proceraea brachycephala n. sp. Die beiden Formen der Borsten, $500 / 1$.

$\rightarrow 2 B \quad, \quad \quad$,

Zahnkrone am Eingange der Schlundröhre, 250/1; * 5 Zähne isolirt, $500 / 1$.

Fig. 3. Nereis diversicolor O. F. Miill. Das 60. Rnder in Seitenlage, 30/1. Fig. 4. Armandia oligops $n$. sp. Kopflappen von oben, $x$ Wimperfalten $70 / 1$.

$" 4 \mathrm{~A} \quad$ " 2 Segmente, der Lünge nach getheilt, $250 / 1$.

Fig. 5. Lagis Koreni M grn. Eine Hakenborste. $\alpha$ in Profil, $\beta$ in verticaler Stellung, * Meisselzahn, hinteres Ende der Hakenborste. $500 / 1$.

Fig. 6. Melinna adriatica $n$. sp. Seitenansicht 8/1.

$b r$. Kiemen, $t$. Tentakeln, $x$ Kragen (Nackenfalte), $y$ dorsaler Kamm, $h$ dorsaler Haken.

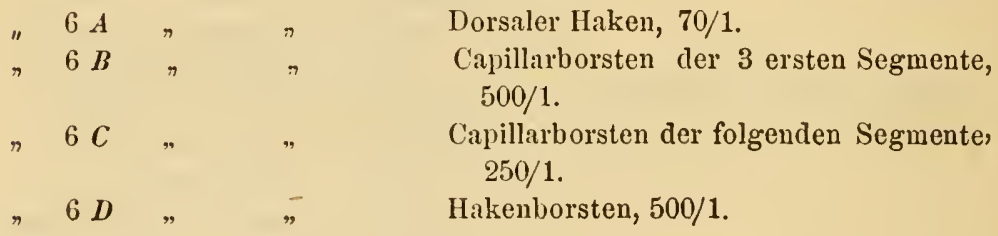




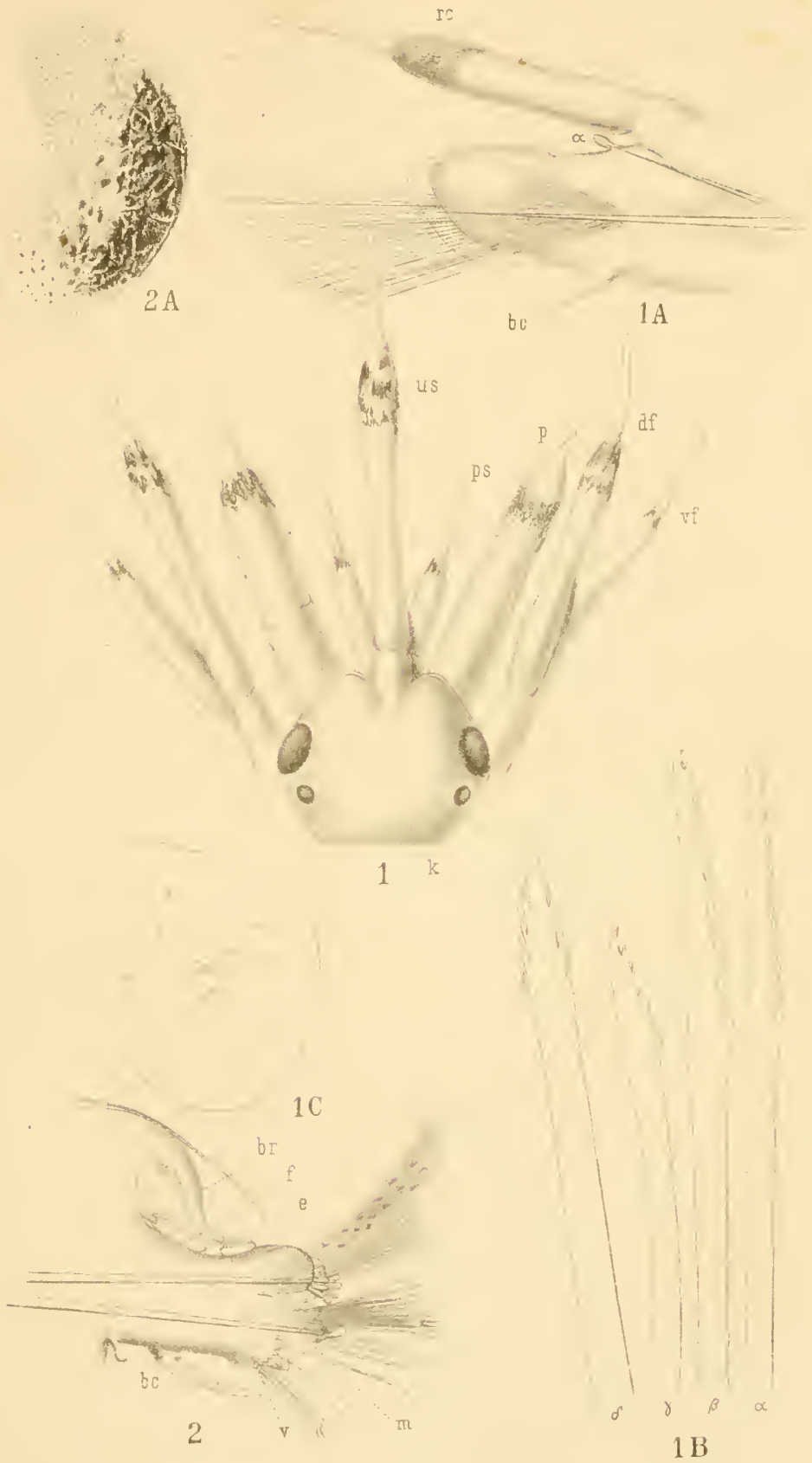





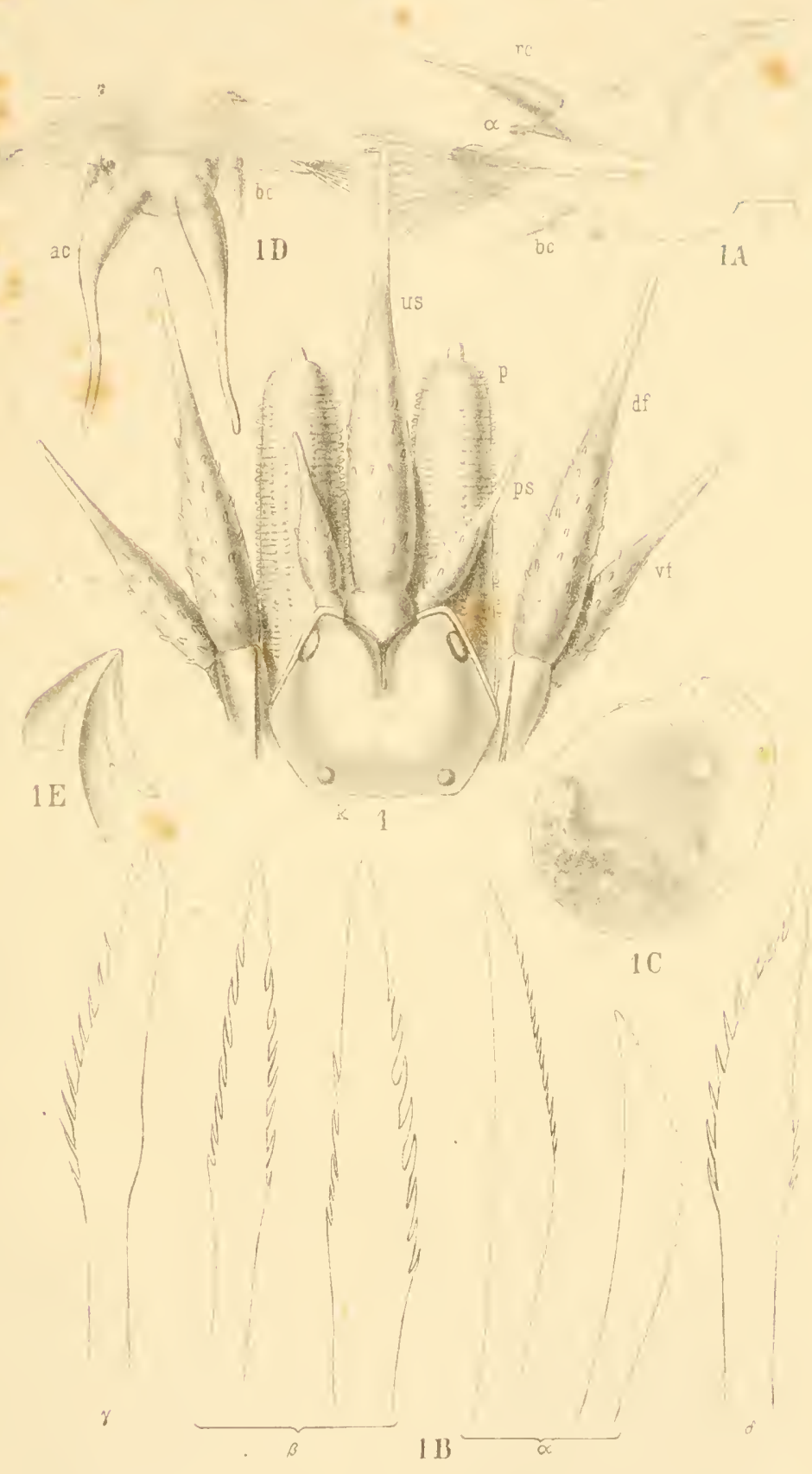

Sitzungsb d k. Akad. d. W. math. u. nat. (1. LUX Bd. I. Abth 187t. 


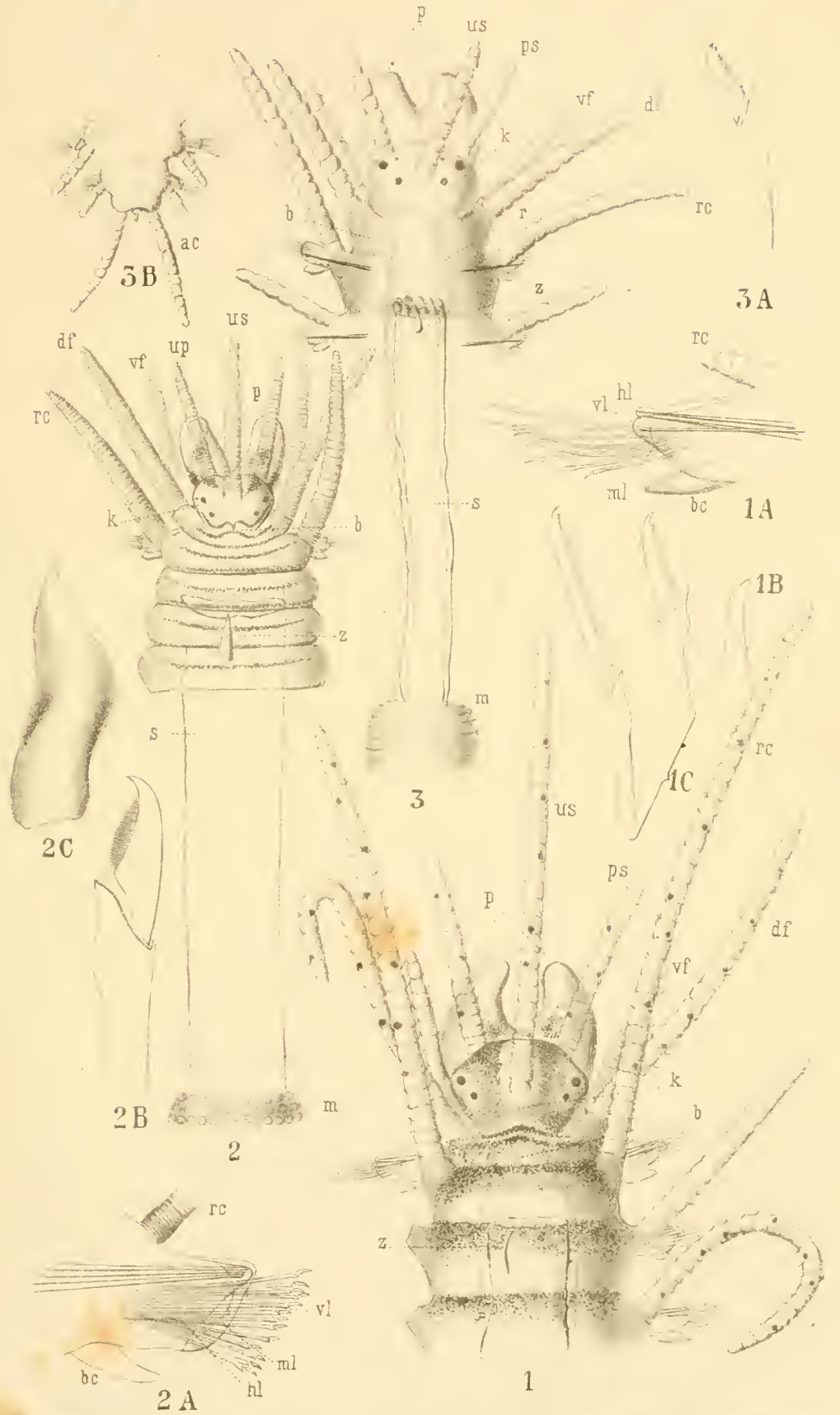

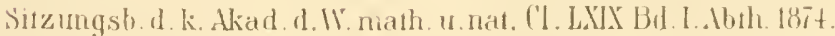





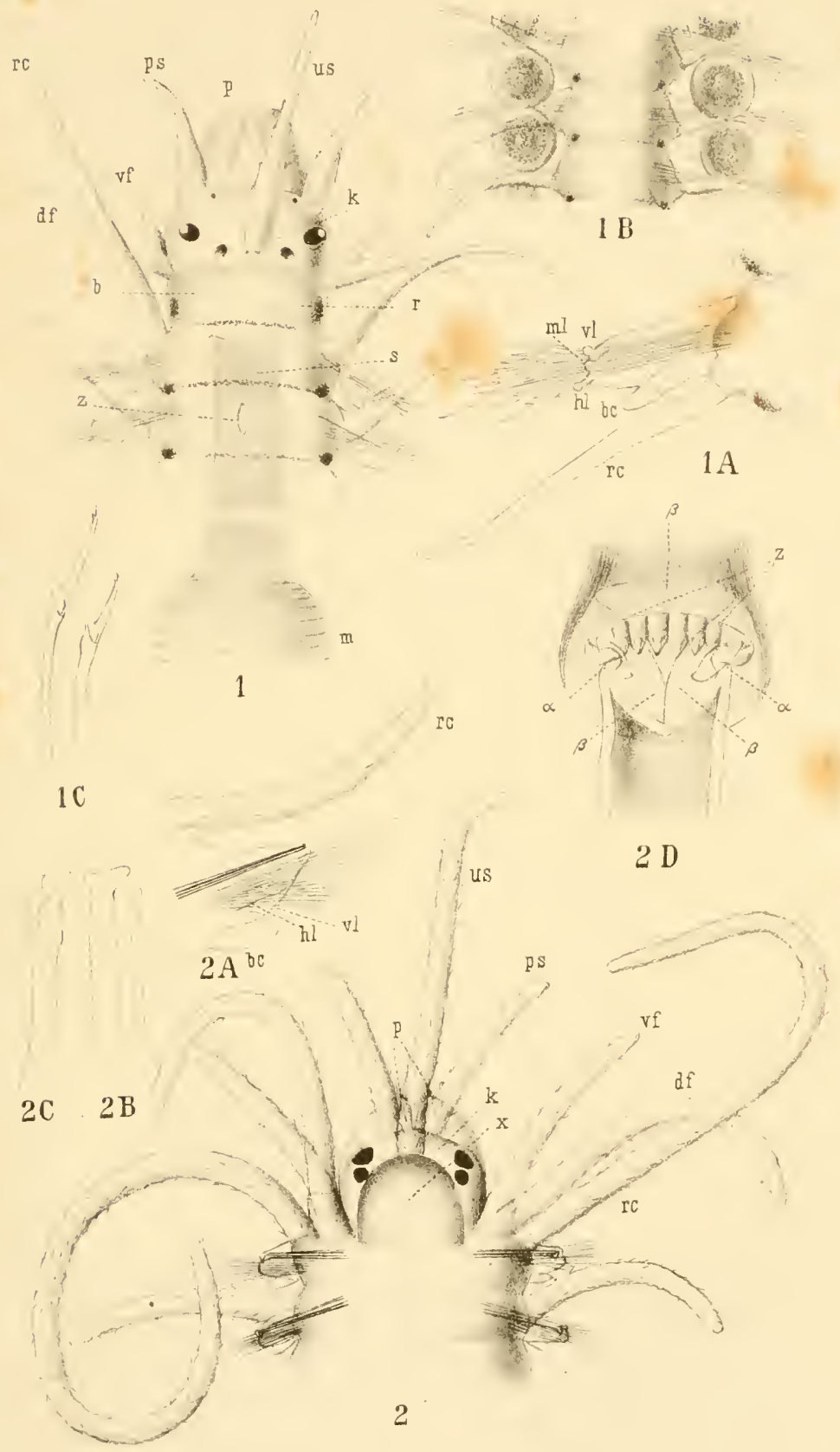


列 

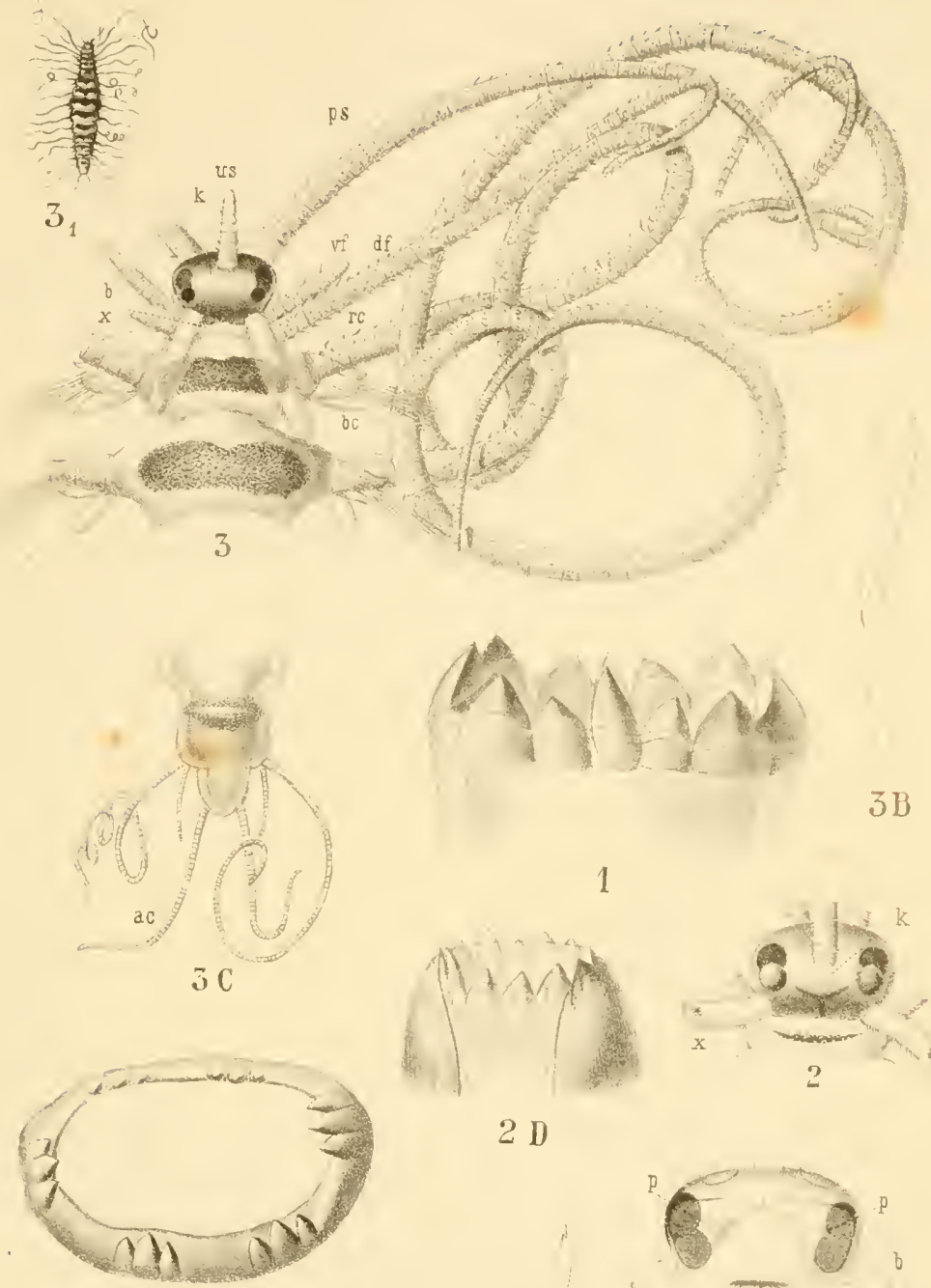

$3 \mathrm{D}$
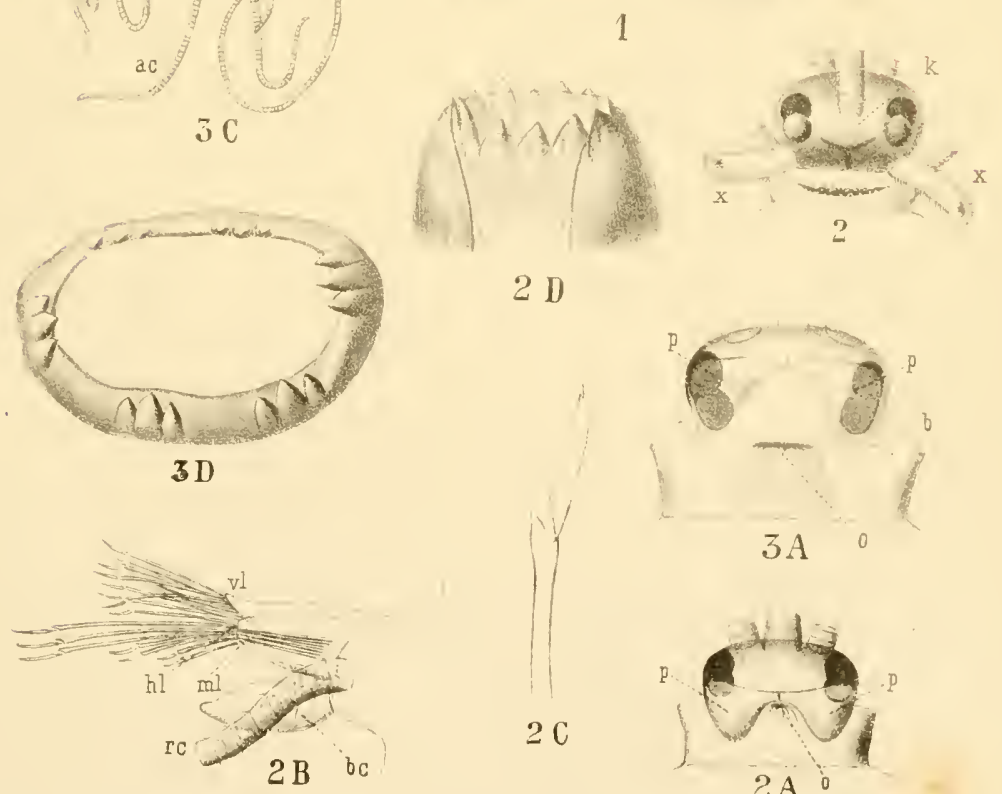

20

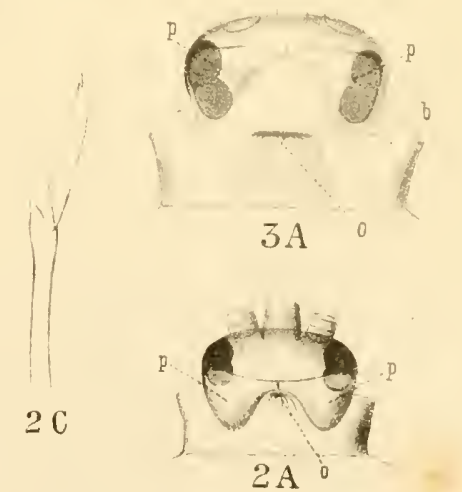

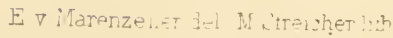

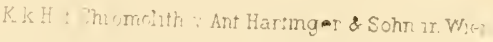

Sitzungsb. d k. Akad. d. W. math. w. nat. (1. LAX Bd I Abth. 1874. 



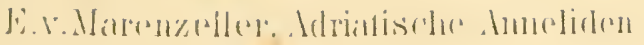

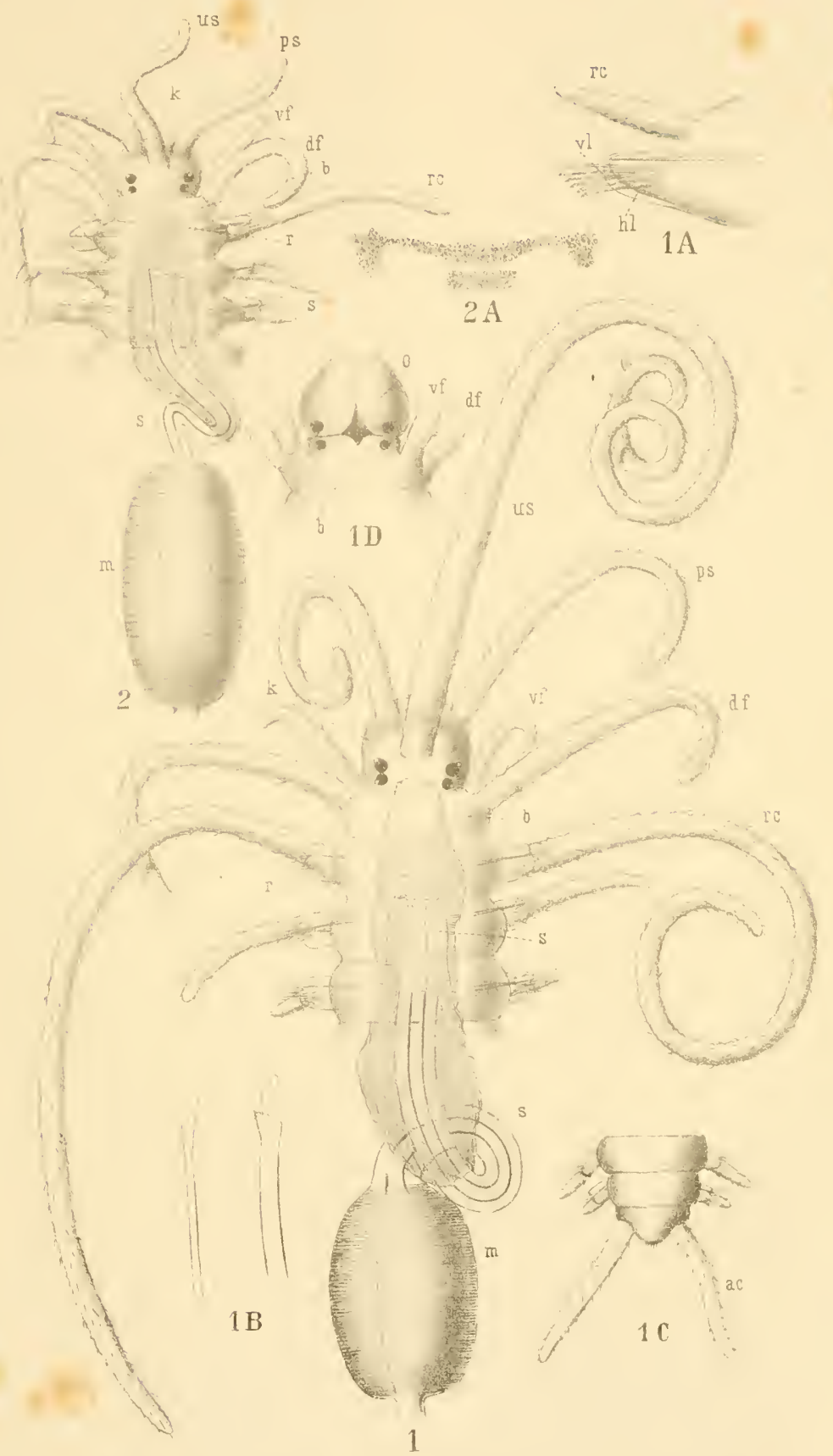

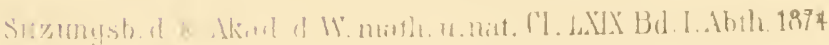




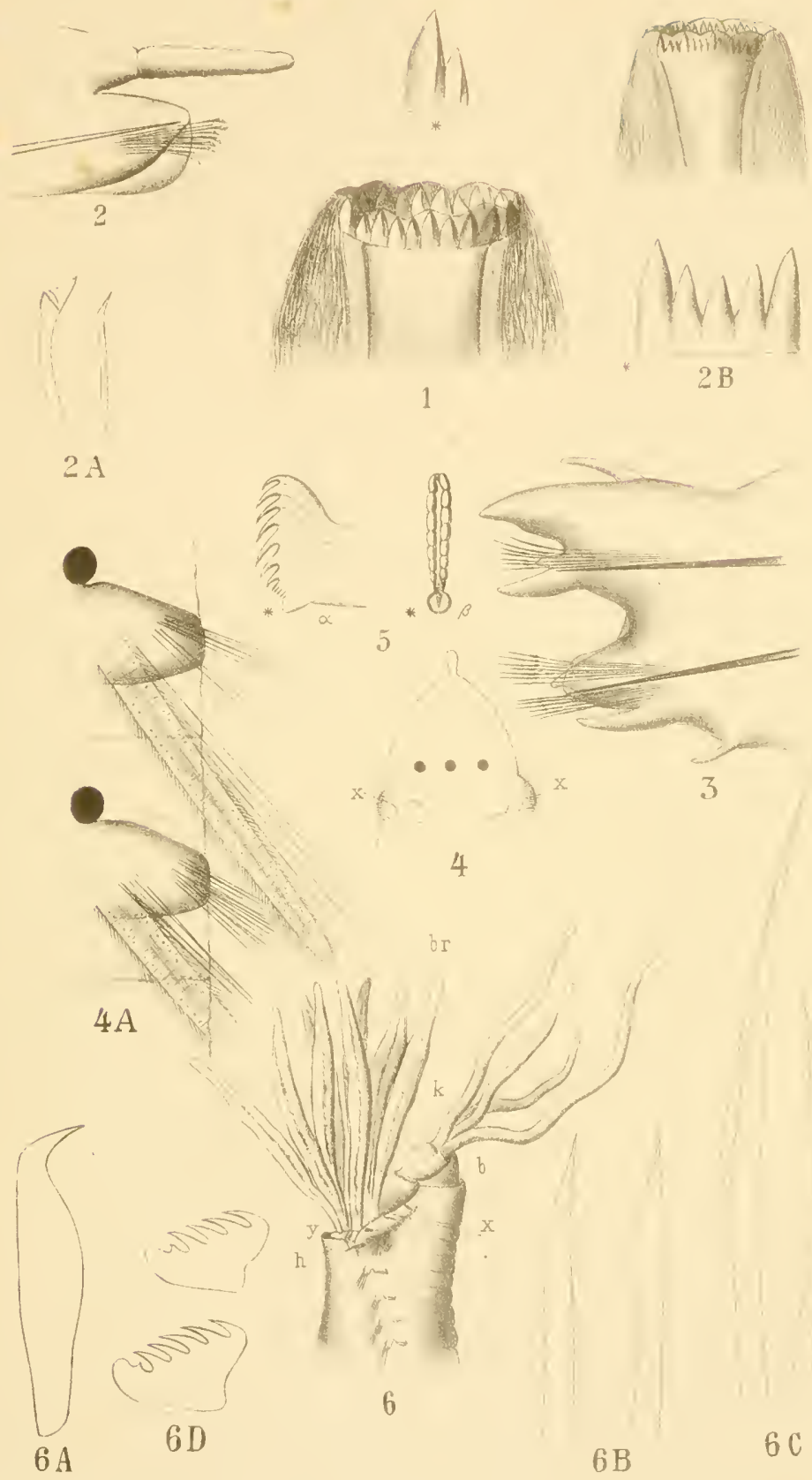

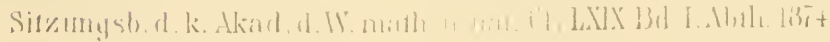



Zur Kemntmiss der adriatischen Ammeliden.

Zweiter Beitrag.

(Polynoinen, Hesioneen, Syllideen.)

Von Dr. Emil v. Marenzeller.

(Mit 4 Tafeln.)

Meine in LXIX. Bande (1874, Seite 407-482) dieser Sitzungsberichte reröffentlichten Beiträge "Zur Kenntniss der adriatischén Anneliden", fanden im rergangenen Herbste in Lussin piccolo and wieder in Zanle bei Triest eine theilweise Fortsetzung. In diesem zweiten Beitrage sind die Polynoinen 5 Arten), Hesioneen (1 Art), Syllideen (7 Arten) beriicksichtiget. Nene Arten sind: Ox'ydromus fuscescens, Syllis ochracea, Eusyllis assimilis, Proceraea macrophthalma.

Die an der französischen Westkiste anfogefundene Leunira Yhleni II gru. lebt anch in der Bai ron In ggia bei Triest.

Dic Untersuchung der acht iibrigen Arten ergab Bemerkungen zur Synonymie nud bei den weniger genan bekannten rollständig nene Beschreibungen.

Auch dieses Mal ist der grösste Theil der Abbildungen nach den lebenden Thieren gefertigt.

Bis anf Leanina Yhleni Mgrn. ggehören sämmtliche Formen der Litoralfanna an.

\section{Lepirlonotus clara.}

Aphrodita claca I ontagn, Deseript. of sev. Marine-Anim. found on the South Coast of Devonshire. 'T'rans. of the Limn. Soe. Vol. IX. 180s, pag. 108. Tab. VII, fig. 3.

P'olynoë scutellata Ri is s o, Hist. natt. d. princip. prod. de l'Europe mérid. Tome IV. Paris 18:6, pag. 414. 
Eumolpe squamulu Delle Chi aje, Mem. sulla Storia e Notom. deglí Anim. senzal rert. del regno di Nipoli. Vol. IV, 1829, pag. 155. Tab. LVII, lig. 8 \& 17.

Polynoë squumatu S a r.; Grube, Actinien, Eehinod, und Wïrmer des Ilittehn. Königsberg 1810, pag. s7.

Polynö̈ clyperatu Grube, Besehreibunğ nener oder wenig bekannter Annel. Areh. f. Naturg. Bd. 26. 1860, p. 71. Tat. III, Fig. 1. Ausflug nach Triest. 1861. pag. 138. 'Taf. II, Fig. 1; Insel Lussin 1864, pag. 77.

Lepidonolus cluvu $\mathrm{M}$ ont., Jolnnston Catal. of the British non Parasitie. Worms. London 1865, pag. 111.

Polynö modesta Qu a trefages, Hist. nat. d. Annèl. Paris 1865. Tome I, jag. 243.

Lepidonotus cluru (II ont.) Johnst., Malmgren Amul. polyeh. Spetzberg. Groenland. ete. Öfiersigt at k. Vetensk. Akid. Forhandl. 186ī, lag. 130.

Polynoè Grubiana Cl a par ède, Annél. ehétop. du golte de Naples. Mém. d. I. Sociét. de Phys. et d'Hist. nat. de Genève. Tome XX. 187i, pag. 373. I'l. I, fig. 2 .

Das Mittelmeer beherberat eine Polynoine, welche die grösste Verwandtschaft mit der Aphrodite squamatu L.' des atlantischen Oceans besitzt, vielfach heobachtet und melufach benannt wurde. Die A. squamatu L. bildet den 'Typus der Gattung Lepidonotus, wie diese von Ma $\mathrm{mgren}{ }^{2}$ begrenzt wurde.

Dic sehr markanten Charaktere liegen in den Ursprunge der parigen Fiihler von Fortsitzen des Koptlaplyens selbst, nicht von dessen Unterfliiche und (zum Unterschiede von Alentiu) in der Zahl der Elytren (12 Pare) sowie in den einfach spitzigen Borsten des unteren Biindels.

Der Lepidonotus squamutus L. besitzt glatte Lnterfiihler, a mit Körnern dicht besetzte gefranzte Elytren, während die Mittelmeerform mit Stäbchen besetzte Tnterfïhler, körnerarme, franzenlose Elytren zeigt. Ferner decken sich bei dieser die Elytren nicht so rollkommen und beriihren sich inr leicht in der Mittellinie.

1 Syst. Nat. Eil. X, p. 655.

a Nordiska Hafs-Ammlater. Öfrers, af k. Vet.-Akad. Förhand. 1865, pag. 56. Es ist nur der Passus, elytra totum dorsum tegentia" zu modificiren.

3 Unterfiihler Subutuculu nenne ich, dem Vorsehlage Grube's (Die Familie der Lyeorideen. 51. Jahresb. d. schlesiseh. Ges. 1. vaterl. Cultur, Ereslan 1874, pg. 57) folgend, die bisher meist als "I'alpen" bezciclmeten Anläinge des Kopflappens. 
Ob und wie weit bei $L$. squamutus bezigglich der Wechselstellung der Elytren Variationen rorkommen, komnte ich, da mir nur Ireingeist-Exemplare vorlagen, nicht coustatiren. An diesen von Edinburghl, Great-Cumbray, ans dem Kattegar, von Christiania und Island stammenden Exenplaren war höchstens gegen das Leibesende ein Anseinanderweichen der Elytren in der Mittellinie zu benterken.

Die gretiipfelte Aphrodite* O. F. Mïller's 1, welehe ron massgebendster Seite und mit rollem Rechte zu L. syunmatus gezogen wird, hatte allerding's nach dessen elster und Abildgaard's 2 nachträglicher Schilderung einen der Läinge nach nackten Riicken, aber es kanı darans nicht mit Sicherheit geschlossen werden, ob es sich hier nm eine individuelle Ansnahme oder um eine Leichenerscheinnng lıurlelte.

Bewegte sich der Lepidonotus des Mittelmeeres, welcher Gegrenstand vorliegender Bemerkungen ist, kriechend, so emeichten die rorderen Elytren kaum die folgenden mit iluen Hinterräudern, nur bei Kriimmungen des Thieres wichen sie völlig anseinander. In der Mittellinie berihrten sie sich zwar mit ilıen medialen Rändern etwas, doch blieb immer zwischen je zwei auf einander folgenden Paaren von Elytren eine rhomboidale Stelle des Riickens mubedeckt. So in mehreren Exemplaren; in anderen folgten die Elytren dichter oder gingen in der Mitte weiter anseinander. Nach der Tödtung der Thiere in Weingeist iiberdeckten sich die Elytren weit mehr. Grombe hat nicht versäinnt, bei Beschreibung derselben Art (als P. clypertu l. e.), darauf aufmerksam zn machen. Daraus nun folgt: Die Elyt ren stelien in natiirlicher Abliangigkeit vou dem Contractionszustande des Individu ums. Bei einer und derselbeu Art kann die Diagnose: Elytra hull imbricutu, subimbricutu, imbricutu variiren.

Die Wechselstellung (ler Elytren ist somit ein Merknual, das nur mit der grössten Behutsankeit benitzt werden dirt'. Es ist

1 Naturg. einig. Wurm-Arten d. siissen n. saliz. Wassels. Kopenhagen 1800, pag. 170 . 'Tal,. XIll.

2 Zoolog. danica. Vol. III. Havniae 1789, pag. 25. Tal, XCVI, fig. $1-4$. 
ceteris puribus ein werthloser Charakter bei Aufstellung neuer Aiten.

Nicht also anf Grund der Stellung der Elytren ist de: Lepidonotus des Mittelmeeres (die Polynoë sentellatu Ris $\mathrm{s} 0=P$. clypeatu Gr. = P. Gruliamu Clap.) eine Art fiir sich, wohl aber in Folge der lis jetzt unvermittelten Beschaffenheit der Elytren and Unterfiihler.

Ich vereinige ihn mit der Polynoë cluru Mo ntagu, wobei ich nicht verhehle, dass ich hiezn weniger dureh die Sehilderung. II on ta g' u's, als durch die nachträigliche vou Seiten Johust on's und Malmgren's gegebene bestimmt wurde. Malmgren bemerkt (l. c.) zu $L$. cluvu Folgendes: .Elytra suborbicularia, rel ovalia, haud ciliata, subglabra vel parce nodulosa, non imbricata, inter se plus mimusve sejuncta. Palpi papillis brevibus in 5 series longitudinales dispositis ornati. Cetera nt in Lepid. squamato". An gleichem Orte bemerkt derselbe Autor iiber L. clypeatus Gr. "Pracedenti ( $L$. clucu) sat similis, differt tamen: elytris oblongioribus magis nodulosis et subimbricatis, palpis papillis elongatis ciliformibus, in series 5 longitudinales dispositis, praeditis". - Grub e selbst gilut als Vaterland der I'. clypeatu neben dem Mittelmeere die Seilly-Insehn an und bemerkt (Insel Lussin 1. e.), dass die Abbildmug von Apleroditu cluru Mont. zu dieser Art passen wiirde, wem sie nicht 14 Paar Elytren zeigte; der 'Text spricht ron 12 orler 13 Elytren. - Ich selbst rerglich einen Lepidonotus aus Great Cumbray, den ich nur als L. cluru bestimmen kann, mit dem adriatischen Lepidonotus und fand die Gestalt und Lagerung der Elytren viel mehr der Mittelmeerform entsprechen, als dies aus 11 al moren's Diagnose zu entnehmen ist. Allerdings sind sie körnerarm und die Unterfiihler zeigen kiirzere Papillen; daranfhin aher zwei Arten anzunehmen, seheint mir iiberfliissig.

Risso lat mosere Art 1800 als P. scutellata kaum kenntlich beschrieben, so dass Grube diese fiir seine $P$. areoluta halten komnte. Delle ('hiaje bildet sie 1829) ab. A udou in und Milne Edwards scheinen sie anch unter den Händen gehabt, jedoch mit $L$. squamatus verwechselt zu haben. Wenigstens fibluen sie an, dass sie $P$. squumatu anch ron Montpellier 
erhalten haben '. Anch Grube hielt sie 1838 und 1840 (l. c.) fiir Polynö̈ squamata L., gab ilı aber 1860 den Namen : clyperata. Dies seheint Clapar ède iibersehen zu haben; denn er schafft fiir die „P. squmata Grube $1840^{\circ}$, welche er untersuchte und als vou der $P$. squamutu L. des atlantischen Oceans verschieden erkannte, 1870 den Namen: Grubiuna.

Ob nicht anch die Polynoë dorsalis Q 11 a tref. aus Marseille und die $P$. fuscescens Quatref. ron St. Malo trotz abweichenden Dimensionen der Fiihler und Unterfïller hieher zu ziehen seien, werden spätere Untersuchungen zeigen. P'. arsulis soll iibrigens leieht gefranzte Elytren besitzen.

\section{Lagiser extenutu.}

(Taf. 1, Fig. 1.)

Polynö extemuata Grube, Actinien, Eehinod. u. Wïrmer des Mittelmeeres, Königsherg 1840, pag. 86.

Polynoë cirrulı O. F. Nïll.; Glub e, Ausflug naeh Triest. Berlin 1861, pag. 23 ․ 81.

Polynö longisetis Grube, Beschreib. nener oder wenig bek. Annel. Arch. f. Naturg. 29. Jahrg. 1863, pag. 37. 'Taf'. IV, Fig, 1.

Polynoë cirrata O. F. M iill.; Grube, Die Insel Lussin. Breslan 1864, pag. 77.

Lagisea Ehlersi M a $1 \mathrm{mgren}$, Amulat. polych. Spetsberg. Groenland. etc. Öfversigt af kongl. Vetensk.-Akad. Förh. 1867, pag. 134 (Olme Beschreibmug.)

Polynö̈ extenuata Grube, Claparède, Annél. du golfe de Naples (Mém. d. la Sociét. de Phys. et d'Hist. nat. de Genève. Tome XIX. 1868, pag. 380. PI. II, fig. 2 mnd ebenda 'Tome XX 1870, p. 372.

Dic folgende Beschreibung ist zum Theil nach WeingeistExemplạren gemacht.

Körper bei 30 mud 33 Mn. Länge, 9 mnd 10 Mm. breit (mit den Rudern), 44-45 Segmente. Ein kleines Exemplar ron $10 \mathrm{Mm}$. Lainge hatte 40 Segmente. 15 Paare Elytren, von welchen das letrte am 32. Segmente steht, so dass 8-13 elytrenlose Segmente das Leibesende bilden. Da aber diese letzteren Segmente sehr liurz sind, so bleibt nur ein ganz greringer Theil des Leibes mbedeckt, z. B. bei einem Exemplar von 20 Mm. ein

I A u d o n in et II ilne Edwards, Recherehes pour servir il l'Hist. nat. du Littoral de la France. Tome see. Paris 1834, pag. 82. 
Stiick ron 1 Mm. Länge. Die Farbe des elytrenbedeckten Thieres heller oder dunkler grau, manchmal hellbräunlich. Aneh die Auhänge des Kopfes und die Rückeneirren sind dunkler oder heller. Alle bis auf die Unterfiihler sind durch zwei dunkle Binden ansgezeichnet.

Kopflappen (Fig. 1 k) abgerundet, hexagonal. Die vorderen Eeken als Spitzen mit stark lichtbrechenden Rändern rorgezogen. Der Vorderrand dureh einen bis in die Mitte des Kopflappens gehenden Einschnitt gespalten. Wo lieser aufhört, beginnt eine seichte mediale Furche, die sich bis zum Hinterrande fortsetzt, so dass der Kopflappen in zwei seitliche Hälften zerfällt, welehe stark von anssen nach innen gewölbt sind und meist noch ein mehr minder dentliches, helles Querband, das sich ron dem hinteren Enile des rorderen Augenpaares zu den Rïndern des medialen Einschnittes hinzieht, zeigen. Man sicht somit zwei vordere grössere und zwei hintere kleinere Felder. Dieses Querband ist nichts als eine pigmentlose Stelle auf dem bräunlich röthlichen Kopflappen. Der durehsichtige Chitinsaum beschräukt sich auf die rordere Hälfte des Kopflappens. Der Vorderrand des Kopflappens ist etwas dunkler als die iibrige Fläehe. Die vorderen Augen sind gross, oval, liegen beiläufig in halber Höhe des Kopflappens oder etwas ror ihr. Dic hinteren sind kleiner, mehr nach innen als die anderen, rom Hinterrande abgeriickt.

Yon den drei Fiihlern des Kopflappens nimmt der un pa are (us) mit dickem Wur\%elgliede seinen Ursprung in dem medialen Einschnitte des Kopflappens. Er ist mehr als dreimal so lang als dieser, eylindrisch; an der Basis kanm merklich verbreitert verschmälert er sich alhuälig. In Ende des zweiten Drittels sehe ich iln sanft anschwellen; dann geht er in die diinne Spitze aus. Bis auf diese ist er mit $0 \cdot 006-0 \cdot 012$ Mnn. langen, feinen Stibehen besetzt. Lnterhalb und oberhalb der katum nemubaren Anschwellung ist er mit dunkelbraunen oder schwirzlichen Flecken gebaindert. Der Raum zwischen den zwei dunklen Stelien heller weiss; der nnterhalb liegende Theil meist bram oder schwärlich violett punktirt. Die paarigen Fibler (ps) sind halb so lang als der unpaare, unbedeutend sehmäler etwas kolbig, 
valeichfalls mit St:ibclien besetzt. Yor dem Beginne des dunklen Endtheiles dunkle Fleeke.

Die Unterfii hler" (uf') cylindrisch, an der Basis mehr als doppelt so breit als der muphare Fihler, allmïlig sich verjingend, an Ende fein ansgezogen. Ilıre Oberfläehe ist rollkommen glatt.

Die Segmente in der Leibesmitte (an den Segmentgrenzen gemessen) cirea 5-6mal so breit als lang, dann aber raseh an Breite ab-, an Länge etwas zunchmend. Die letzten 10, 12 oder 13 elytrenlosen Segmente verschmälern sich so stark, dass sie 1u1 $\mathrm{um}$ ein Viertel breiter als lang sind.

Der Riicken der Segmente ist mit bräunlichen oder schwär'zlichen Streifen gezeichnet. Man kamn einen breiteren, stärkeren vorderen und einen schmäleren, hinteren unterscheiden. Letzterer ist, zumal nach hinten, intensiver gefiirbt als der erstere. Eine nach Elytren- oder Riickencirrentragenden Segmenten abwechselnde Zeichnung ist mir nicht anfgefallen. Die ganze Fä1bung des Riickens ist rorme minder dentlich ausgepright. Die weiter unten anzufillıenden Höcker anf den Riteken jener Segmente, welche mit den Elytrentragenden abwechsehn, und nach dem 32. Segmente munterbrochen anfeinauder folgen, sind durch einen Pigmentfleck markirt.

Das B i ecalsegme nt ist ron oben nicht sichthar. Es tright zwei Paar Fithlereirren ron der Gestalt des mparen Fiihlers. Der dorsale Fiihlereirus $(d f)$ ist so lang oder etwas länger als dieser, der ventrale etwas kiirzer; doch habe ich anch beide gleich lang gesehen. Der Trïger des dorsalen Fihlereirus schliesst eine Acicula und zwei nach vorne gerichtete Borsten ron der Gestalt derjenigen des oberen Ruderastes ein.

Díe Ruder (Fig. 1 $A$ ) erreichen an dem vorderen Körpertheile anch mit den Borsten nicht die Breite der Segmente. Mit der Verschmälerung des Kïrpers aber werden sie um ein Drittel und mehr länger. Dass sie, wie Grube bei P. longisetis angibt, schon an 10. Segmente mit den Borsten dieses un ein Drittel iiberragen, habe ich nicht gesehen; ist iibrigens auch an der Zeichnmo (I. (. Fig. 1) nicht ersichtlich. Der obere höckerförmige Ast des Ruders gelit in einen kurzen nach anssen gestreckten Fortsatz aus. Der untere Ast besteht ans zwei rertical gestellten Lappen, einem rorderen kiirzeren, dessen oberes Ende in Form 
eines dreiekigen Fortsatzes naeh anssen sich verlüngert und ans einem hinteren, abgerundeten etwas längeren. Zwischen beiden tritt das Borstenbindel ans. In jedem Aste eine Aeienla.

Die Borsten des oberen Astes (Fig. $1 B \alpha$ ) sind breiter als die des unteren, von gewölnnlicher Form. Hie und da sah ieh sehr unvollkommene Anlagen zn einer zweizähnigen Spitze. Die

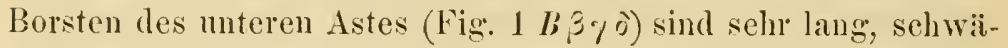
cher als die des oberen. Der Rand des etwas messcrförmig vermreiterten Endes ist bis anf eine kurze Streeke ror der Spitze mit Dürnchenreihen besetzt. Die Spitze ist fast durehgehends zweizïhnig, nur an einigen wenigen der alleruntersten Borsten einfach (o). Der kleine Zahn ror dem Ende ist oft abgebrochen oder mangellaft ausgebildet. Die im Bïndel zu oberst liegenden Borsten ( $\beta$ ) sind etwas sehlanker und haben einen längeren messerförmigen Theil als die folgenden. Über 30 Borsten in einem Biundel des miteren Astes. Ihre Farbe ist leicht gelblich. Die Borsten des oberen Bündels sind häufig von Anflagerungen rauh, bräunlich.

Dem Riicken der Ruder des 2., 4., 5., 7., ....2.23, 26, 29., :32. Segmentes sitzen nahe dem Lrsprunge die grossen rundliehen Blytrenträger anf. Die eylindrisehen Träger der Riickencirren auf den Rudern aller uibrigen Segmente sind mehr nach anssen und linten gelegen, hart an ilem oberen Aste.

Aussertem ist jedes Riickencirrentragende liuder mit einer höckerartigen Erhöhung ausgeriistet, welehe kleiner als der Elytrenträger ist und melır medial liegt. Sie fehlt den Elytrentragenden Rudern. Bei einer Inspection von oben sieht man somit eine ununterbrochene Reibe von Knoten und Knötchen herablanfen.

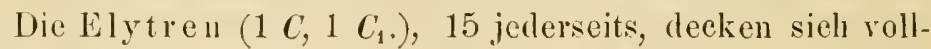
kommen mit ihren hinteren und inneren Rändern und reichen mit ihrem Aussenrande kann iiber die Hälfte des oberen Borstenbiindels. Die des ersten Paares stets rundlich, die iibrigen lïnglich oval, leicht nierenförmig oder mehr ins Rundliche, Rundlichcekige gehend. Bald hell, unregelmässig bräunlich-gran pigmentirt mit einem solchen Fleeke iiber der Ansatzstelle an den Trägrer, der dann von einem hellen Kreis umgeben erseheint, oder dunkelgran, wobei dann unter der Ansatzstelle der Elytre eine weissliche, helle, rundliche Stelle erseheint, die nach anssen ron 
einem dunklen Fleck begrenzt wird (Fig. $1 C$ ). Der Aussenrand und die ïussere Iälfte des Hinterrandes etwas dunkel gesäunt, die innere Hälfte am lichtesten; in Übrigen ist die Elytre helle! und dunkler schattirt, zumal auf der Fläehe der inneren Hälfte. Schon mit freiem Ange oder bei schwacher Lupenvergrösserumg gewahrt man an Rande der äusseren Hälfte grosse dunkle Punkte und Erhabenheiten. Bei einer 90fachen Vergrössermug (Fig. 1 ll) sieht man die Elytre bis anf eine Zone hinter der inneren Hälfte des Vorderrandes mit dunklen, lıellgerandeten Punkten besäet, an der iiusseren Hiilfte des Hinterrandes und zum Theil an Aussenrande eing grössere knotenartige oder eylindrisch verlängerte Warzen. Zwischen diesen und iiberhaupt an dem Rande der äusseren Hälfte treten noch kiirzere oder längere, blasse Palpillchen auf, wie an den Elytren anderer Arten. Diese Papillen sind abes. nielıt anf den Rand allein beschränkt, sondern findlen sich auch zerstrent auf der Oberfläche der Elytre selbst. Faltet man eine Elytre und vergrössert sie stark, so bekonmm man erst einen Einblick in das Wesen der dunklen, helleontmirten P'nnkte der Oberfläche. Es sind stmmpfe oder conisehe Stachelehen mit dunkler Axensehichte und heller Peripherie, die man in horizontaler Lage vor sich hat. Dieselben ron oben gesehen, maehen natiirlich den Eindruek dunkler Punkte umgeben von einem hellen encentrisehen Kreise (Fig. 1 E).

Das Pigment der Elytre ist in dicht gedraingten oder netzartig angeordneten, polygonalen Zellen eingelagert. Dochls sah ich es auch diffus. Frische Elytren wurden nicht untersucht. Bei schwacher Vergrössermng sieht man die Elytren oft radienartig gestreift. Dies riihlut nicht so sehr von einer derartigen Anordunng der Stachelchen her, als ron der Vertheilung des Pigmentes in hellen und dunklen streifen.

Die Ritekencirren ( $r$ c) gleichen dem mparen Stimfiihler. Sie sind lïnger als das untere Borstenbiundel, wie alle Anhänge bald heller bald dunkler pigmentirt. Man erkennt deutlich in deu dunkeln Pigmentzellen den hellen Kiern.

Die Baucheirren (bc) stehen beiläufig in der Mitte der unteren Ruderfläche, iiberragen zwar das untere Ende des Ruders, erreichen aber nicht den zungenförmigen Ausläufer des oberen Randes. Sie sind kegelfürmig zngespitzt, meist glatt ohne 
Stabehenbesatz (Weingeist-Exemplare). Nur in einem Falle salı ich ganz kure rudimentäre Stäbchen.

Hart am Ursprunge des Ruders ragt von dessen unterer nud hinterer Fläche eine ganz kume stumpfe Papille (Fig. $1 \boldsymbol{A} x$ ).

Das Aftersegment mit zwei Cirren von der Liuge der letzten 10-12 Segmente. Sie sind an der Basis breiter als die Riickenciren, anch lïnger als diese, stehen dicht aneinander, verjiugen sich gegen das Ende zu und sind mit Stäbelien besetzt.

Bei einem mittelgrossen Exemplare reichte der mit vier Kiefern bewatfnete Magen rom 5. - 15. Segmente.

Fundorte: Neapel (Grube, Claparè e); Zaule, Cherso, Lussin (Grube), Zaule, Lussin (Ich); Spalato, Venedig (k. k. zoolog. Hof-Museum).

Diese gemeinste Polynoine des adriatisehen Meeres ist bis anf M alugren immer mit der Polynoë cirruta O. F. M iill. = Ilurmothö̈ imbricutn L. verwechselt worden. Linter diesem Samen wurde sie ron Grube fiir meluere Pnnkte der Adria anregeben, und diirfte sich so bezeiehnet in den Sammlungen adriatischer Anneliden rorfinden. Malmgren bekam von Grube Exemplare ans Lussin, untersuchte sie, fand die Charaktere semer Gattung Lagisca und namte sie 1867 (1. c.) Lagisen Ehlersi, olne sic aber näher zu beschreiben. Ich beschloss dies nachzuholen, fand aber bald, dass dasselbe Thier von Grube 1863 als Polynö̈ longisetis n. sp. und 1868 von Claparede als P. extemuru Grube war bezeiehnet worden. Claparide traf diese Art bei Neapel und fuilute sie anf die ron Grube 1840 kur\% gesehilderte $P$. r.tenuntu zurilck; $P$. longisetis scheint ihm entgangen zu sein.

Claparcide's Beschreibung weicht ron meinen Beobachtungen nur ab hinsichtlielı der Elytren, der Bancheirren und der Aftereirren. Jene sollen am Rande glatt ohne Papillen, die Batuchcirren mit Staibchen besetzt sein, die Aftereiren ${ }^{1}{ }_{4}$ der Lainge der Riickenciren betragen. Alles dies ist gegeniiber der völligen C̈bereinstimmung in den iil)rigen Nerkmalen nehensäichlich. Grube's I'. longisetis war ein sehr grosses mud breites Individuum. Stichlualtige Unterschiede von Claparede's sowie meiner Beschreibung und der $r$. longisetis lassen sich nieht anfstellen. 
Es wirl rielleicht Manchem meine abermalige Beschreibung iiberfliissig erscheinen; ich glaubte sie aber dennoch geben zu sollen, weil Clapar ède gewissen Merkmalen weniger Anfmerksamkeit geschenkt, so den Elytren mol Borsten und anch seine Abbildungen nicht ganz zntreffend sind, weil weiters die $P$. longisetis Gr. eine nicht gewöhnliehe Form darstellt.

Endlich erblicke ich darin ein Mittel, einen Vergleich mit Lagisca-Arten des atlantischen Oceans anzubahnen, der bei den bestehenden auffallenden Verwandtschaftsverhältnissen einiger Arten zu Verschmelzungen fiihren diirfte.

\section{Lepialrsthenia elegrus.}

Polynoë elegans Grub e, Actinien, Echinod. und Wïrmer. 1810, pag. 85. Lepidasthenia elegans Grub e, Malmgren Annulat. polych. Spetzberg. ete. Öfversigt af. kongl. Akad. FörhandI. 1867, paıg. 139.

Polynoë lamprophhalma Ma a nz eller. Znr Kenntuiss d. adriat. Amnel. Diese sitzungsberiehte Bd. LXIX, 1874, pag. 408, Tal. I, Fig. 1, (pag. 2 d. Separat.).

Ich habe die P. lamprophthalma beschrieben nicht ohne daran zu denken, dass ich möglieherweise nur einen unentwickelten Zustand irgend einer anderen Polyuö-Art ror mir habe. Wem ich sie aber trotzdem als eine nene Art hinstellte, so geschah es, weil ich sie mit keiner der bekannt gewordenen kurzen, elytrenarmen Formen zusammenzubringen vermochte. Icli kan nicht auf die Vermuthung, meine $3 \cdot 5$ und 7 Mm. langen uit 9 und 14 Elytrenpaaren ansgeriisteten Thiere könnten die Jugendformen einer bis iiber $60 \mathrm{Mm}$. langen und mit melı als 30 Elytrenparen versehenen Art, der P'olynoë $=$ Lepidasthenia elegans Gr. sein. Als ich diese im vergangenen Herbste anderer Ursachen wegen untersuchte, fiel mir sofort die grosse Ähnlichkeit in der Gestalt der Ruder und Borsten mit der I'. lumprophthalma anf - anch P. elegaus fehlen die Borsten in den oberen Aste des Ruders - ich stellte weitere Vergleiche an, nnd bin liente iiberzengt, dass beide zusammengehören.

Polynoë elegans genigend dureh die Beschreibungen ron Grube und M a l m gre n, welch' letzterer fiur dieselbe die Gattung Lepidusthenia schuf, bekannt, zeigt uns eine charakteristische Fairbung, welche diese Art jedem, der sie eimmal gesehen, nicht 
leieht vergessen macht. Hievon sieht man an den jungen Exemplaren nichts; sie sind bis anf den röthlichen Kopflappen farblos, durchsichtig.

Die Fïller, Fiillereirren und Riickencirren sind in allen Alterszustïnden rollkommen glatt. Die Ruder, Borsten und Elytren erleiden ebenfalls keine wesentlichen Verinderungen, jene die relative Grösse betreffend ausgenommen. So sind die Elytren, welche im erwachsenen Zustande in der Umgebung der Ansatzstelle an den Träger etwas weniges schwärlich granes Pigment eingelagert haben, anfangs unverhältnissmässig gross. An vollkommen erwachsenen Thieren, wo z. B. die Breite des Körpers ron einem Elytrenträger zum anderen :399 Mm. betrug, sind die Elytren $0.75-0.8 \mathrm{Mm}$, breit; an einem jugendlichen Thiere, wo die erste Dimension $0.9 \mathrm{Mm}$. war, aber 0.50 . Wenn also die Körperbreite un das Vierfache zunimnt, wachsen die Elytren nur $u$ m 2 - 3 Zehntel.

Der Vorderrand des Kopflappens der erwachsenen Thiere geht in zwei seitliche nach vorne gerichtete Fortsätze aus, auf welchen die parrigen Fühler sitzen, und man kann dentlich sehen, wie der glasige Chitinsaum des Kopflappens ununterbrochen in jenen der Fortsätze iibergeht. An den Jungen habe ich die Vorderecken des Kopflappens sich abrunden und den glasigen Samm gegen die Mittellinie ziehen gesehen. (Wiehe l. e. Taf. I, Fig. 1). Die Wurzelglieder der parrigen Fihler waren mehr nach unten geriiekt, heller als der Kopflappen. Überhanpt waren die parrigen Fïhler von dem mittleren verdrängt, wïhrend bei den Erwachsenen alle drei in einer Ebene liegen. Es seheint also manchmal, wenn anch vielleicht nicht immer, die Verwachsung zu einem Fortsatze des Kopflappens später zu erfolgen. Man sicht selbst an dem vollkommen entwickelten Thiere meist eine helle stelle, welehe die 'Träger cler Fihler von dem eigentlichen Kopflappen abgrenzt. Stellung und Charakter der Augen in allen Alterszuständen gleich.

In Alter nimmt das Missverhältniss der paarigen Fïhler zu dem unparen ab. Jene werden länger. Ferner sah ich die Untertiihler in nicht contralintem Zustande mächtig vorragen, selbst den mittleren Fiihler an Länge iibertreffend. In die Träiger der Fiblslercirren dringt eine Acicula ein. Die oberste Lage in cinem 
Borstenbindel nehmen immer 2-3 sehr diinne Borsten von der Gestalt $\alpha, \beta$. (l. c. Taf. I, Fig. $1 \boldsymbol{B}$ ) ein, dann folgen erst 1 oder 2 viel stärkere als diese und iiberhaupt stiirker als alle anderen. Diese starken dunkelgelb gefäirbten Borsten haben einen kräftigen Dorn anf ihrer Schneide, ron der Spitze etwas entfernt. Daher sagt Ma lmgren l. e. ron ibnen: apree integro.

\section{Hermadion pellucidum.}

Polynö̈ pellucida Ehlers. Die Borstenwürmer. Leipzig 186t-68, p. 105;

Taf. Il, Fig. 10; 'Taf. III, Fig. 5, 7-13; Taf. IT, Fig. 1-3.

Hermadion frayile' Clap a ì de, Amnél. chétop. du golfe de Naples. Mém. d. 1. Sociét. d. Phys. et d'Hist. nat. de Genève. Tome XIX, 1868 pag. 383. Pl. Y, Fig. 2 und ebenda. Tome XX. 1870, pag. 380. Pl. Il, Fig. ?.

Im Herbste 1875 traf ich in der Bai ron Muggia von Triest diese schöne Polynoine an einer mit dem Schleppnetze ans einer Tiefe ron 18 Meter heraufgebrachten Ophiothrix aloperurus M. Tr., wohl nur zufïllig herumkriechend. Sie hatte 33 Segmente und war 10 Mm. lang.

Der Vergleich mit den oben eitirten Besehreibungen beseitigte jeden Zweifel, dass Clapar ède dieselbe Form wie Eh fers ror sich gehabt.

Die Figur 8 anf Tafel III bei Ehlers gibt keine gute Torstellnng des Vordertheiles dieses Thieres. Im Verhältnisse zum Kopflappen sind die Fïhler und Fiihlercirren zu dick und zu kurz. Der verjingte Theil wurde ron Claparide, dessen Abbildung (1. e. Pl. V, Fig. 2) sehr tren ist, und ron mir viel länger gesehen. Der unpare Fiihler fehlte allen Exemplaren ron Ellters. An dem einzigen Individum, das ich fand, war er so lang als Claparide angibt, lingegen waren die paarigen kiirzer, die Fibhlercirren aber wiederum fast zweimal so lang als jene, so dass eigentlich in Bezng auf die relative Länge der Fiihler und Fiihlereirren alle drei Befunde, ron Eh lers, Cl a paried e und mir in Widersprneh stehen.

Clap a rède gibt zuerst (1868) 12 Elytrenpare an. Das letzte steht am 24. Segmente, hierauf sollen noeh 11 elytrenlose Segmente folgen. Genaner gibt er 1870 an, dass 14 Elytrenpailre rorhanden seien, welehe am 2., 4., 5., $7 ., \ldots \ldots .21 ., 24$. 
27., 30. Segmente stehen, worauf noch 10-15 elytrenlose Segmente folgen. Es diirfte sich wohl hier um einen Irrthum handeln. Elytren an den oben bezeichneten Segmenten wiren etwas ganz Aussergewöhnliches. An meinem Exemplare hielten die Elytren - 14 Paare - die normale Folge ein: 2., 4., 5., 7., .....21., 23., 26., 29. Segment. Dann folgten noch 3 rudimentiire Segmente.

Elılers gibt 22 Segmente und 10 Elytrenpare an.

Diese Widerspriiche, so wie die frïheren, sind in der iibergrossen Fragilität der Thiere und der grossen Hinf:̈lligkeit der Elytren und iibrigen Anbänge zu erklïren.

Fiihler, Riickencirren, Elytren gaben mir das rollstaindige Bild der Beobachtungen Cla prar è de's iiber die Verbreitung der Nerven in diesen Organen. Hermadion pellucidum ist das lenkbar vorziiglichste Object zu solchen Studien. Bemerken will ich nur, dass ich die Nervenverzweigungen in den Elytren stellenweise, besonders am Rande, anschwellen sah und jeder solchen Anschwellung sass dam eine mit Tastharen versehene kleine Papille auf.

Die Borsten sind ebenfalls genamer von Claparède als von Ehlers alugebildet.

Ich fitge Folgendes hinzu: Betrachtet man eine Borste des oberen Buindels im Profil, so sieht man den convexen Rand mit Dörnchen besetzt. Diese simd jedoch nur der Ausdruck kleiner, gewissermassen taschenartiger Aufsitze, deren Vorderrand sehr fein zerschlitzt ist. Dasselbe gilt auch von dem ..Dorne“ an der Übergangsstelle der Borsten des unteren Bindels in das messerartige Ende. Die Borsten des unteren Bindels sind melır minder deutlich zweizïhnig an der Spitze.

\section{Leamira Yhleni.}

Malmgren, Anmulat. polyel. Spetzherg. Groenland. etc. Öfvers. af kongl. Yetensk. Akad. Förhandl. 1867, pag. 40.

Von dieser ron Yhlen 1865 bei Isle de Rè nächst la Rochelle in Frankreich gesammelten Art, fand ich anch in der Bai ron Muggia mehrere Exemplare in einer Tiefe ron 18 Meter. Sie hat die grösste Ähnlichkeit namentlich im Bau der Ruder mit 
Leanion (Sigalion) tetragona Oerstedt (vide Malmgren Nordisea Hat's-Anumlat. Öfver's af kongl. Akad. Forhandl. 1865, pag. 88, Taf. XI, Fig. 14). Malmgren's Diagnose besteht daher nur hervolzuheben, dass sie sich von L. totrugona durch ganz glatte, linglich ovale Elytren und $t$ Angen - letatere hat eiforrmig ovale, halbnierenförmige am hinteren Rande gefranzte Elyıen, keine Augen - unterscheide.

Da ich L. Yhleni nicht lebend untersuchte, so riehe ich es vor, erst in der Folge eine ausfilhrlichere Beschreibung zu greben.

\section{O.xydromus Grube, 1857.}

In meiner friiheren Arbeit 1 beschränkte ich die Gattung Oxydromus Grube anf die Arten O. fluccidus Gr. Oersd, und O. longisetis Gr. O ersd, die beicle amerikanischen Ursprungs sind. Es iiberraschte mich daher sehr angenehm, bei St. Servola in der Bai von Muggia bei Triest, eine noch unbesebriebene Hesionee aufzufinden, welche vollkonmen in den liahmen dieser Gattung passt, so dass nummehr anch ein emopaiischer Repräisentant gegeben ist.

Die Charaktere der Gattung O.xydromms sind folgende: 3 Stimfiiller, zweigliedrige Palpen, 16 Fibluereiren, Ruder zrveiästig.

\section{Oxydromms firsescens n. sp.}

(Taf. II, Fig. 1.)

Körper des einzigen vollstiindigen Exemplares $10 \mathrm{Mm}$. lang, Ruder und Borsten eingerechnet 4 Mm. breit, aus 27 rudertragenden Segmenten zusammengesetzt. Ein zweites verstimmeltes Individum war grösser. Leib vorne zienlieh gleich breit, nach hinten zugespitzt. Farbe braunöthlich. Der Vordertheil hyalin und (dureh den starken, eylindrischen Magen) gewölbt, ler Hintertheil opaker, flacher. In Folge dessen entsteht der Eindruek, als wäre das Thier aus zwei ganz rerschiedenen Körper-

1 Diese Sitzungsberichte, Bd. LXIX. 187t, pag. 430, (1)ag. 24 der Separat.). 
ahschnitten zusammengesetzt. Es schwimmt raseh und träigt häufig die ron dem dunklen Leibe stark abstechenden weisslichen ('irren vertical nach anfwärts.

Der Ko p flappen (k) in die folgenden Segmente eingesenkt, beiläufig trapezförmig; halbkugelförmig gewölbt, breiter als lang, bräimlich mit einem dunkler gefürlbten verlïngert herzförmigen Flecke in der Mittellinic. Vorler- und Hinterrand stark, Seitenräinder nur mässig eingebuclitet. 2 Paar schwarze Angen. Die vorderen viel grösser, oval, rom Vorderrande etwas entfernt, aber hart am Seitenrande. Dicht hinter ihnen, jedoch mehr auf die Fläche des Kopflappens heraufgeriickt und daher einander mehr genïliert als die rorderen, die mehr rundlichen, kleineren, hinteren Angen. Der Stimrand mit Cilien besetzt. Der ausgeschweifte Hinterand durch eine brame Linic gekennzeichnet. Immittelbar vor dieser ein mit Cilien bedeckter niederer Wulst, der sich kragenartig um die Seiten des Kopflappens herumschlingt (Fig. $1 w$, nnd Fig. $1 A w$ ).

Am Kopflappen stehen 3 Fihler und 2 Interfïhler. Der unpaare Fiihler (us) ist sehr klein, nicht halb so lang als der Kopflappen und sitzt in dem Einschnitte des Vorderrandes. Die diinnen paarigen $(p s)$ sind iiber $1 \frac{1}{2}$ mal so lang als der Kopflappen und entspringen etwas unter dem Vorderrande des Kopflappens ohne Irurzelglieder. Alle :3 sind ungegliedert.

Die Un terfï h ler (uf') sind zweigliedrig. Sienehmen von der muteren Fläche des Koptlappens unweit des Vorderrandes mit cylindrischen breiten Basaltheile Trsprung. Auf demselben sitzt ein schmäleres conisches Endglied. Es ist contractil, kanm lïnger als seine Basis und bald gestreckt, bald in winkliger oder gekriinmter Stellung zu dieser. Werden die Lnterfiiller nach vorne gerichtet, so erscheinen sie fast so lange als die paarigen Fiiller:

Die Segmentirung des Leibes ist nicht ausgepriigt. Sie wirl nur an den Seiten rureh die stark vorspringenden Ruder erkenntlich. Darmach kann man schliessen, dass die Segmente durelischnittlich dreimal so breit als lang sind; nur gegen das Leiluesende nimmt dieses Verhiiltniss der Breite zur Länge ab. Das erste mit den folgenden verschmolzene Segment ist dureh 
eine braune seinen Vorderrand begleitende Linie gezeichnet und legt sich mit einer medialen Spitze in den Ausselmitt des Hinterrandes des Kopflappens. Der Riicken der vorderen Leibeshälfte ist dureh den durehschimmernden Magen leicht br:imnlich gestreift.

Hinter dem Kopflappen folgen vier Pare Fithlerciren jedcrseits, welche ich als den vier ersten Segmenten angehörig betrachte. Sie entspringen von einem cylindrischen Wurzelgliede, in das eine Acienla eindringt. In jedem Pare lässt sich ein dorsaler (df) und ein ventraler ( $v f$ ) Fiihlercirrus unterscheiden. Die ersteren sind stets liinger und breiter als letztere. Die ventralen besitzen anch ein schmäichtigeres Wurzelghied als die dorsalen, sind unter sich ziemlich gleich lang und nur etwas breiter und eirea $1 / 4$ lïnger als die paarigen Fiihler. Unter den dorsalen Fiihlereirren ist der zweite der mächtigste, anch ansgezcichnet durch ein sehr breites und starkes, an seinem Ursprunge vom Körper mit einem bramen Flecke markirtes Wurzelglied. Über die Stellung der Fühlereirren gibt die Fig. $1 A$ Aufschluss. Das Wurzelglied des dritten dorsalen Fiillereirus steht tiefer, nehr ventral, als die drei iibrigen. Alle Fühlereirren sind ungegliedert, die dorsalen mit brannem Pigmente bestäubt.

Die Ruder (Fig. 1 B) nehmen von vorne nach hinten snceessive an Länge zu. An jenem Theile des Leibes, wo der Magen liegt, sind sie nicht ganz hall so lang als jener breit ist. Dahinter werden sie anf Kosten des Körpers länger. Die Ruder sind bis anf das erste Paar, welehes klein und einästig ist, zweiästig. In jeden Ast des Ruders tritt eine Acicula, doch ist die des oberen Astes nur lialb so stark als die des unteren. Jeder Ast besteht aus zwei senkrecht gestellten Platten, von welchen die hintere abgerundet und kiirzer, die andere länger ist und in einem scharfen Winkel endet.

Zwischen den Lappen treten die Borsten ans. Der obere Ast ist viel kleiner als der untere und fehlt dem ersten Ruderpaare. Das obere Borstenbiindel besteht nur ans selir feinen einfachen Capillarborsten (Fig. 1 C. $\alpha$ ) und erreicht nur die halbe Länge des unteren Borstenbinndels. Die Borsten des unteren Astes sind zusammengesetzt. Das ziemlich lange messerfürmige 
Ende geht in eine einfache gekriimmte Spitze ans. Die Schneide ist sebr fein gezähnt (Fig. $1 C \beta$ ). Capillarborsten und die stäbe der zusammengesetzten Borsten sind quer gestreift. An den ersteren bemerke ich mur ein einziges System von Querstreifen, bei den letzteren an der Seite des Stabes, welehe der. Sehneide des messerförmigen Endes entspricht, eine breite Reihe in grösseren Zwischenräumen folgender Querstreifen und an der anderen Seite eine schmale gedrängter stehenden Streifen (Fig. A D). Betrachtet man das verbreiterte Ende des Stabes, so sieht man mehrere Reilıen von Querlinien in einem Punkte zusanmenstrahlen, der am Ende des Stabes auf der Seite der Schneide des messerförmigen Endes liegt. Sie sind aus der Spaltung der beiden vorerwähnten Systeme entstanden.

Die Riickencirren ( $r c$ ) entspringen, in der Mitte des Ruderrickens etwa, ron einem cylindrischen Wurzelgliede, breitere und kiirzere mit sehmäleren und längeren abwechselnd. Sie sind ziemlich gleich breit, erst gegen das stumpfe Ende etwas schmäler, erreichen oder überragen das Borstenbiindel des unteren Astes, zeigen keine Gliederung und sind etwas brïinlich gesprenkelt.

Die Baucheiren (bc) schlank, cylindrisch, weiter nach aussen als die Ruickencirren von ler Unterfliche des Ruders entspringend, besonders riickwärts dessen Spitze beträichtlieh iiberragend.

An dem A fte r segmente standen zwei kurze dicke Cirren. Es bleibt mentschieden, ob dies das normale Verhalten.

Bei beiden Exemplaren war der Magen vorgestiilpt. An dem einem stand der Anfang noch linter dem Vorderrande des Kopflappens, an dem anderen ragte er iiber denselben hinaus (Fig. $1 \mathrm{Am}$ ). Der Magen ist cylindriseh, $3 \mathrm{Mm}$. lang, $1 \mathrm{Mm}$. breit, seine Wand 0.2 Mm. dick. Er erseheint von dichten Ringmuskeln rnergestreift. Die Wände schimmern graulich, die Innenseite braun durch die Hautdecke. Nach hinten verjiingt sich der Magen eonisel. Kiefer sind keine vorhanden. Der Rand des Einganges ist eiwas wellig.

Gefunden in durehlöcherten Steinen bei St. Servola (Bai von Mnggia bei Triest), Tiefe 2-3 Neter. 


\section{Syllis ariegata.}

('T'uf. II, Fig. 2.)

Grube, Beschreibung neuer oder wenig bekanuter Annel. Arelı, f. Naturg. Bd. 26, 1860. pag. S5. 'Tat. III, Fig. 6.

- Ausflug nach Triest. Berlin, 1861, pag. 143, 'Taf. III, Fig. 6.

Da ich dieser Annelide bei Zanle und Lussin häufig begeg'nete, so bin ich in der Lage Grube's nach einem einzigen und in Alcohol conservirten Exemplare gemachte Beschreibung mehrfach zu erweitern.

Die grössten Exemplare waren $20 \mathrm{Mm}$. lang, 1.1 Mm. breit, bei 69 Segmenten, wïhrend andere 70 und 83 Segmente zählten, und doch nur 11 und $14 \mathrm{Mm}$. lang und 0.6, 0.8 $\mathrm{Mm}$. breit waren. Es fand sich aber anch ein Individum vou 68 Segmenten mit, im Gegensatze zum ersten, nแ1 $15 \mathrm{Mm}$. Länge. Diese beiden waren in der Stolo-Bildung begriffen. Man sieht somit, dass auf die Zahl der Segmente kein Gewieht zu legen ist; denn gerade segmentarme Thiere waren grösser und schickten sieh zur Fortpflauzıng an.

Auch die von Grube hervorgehobene so eharakteristische Zeichung ist nicht immer gleich gut ausgeprägt. Sie beschränkt sich auf brame, nach aussen hin intensivere Linien am Anfang. und Ende der Segmente und einen wenig intensiven medialen rhombisehen Fleek, von dem nach rechts und links ein zarter Streifen zu den Seiten des Segmentes zieht, wo meist die Basis der Riickeneirren noch dureh braune Pigmentablagerung ansgezeichnet wird. In einem anderen Falle war der Körper rorne diffus brïunlich gefärbt. Damn trat die oben erwïhnte Zeichnumg anf, jedoch nur schwach angedentet. Auf den Segmenten. wo sie erschien, waren je zwei seitliche helle Stellen und anch in der Vitte des rhombisehen Fleckens fehlte das Pigment. Einen Gegensatz bildete wieder ein auffallend dunkel gefürbtes Exemplar.

Aueh linsichtlieh der Länge der Stirnfiuller, Fiihler- und Riickeneirren obwalten Schwankungen.

Ich schildere hier ein Individuum ron $14 \mathrm{Mm}$. Länge, $0.8 \mathrm{Mm}$. Breite mit 83 Segmenten.

Der Leib nach rorne und hinten etwas versehmïlert. 
Der Kopflappen (k) stumpf sechseckig, breiter als lang. Der Hinterrand eingebuchtet. Vier schwarze Augen. Die vorderen grösseren beilünfig rom Vorderrande soweit als rom Hinterrande entfernt, die hinteren kleineren in geringer Entfernung hinter ilnen, aber rom Seitenrande mehr abgeriickt, daher einander mehr genühert als die rorderen.

Die Un ter fii h ler (uf') an der Basis in kurzer Ausdehnung mit einander verwachsen, im gestreckten Zustande ${ }^{1}{ }_{2}$ mal länger als der Kopflappen, gewöhnlieh etwas eontrahirt, wenig divergirend, an ilırem medialen Rande ansgehöhlt.

Der un pare Stirnfühler (us) zweimal so lang als Kopflappen und Unterfiihler zusammengenommen, in gleicher Höhe mit dem hintern Angenpare entspringend, eirea 30gliederig doch sind die Glieder an der Basis sehr sehmal. Glieder nieht ganz quadratiseh, die Seitenwände etwas ansgebancht.

Die parigen Stirnfühler ( $p s$ ) halb so lang als der unpare, 20gliederig:

Die Segmente in der Leibesmitte $t^{1} / 2$ mal so breit als lang, vorne :3mal, nach hinten $2^{1} / 2^{\text {mal }}$ so breit als lang. Das Bucealsegment halb so lang als das folgende. Es crstreekt sich mit winkligem Vorsprunge in den Aussehnitt des Kopflappens und träigt auf starken, nael vorue gerichteten Träigern zwei Paar Fithlercirren. Vorder-, Hinter- und Seitenrand sehwaeh bräunlieh pig'mentirt. Dic Hant des Riickens zeigt bei stärkerer Vergrösserung eine ähnliehe Structur wie Syllis hyulina Gr. Sie erseheint in, dureh sehmale helle Zwisehemrämme getrennte, Falten gelegt und in diesen eben ist das bräunliche Pigment abgelagert. Die brillenartige Zeiehnung verliert sieh sehon gegen das 34. Segment. Über dieses hinaus bleiben nur ein Paar quergezogene Flecken hinter den Anfïngen und an Ende der Segmente. Aneh der ainsserste Rand der segmente ist vorne und hinten, sowie an der Basis der Riiekeneirren bram pigmentirt. Ton den Fiihlereiren ist der dorsale (df) etwas kiirzer als der umpare Stimfiihler, $28 \mathrm{gliederig;}$ der ventrale $\left(\bullet f^{\prime}\right)$ etwa so lang als die paarigen Stirnfuihler.

Der Riickencirrus (rc) des zweiten Segmentes unbedentend länger als der dorsale Fühlereirrus, nicht so weit als der umpare Stirnfiihler vorrageud, 32gliederig. (In anderen 
Fïllen sind der dorsale Fiihlercirrus und der Riickencirrus des zweiten Segmentes gleich lang.) An Länge wird er von Riicken. cirren, welehe der Mitte des Leihes angehören, iibertroffen.

Die Riickencirren $(r c)$ sitzen knrzen quadratischen Trägern auf. Längere und kïrzere alterniren ziemlich regelmilissig.

Die langen iibertreffen die Breite des Leibes, die kurzen erreichen sie nicht immer. Das Verhiiltniss ist abhängig von den versehienlenen Regionen des Leibes. Die lïngsten Riickencirren werden bis $40 \mathrm{gliederig.} \mathrm{Die} \mathrm{Glieder} \mathrm{an} \mathrm{der} \mathrm{Basis} \mathrm{sind} \mathrm{kurz.}$

Der Habitus der Cirren ist derselbe wie der der Fïhler. Anch sind keine bemerkenswerthen Untersehiede in der Stärke hervorzuheben.

Die Ruder circa $0.15 \mathrm{Mm}$. lang, rorne etwas länger. Der Rand der Vorder - und Hinterlippe springt etwas ror, die Mittellippe ist kiirzer, aber deutlich. In den ersten 19 Rudern 5 und dam 4 Aciculen, darunter zwei mit mehr minder dentli(hem fussförmigem Ende, die anderen stumpfspitz. An den iibrigen Segmenten drei Aciculen, von welchen die rorderste etwas schwächer ist und fussförmig endet.

9-15 am Ende zweizïhnige, an der Sclneide gebärtete Borsten in einem Ruder. Zu oberst liegen in jedem Bindel Borsten mit längerem Stabe und schlankerem messerförmigem Endtheile, zu unterst kiirzere aber kräftigere. Diese Art nimmt in den Rudern der hinteren Segmente auf Kosten der ersteren iiberhand (Fig. 2A).

Die Ba ucheirren lanzettlich, das Ende des Ruders nicht ganz erreichend.

Das Aftersegment mit 2 sehr langen gegliederten Cirren, zwischen welchen ein kuryer ungegliederter steht.

Die Mundöffnung liegt an Anfange des ersten Segmentes auf der Bauchfläche. Eine kurze Riisselröhre fuihrt zu dem von 12 weichen Papillen umstellten Eingang in die Schlundröhre, weleher im dritten Segmentc gelegen ist. Die Schlundröhre ist mit einem etwas hinter dem Eingange liegenden Zalne bewaffnet md nimmt 7 Segmente ein. Mit dem 10. beginnt der Driisenmagen. An diesem lässt sich ein grösserer rorderer, das 10., 11., 12. und 13. Segment eimnehmender und noch etwas in 
das 14. hinreichender, mit Drisenzonen rersehener Antheil nnd ein in das 14 . und 15 . Segment sich erstreckender, driisenloser, aber diekwandiger Abschnitt miterscheiden. Im 16. Segmente liegt der Übergangstheil zom Darme, und hier entspringen zwei T-förmige Drisenanhänge, welche nach vorne bis ins 14., nach hinten bis ins 17. Segment reichen. Der mit Driisenreihen versehene Theil des Magens war 1.2 Mm. lang; 0.4 Mm. breit, der drisenlose Abschnitt 0.3 Mm. lang, 0.25 breit. Ieh zäblte 31 Driisenreihen. Die Dicke der Magenwand war 0.1. (Bei meinem grössten Exemplare waren die entsprechenden Partien $1.45 \mathrm{Mm}$. lang; $0.7 \mathrm{Mm}$. breit und $0.55 \mathrm{Mm}$. lang und $0.4 \mathrm{Mm}$. breit. Die Lage in den Segmenten blieb dieselise.)

Die stolobildenden Thiere waren beide Weibchen mit 68 und 69 Segmenten. Die Kopfbildung erfolgte das eine Mal im 52., das andere im 47. Segmente.

Syllis varieguta wnrde bis jetzt an folgeenden Punkten der Adria gefunden: Cherso; Cigale, Neresine anf Lussin (Grube). Im Hafen ron Lussin piceolo, Bai ron Muggia bei Triest (I c h). Grnbe fand sie auch 1868 an der französischen Westkiiste bei St. Nalo.

\section{Syllis hyalina.}

Grube, Beschreibung neuer oder wenig bekamter Anneliden. Arch. f. Naturg. 29. Jahrg. 1853, pag. 45. Taf. IV, Fig. 8.

Syllis pellucida Eh ] e rs, Die Borstenwiirmer. Leipzig 1861-1868, p. 239, Tat. X, Fig. 6-11.

Syllis mucrocola II a renzeller, Zur Kenntniss der adriatischen Anneliden. Diese sitzumgsb. Bd. LXIX 1874, pag. 443, (pag. 37 der Seprarat.) Tatf III, Fig. 3.

Zum Sehlusse meiner Beschreibung der S. macrocolı hob ich die Öhnliehkeit mit $S$. hyulinu Gr. und $S$. pellucida Elıl. hervor und dentete Unterschiede an. Ehlers hatte gleichfalls angegeben, dass seine $S$. pellucidn der $S$. hyulim Gr. sehr wahe stehe, dass ihn aber die grössere Lüinge des Driisenmagens bei letzterer, der anders gestaltete Kopflappen und endlich der Mangel des Zahnes in der Schlundröhre bei $S$. pellucidı -- iiber dessen Fehlen oder Vorhandensein bei $S$. hyalinu von Grube freilich keine Bemerkung genacht worden - bestinmte eine eigene Art anzunehmen. Die Borsten der S. hyalina sind ferner 
nach der Zeichmung (Fig. 8 / l. c.) an der spitze einfach, nicht zweizähnig wie die von $S$. pellucidu.

Als ich meine $S$. mucrocola untersuchte, die ich, wie Ehlers seine $S$. pellucidu, nur in einem einzigen Exemplare aufgefunden hatte, crgaben sich Merkmale, welche dieselbe von der $S$. hyaliun Gr. noch viel weiter entfernten als dies bei $S$. pellucidu der Fall gewesen, und eine Tremmung von dieser hielt ich für nöthig, weil der Kopflappen anders gestaltet, die Riickencirren kiirzer waren, die Schlundröhre mit einem Zahne bewaffhet war und der Driisenmagen andere Dimensionen anfwies. In der That wird ein Vergleich der Beschreibungen der S. hyalinu, pellucidu und mucrocolu scheinbar genügende Anhaltspunkte zu einem Auseinanderhalten der drei Arten liefern.

Niehtsdestoweniger bin ieh heute rollkommen belehrt, dass alle drei zusammenfallen und der Grube'sehe Name allein zn Recht besteht.

In Lussin, also derselben Loealität, wo Grube die $S$. hyulina entdeckte, fiel mir wiederholt eine Syllis in die Hände, die ich obne Viihe als die $S$. pelluciulu Ehlers ancrkannte. Die charakteristische Zeichnung der Riickentläche, zarte bräunlichröthliche, unterbrochene Querlinien, war oft, nicht immer, und besonders in der vorderen Körperhälfte deutlich ausgeprägt. An einzelnen sah ieh ventral jederseits einen orangerothen Fleck auf den Segmenten. Nur hatten alle 16 Exemplare, die ich untersuchte, einen Zahn in der Schlundröhre, so dass ich annehmen muss, Ehler's sei ein verstiimmeltes oder abnormes Individum vorgelegen. Ferner muss ich anf das Bestimmteste aufrechthalten, dass die Unterfiihler nieht bis auf den Grund, das ist der Vorderrand des Kopflappens, getrennt erscheinen, vielmehr bleiben sie in grösserer oder geringerer Austehnung, 1/4-1/3 ihrer Länge, an der Basis vereinigt. Eine helle Linie zeigt die Verwachsungsstelle an. Der Vorderrand des Kopflappens ist nicht constant geradlinigg orler ausgesehnitten (E h l e r s), sonderu auch vorgewölbt. Ich sah dies sehon am lebenden Thiere, wie aus meiner Zeichnung der $S$. macrocola ersichtlich ist, und an allen als mikroskopische Präparate in Glyceriı-Chromsäure aufbewahrten Stiicken. Auch Grube sagt ron S. hyulinu: Lobus eapitalis transversus, animalis vivi subpentagonus. Supplemen- 
täre Augenflecken nahe dem Vorderrande des Kopflappens fehlen, oder sind rorhanden. Fiihler und Cirren wechselnd an Länge und Gliederzahl. Die Glieder mit feinen Härchen besetzt. Zwei aher anch drei Acienlen, die Schneide der Borsten zerschlitzt. In der Lage des Driisenmagens ergeben sieh gleichfalls Differenzen. Ich betone aber ansdricklich, dass ich nur jene im Ange habe, welche durch eine Verschiedenheit der absoluten Liinge des mit dentlichen Drisenreihen versehenen Theiles des Magens bedingt werden.

Dieser Fall hat mir deutlich gezeigt, dass die blosse Angabe "der Driisenmagen nehme so und soriel Segmente ein" nicht ausreicht, wenn es sich um den Tergleich einer nach lebenden Thieren gemachten Beschreibung mit einer auf Weingeist-Exemplaren basirten handelt; dem zieht sich der Körper zusammen — bei der Tödtıng in Alcohol ist dies gewöhnlich sehr stark der Fall - so drängen sich die Segmente aneinander, und es kann kommen, dass man anf eine grössere Länge des Drïsenmagens darum schliesst, weil er eine grössere Zahl ron Segmenten einnimmt. $S$. hyalina soll einen Drüsenmagen haben, der rom 10 . bis ins 19. Segment reicht, also 9 Segmente lang wäre; bei $S$. pellucida soll nach Ehlers der Driisemmagen rom 10 , bis ins 15 . Segment sich erstrecken, also 5 Segmente lang sein. Dieses letzte Verhältniss fand auch ich durehschnittlich an den lebenden Thieren; warf ich sie aber in Aleohol, so wurde der Driisenmagen ,9-10 Segmente lang!“

Ich habe den Driisemagen gemessen bei Individuen ron 34-94 Segmenten und 3-18 Mm. Läng’e. Er war 0·37, 0.5$0.95,1,1.2 \mathrm{Mm}$. lang und nahm $5-7$ Segmente ein. Bei nahezu gleich grossen Individuen fanden Schwankungen in der Länge statt, ferner hatten grössere desswegen noch nicht einen längeren Driisemmagen. Dadureh wird selbstrerständlich die Lage in den Segmenten unter den normalsten Verhältnissen geändert werden. Immerhin nimmt der Driisemmagen bei $3-4 \mathrm{Mm}$. langen Thieren mit 34-44 Segmenten 5, 5 $\frac{1}{2}$ Segmente ein, wiewohl er fast $2 \frac{1}{2} \mathrm{mal}$ kiirzer ist, als bei $11-15 \mathrm{Mm}$. langen Individuen mit 70-94 Segmenten. Man sieht also, dass selbst um $1 / 3$ kleinere Thiere ein analoges Verhältniss zeigen wie die erwachsenen. 
Nur die Syllis macrocola bietet in der ganzen Reihe das Auffallende, dass der absolut unbedentend kiirzere Drisenmagen nur 3 Segmente eimmahm, jedoch waren diese viel linger, als bei den anderen von mir untersuchten Individuen.

Dass Syllis pellucida Ehlers und $S$. macrocolu Marenz. wirklich die $S$. hyulina Grube sei, wurde mir nach Vergleiehung: von Weingeist-Exemplaren mit lebenten klar. Ich habe solehe mit 112 und 116 Segmenten, also nahezn so vielen wie an Grube's Exemplaren, untersucht. Die Beschreibung Grube's passt zum grossen 'Theile besser anf das lebende Thier als die Zeichnumg. Grube hebt selbst (l. c. pg. 45) die Wirknug des Aleohols in der Verkiil'zung und Verbreiterung der Unterfïhler und Segmente herror.

Zn verbessern ist nur: 1. Palpis profunde sejunctis - sie sind, wie erwïhnt, an der Basis nicht getrennt. 2. Die Borsten sind nicht, wie Fig. 8 a zeigt, mit einfacher Spitze, sondern zweizähnig und iiberdies nicht alle mit so kurzer Sichel als angegeben wurde. 3. Die Lage des Magens "rom 10.-19. Ruder"6 entspricht nur dem contrahirten Thiere. An solchen sah ich aneh den Magen rom 13._-22. und rom 15.-24. Segmente reichen.

Syllis hyalina ist bis jetzt ron folgenden Punkten der Adria bekannt geworden: Lussin grande, Neresine, Crivizza (Grube), Zurkowa bei Finme (Ehlers), Zaule bei Triest, Lussin piccolo (I ch). Ansserdem hat sie Grube (Mittheilg. iiber St. Malo und Roscoff 1872) bei Roscoff an der französischen Westkiiste gefunden.

\section{Syllis brevipentis.}

Pseudosyllis heripennis Grube, Bescheibung nener oder wenig bek. Anneliden. Archiv f. Naturg. 29. Bd. 1863, p. 43. Taf. IV, Fig. 5.

Syllis scabra Ehlers, Die Borstenwiirmer. Leipzig 1864-68, pag. 244. Taf. XI, Fig. $1-3$.

Die ron Grube als Amme der Tetraglena rosacea beschriebene Pseudosyllis brevipenuis ron Crivizza und Neresine auf Lussin, fand ich im Hafen ron Lnssin piccolo in zwei Exemplaren und iiberzengte mich, dass mit ilu die Syllis scabra Ehlers von Finme zn rereinigen sei. In wieweit mein Befund von den beiderseitigen Beschreibungen abweicht, wird aus der folgenden ergänzenden Zusammenstellung ersichtlich. 
Jeine Exemplare hatten 51 und 61 Segmente, waren 6 und $7.5 \mathrm{Mm}$. lang und $0.4 \mathrm{Mm}$. breit. Die grösste Breite fiel in das 16. Segment beiläufig. Der Kopflappen nicht so lang und trapezförmig, wie Eh] er's zeichnet, mehr in die Quere gezogen, kiirzer, stumpfrechteckig. Zwei gelbliehe, glänzende, ölartige Flekken hinter den Augen. Vor dem vordersten Augenpare jederseits noch ein Pigmentfleck. Die Spitzchen am Kopflappen und den Segmenten sehr spärlich, daher der Vorderrand des Kopflappens und die Seitenränder der Segmente niclıt gekerbt. Der Vorderrand des Kopflappens mit Cilien besetzt, ebenso die Seiten des Körpers. In den Gliedern der Cirren $1-3$ orale, gelbe, goldglänzende Körper. Die Glieder mit wenig'n steifen Härchen besełzt.

Der unpaare Stirnfiihler etwas hinter dem Vorderrande des Kopflappens, die paarigen unmittelbar an diesem. Die durchaus getremnten Unterfühler im Leben anseinanderweichend, bei den conservirten Exemplaren ancinander liegend. Die Acicula sehr stark. Die Borsten an der Spitze nicht einfach, sondern zweizähnig. Auch in den über das Ruderende etwas vorstehenden Bancheirren einzelne glinzende Körper. Das Aftersegment ist sehr breit und hat einen dichten Wimperbesatz. Die nur an dem einen Exemplare erhaltenen Aftereirren waren sechsgliedrig. Der Eingang in die Schlundröhre, im Anfange des 3. odes 4. Segmentes liegend, wird rou 10 kugelförmigen Papillen umstellt und ist nicht wehrlos, wie Ehle rs angibt, sondern fiihrt einen derben ziemlich stumpfen Zahı. An dem Magen sind zwei Regionen zu unterscheiden. Eine vordere lïngere mit Drïsenzonen versehene, und eine hintere kiirzere, driisenlose, aber dickwandige, conisch zulanfende. Die erstere war $0 \cdot 195$ und $0.24 \mathrm{Hm}$. lang, $0 \cdot 1 \mathrm{und}$ $0 \cdot 129 \mathrm{Mm}$. breit, die zweite $0 \cdot 15$ und $0 \cdot 12 \mathrm{MIm}$. lang.

In dem einen Falle lag der Nagen im 8., 9., 10., 11. Segmente, woron die beiden letzten anf den drissenlosen Antheil kamen, in dem anderen lag er zum Theile im 8., dann im 9., 10. und 11. Segmente. Das 11. Segment nalm den driisenlosen Antheil anf. Im 12. Segmente begann in beiden Fiallen der gekammerte Darm.

In Betreff Grube's Schilderung der Pseudosyllis lrevipennis habe ich noch zu bemerken, dass der Leil, hinter dem Kopflappen zu breit angegeben ist, dass kein Ruderfortsatz am ersten 
Segmente vorhanden, endlich dass die Zahl der Borsten in einem Ruder zu niedrig angegeben wurde.

Auch fiur Syllis breripennis gelten die einleitenden Worte zur Beschreibung der folgenden Art.

\section{Syllis ochrocen n. s].}

(Taf. III, Fig. 1.)

Diese Art ist der Reprïisentant eines eigenen Typus: Kopflappen kurz aber breit. Stirnfibhler, Fiihlercirren und die Riickencirren des 2. und 3. Segmentes kenlenförmig, ungegliedert; die iibrigen Riickencirren deutlich gegliedert. Schlund unbewehrt. Ich hätte fiir sie eine eigene Gattung anfstellen können; allein ich hielt es für zweckmässiger dies vorläufig nicht zu thum. Die Zerlegmg der Gattung Syllis, wie sie heute begriffen wird, ist nur eine Frage der Zeit. Ein reichlich anwachsendes Material und Nachuntersuchungen bereits beschriebener Arten werden sie rechtfertigen und beschlennigen.

Der folgenden Beschreibung dienten zwei Exemplare, welche ich todt am Boden eines mit Algen gefiillten Glases gefunden.

Der Körper gedrungen, 4 Mm. lang, $0 \cdot 45$ Mm. breit, gegen den Kopf und das Hinterende etwas rerschmälert ( $0: 3 \mathrm{Mm}$. breit), ans 43 Segmenten bestehend. Farbe des Leibes opak oekergelb, die Anhänge hell mit wenig eingestrenten, gleichfarbigen Pigmentanliaiufungen.

Der Kopflappen (Fig. $1 k$ ) ein zusammengedriiektes Queroval, circa $2^{1} / 2^{\text {mal so }}$ breit als lang, ron vorne nach hinten stark geirölbt. Vorderrand fast gar nicht convex, Hinterrand vollständig gerade. 4 zienlich gleich grosse brammothe Angen. Das hintere Paar liegt in gleicher Höhe mit dem Ursprmge des unpaaren Stirnfiihlers, das vorlere nahe an dem hinteren aber mach aussen. Die vorderen Augen stehen demuach weiter auseinander als die hinteren mud sind dem Aussenrande mehr genëihert, iibrigens übersehreiten sie kanm die Mitte des Kopflappens. Vor ilmen noch ein kleiner Angenfleck jeclerseits.

Die Unterfïhler (uf') stumpfeonisch, breit, so lang als der Kopflappen, nur am Grunde in geringer Ausdehnung rerwachsen. Ein ziemlich breiter Zwischenraum trennt beide. Ihr Aussenrand 
biegt sich auf die Banchfläche um und erseheint von nuten gesehen in Gestalt eines schief nach aussen gerichteten polsterartigen Orales.

Die drei St irnfulhler sind ungegliedert und gleichen einer an Ende etwas zugespitzten Kenle. (ielbliches Pignent ist spärlich eingelagert. Der un par a (us) hinter der Mitte des Kopflappens entspringende, ist fast 3mal so lang als der Koptlappen, $11 / 2$ mal so lang als die paarigen.

Die parigen Stirufiuller $(p s)$ sitzen den immeren Viertehn des Vorderrandes des Kopflappens auf.

Das Buccalsegment $(b)$ ist nur halb so lang und etwas sehmäler als das 2. Segment. Zwei Fiihlereirren jederseits stehen anf kurzen Trägerm. Der dorsale Fii lı lereirrus (df') hat die Länge des mparen Stirnfiblers, der ventrale (rf) die der paarigen Stirnfiilıler. Ihre Gestalt und Beschaffenlıeit gleicht jenen.

Die Segmente sind in der Leibesmitte 5 mal so breit als lang, folgen ziemlich dieht anfeinander und ihre Ränder springen deut. lich ror. Die Körperhant ist in Folge des eingelagerten dichten gelben Pigmentes fast mudurchsichtig. Vom zweiten Drittel des Körpers an bemerkt man auf der Riickenflïche der Segmente, etwas hinter der Mitte, schon unter 7ofacher Vergrösserung cine zarte perlschmurartige Querlinie, welche rom Pigment ganz oder fast ganz frei l)leibt.

Die Ruder sind kurz, 8-9mal in der segmentbreite enthalten, ron gewöhnlicher Form. Von oben gesehen ist die Vorderlippe die kiirzeste und sehwïchste, die Mittellippe gut entwickelt und anch die Hinterlippe stärker als erstere. In der Seitenlage sieht man auch bei dieser Art die Hinterlippe gegen die Banchfläche zu, an Breite abnehmen. 3 Arten von Aciculen (Fig. 1 A).

Die Formen " und b liegen dicht ancinander, ron $b$ ansnahmsweise zwei Exemplare in einem Bündel. Die Form $c$ ragt iiber das Ruder in das Borstenbiudel hinein, wo sie zu oberst liegt. 14-1s Borsten in einem Rnder. Die Borsten (Fiz. 1B) hinsichtlich der Länge des Eudgliedes und Stabes verschieden. Immer einige längere in einem Büindel. Das messerartige Ende ist ungebärtet mul endet in zwei nur mit den stiirksten Vergriossermugen wahruehmbaren Zähnehen. 
Die Riickencirren ( $v$ c) des 2. und :3. Segmentes sind von ähnlicher Crestalt wie die Stirnfiihler nud Fiihlereirren, doch etwas breiter an der Basis, und zumal an jenen des 3. Segmentes lïsst sich die erste leichte Andentung einer Gliedermug bemerken. Die Riickencirren des 4. und 5. Segmentes sind an der Basis weniger dentlich gegliedert als gegen das Ende, wo die Glieder scharf abgeschniirt, fast kuglig erscheinen. An den tibrigen ist letztere Eigenschaft durchwegs dentlich. Die Riickencirren sind gegen das Ende schmächtiger als an der Basis, nicht ganz farblos, stechen aber doch von der Grundfarbe des Körpers stark ab, da das Pigment in den einzelnen Gliedem nur zerstreut anftritt.

Die Ba nchcirren (bc) ungegliedert, lanzettlich mit stumpfem Ende, so lang oder nach hinten etwas länger als die Ruder.

Das Afters egment halbkreisförmig, zweimal so breit als lang, mit ansgerandeten Seiten, an welchen zwei gegliederte Cirren stehen. Diese waren so lang $(0 \cdot 18 \mathrm{Mm}$.) als die drei dem Aftersegmente vorangehenden Segmente zusammen genommen und viel zarter und rosenkranzförmig als die zmäclist befindlichen Riickencirren. Zwischen den beiden langen war noch ein dritter ganz kurzer Aftercirrus.

Der Mund liegt im Anfange des anf der Banchfläche bedentend längeren, vorgewölbten und in der Mitte etwas eingeschnittenen Bucealsegmentes. Der Eingang in die Schlundröhre entspricht dem 3. Segmente. Über Papillen habe ich mir keine Aufzeichnungen gemacht. Eine Schhundbewaffnung konnte ich nicht wahrnehmen. Der Drisenmagen nimmt das 8., 9., 10., 11. Segment ein und reicht noch in das 12 . Er ist $0.36 \mathrm{Mm}$. lang, $0.2 \mathrm{Mm}$. breit. Die Dicke der Wand betrug $0.04 \mathrm{Mm}$. Ich zälılte eirca 32 Driisenreihen.

Ans dem Hafen von Lissin piccolo.

Eine sylidee mit gleichem Verhalten der Stimfïhler, Fïhlercirren und Riickencirren hat Marion bei Marseille gefunden (Sur les Annel. du golfe de Marseille. Note. compt. rend. T. LXXIX, Nr. 6. Aô̂t 187t, pg. 398). Er fiilnt sie ohne nähere Bezeichmug als eine Art der Gattmo Anoplosyllis Claparede (Amnel. chétop. d. Naples 1868) an. Mit dieser aber, welehe nur rerkimmerte nicht vorragende Unterfiihler, ein sehrlanges Buceal- 
segment, eine sehr kurze schlundröhre und einen kurzen Driisenmagen besitzt, hat $S$. ochrocen nichts gemein.

\section{Eusyllis: assimilis n. sp.}

(Tal. III, Fig. 2.)

Kürper $6 \mathrm{Mm}$. laug, $0.7 \mathrm{Mm}$. breit ron gedrungenem Habitus, gegen den Kopf kaum merklich, nach hinten plötzlich rerschmälert. 45 s'egmente, Farbe orangeroth. Pigment namentlich in der vorderen Hälfte des Körpers stärker entwickelt. Stimfïil ler, Fühlercirren, nicht aber die Riickeneirren an der Spitze ghleichfalls röthlieh.

Der K o p fl ap p en (Fig. $2 k$ ) ahgerundet pentagonal, $1{ }^{1}, 2$ mal so breit als lang, mit scharf rorspringendem Vorderrande. 4 dunkelrothe in der vorderen Hïlfte des Kopflappens liegende Angen. Das vordere grössere Paar nahe dem Vorderrande nacl anssen der Basis der paarigen Stirnfithler, die binteren kleineren dicht an den vorderen, aber mehr nach inuen. Hart an der Basis der paarigen Stirnfïhler, etwas nach innen, ein kleiner Angenfleck.

Die Unterfiihler (uf ${ }^{\prime}$ ) kiirzer als der Kopflappen, breit abgerundet, an der Basis in kurzer Ausdehnung rerwachsen. Steife Härrchen bekleiden ilı vorderes Ende.

Von den drei Stirnfiihlern zeigt nur der unpare eine ganz unvollkommene Gliederung. Alle drei verschmälern sich gegen das Ende und haben eine runzlige Oberfliche.

Der unpare (us) eirca $2 \mathrm{mal}$ so lang als clie parigen, in gleieher Höhe mit dem vorderen Augenpare und ein wenign hinter den paarigen von der Fläche des Kopflappens entspringend. Die paarigen ( $p s)$ etwas länger als Kopflappen mol Unterfiihler zusammen, etwas schmäler als der unpare, ungegliedert, etwas hinter dem Vorderrande des Kopflappens anfsitzend.

Das Bucealsegment (b) fast so lang als das zweite, etwas schmäler. Der dorsale Fiillereirrus $\left(d f^{\circ}\right)$ nur etwas kïrzer als der unpaare Stirnfülller, der ventrale gieichfalls kürzer als die parrigen. Beide mngegliedert mit muregehnässigen Räudern, breiter an der Basis, gegen das Ende sich verjiingend. Sie sitzen kurzen Fortsïtzen anf.

1 Il a lmgren, Annulat. polychaeta Spetzberg. Groenland. ete. Öfvers. af kongl. Vetensk. Akad. Förhand. 18fj, jag. 159. 
Die Segmente sehon rom 6. an $44_{2}^{1}$ mal so hreit als lang; hinter der Leibesmitte schmiller. Der Seitemrand breit abgerundet, nieht anffallend vorspringend.

Die Ruder (Fig. 2A) 0.06 $\mathrm{Mm}$. vorragend mit gut ansgeprägten Vorder-, Vittel- mil Hinterlippen. Drei Arten von A cieulen (Fig. $2 B \alpha, \beta, \%$ ). In den ersten 8 Segmenten zwei Acieulen, die eine in Gestalt eines nach rome stark, fast winklig gebogenen Hakens $(\alpha)$ endend, die zweite an der Spitze einfach gebogen $(\beta)$. You dem 9. bis 25. Segmente sehe ieh nur die erste Form. Sie ist sehr kräftig, 0.009 breit. Der Haken steht oft aus der Mittellippe des Ruders hervor. Vom 25. Segmente an sehe ich weit ins Borstenbiindel hineimragen eine sehr feine, nur 0.0016 Mm. starke, gekriimmte, an der Spitze kaum wahrnehmbare zweizïhnige Aeienla ( $\%$ ). Das Borstenbiintel 0.12 $\mathrm{Mm}$. lang, eirea 12-15 Borsten in einem Biindel. An den hinteren Segmenten suceessive weniger. Die Borsten (o) zusammengesetzt, mit kurem, an der Spitze zweizïhnigem Endgliede. Dieses in der Länge wenig schwankend, 0.0141-0.016 $\mathrm{Mm}$. lang. Breite der Staibe $0 \cdot 0048 \mathrm{Mm}$.

Yom 40. Segmente sehe ich noch eine aus einem einzigen Stiieke bestehende, an der Spitze zweizähnige Borste in jedem Ruder $(s)$.

Die Riiekeneiren (re) an ihrer Basis etwas eingezogen, kurzen Wurzelgliedern aufsitzend. Gestalt die der Stirnfiihler und Fühlercirren. Sehr grobe Andeutungen an eine Gliederung hie und da. Mit Ansuahme des Riiekencirrus des 2. Segmentes sind alle kiirzer als die Segmente breit. Dieser ist der laingste Anhang des Körpers - nicht ganz zweimal so lang als der unpare Stirnfiihler. Im Ganzen alterniren kiirzere und etwas längere Cirren. Der Rüickencirrus des 5. Segmentes ist läinger als der des 3 . und 4. und der folgenden.

Die B a u cheirren llattartig;, sehr breit ( $0.06 \mathrm{Mm}$.$) , kiirzer$ als die Rnder (Fig. $2 \boldsymbol{A}$ l c ). Der Baucheirus des ersten Ruders nicht grösser als die iibrigen. Das Aftersegment (Fig. 2C) halbkreisförmig mit zwei langen (0.7 Vm.) endständigen, einander genäherten ungegliederten Aftercirren und einem ganz kurzen mittleren. 
Der in zweiten Segmente liegende Eingang in die Schlundröhre ist dreieckig. Der Rand des Dreieckes mit zahlreichen chitiuösen Spitzen (Zähnchen) besetzt; nur gregen den der Dorsalseite zugewandten Winkel hin werden sie schwächer und fehlen damn ganz. Hier stelıt jedoch ein starker Zahn ron gewöhnlicher Form (Fig. 2D). In der hinteren Hïltte fällt eine dunkle dreieckige, etwas helleonturirte Stelle anf, deren Bedeutung mir nicht klar geworden. Der Driisenmagen ist $0.83 \mathrm{Mm}$. lang, 0.4 Mm. breit. Er nimmt das 7., 8., 9. und 10. Segment ein. Die Dicke seiner Wand betrug 0.11 Mm. Driisemreihen cirea 50.

Im Hafen von Lussin piceolo unter Algen in einer Tiefe ron 2-3 Yeter ein vollständiges und ein verstiimmeltes Exemplar.

Wiewohl ich die weichen Papillen um den Eingang der Schlundröhre nieht gesehen und die diese Region darstellende Abbildung Malmgren's (1. e. Tab. VII, Fig. $43 \mathrm{~F}$ ) etwas abweicht, so passt doch das Übrige, die Form der Ruder, der Borsten rollstïndig auf die arlriatisehe Art. Eusyllis Blomstrondi II grn. aus Spitzbergen hat ebenfalls ungegliederte Cirren und ist bis anf andere Längenverhältnisse der Fühllercirren nud der Riickencirren des 2., 3. nnd 4. Segmentes sehr ähnlich. Marion fand Eusyllis in Marseille durch zwei Arten reprïsentirt (Sur les Annel. du golfe de Marseille. Note. Comptes rend. T. LXXIX Août 1874, pag. 398; und ebenda T. LXXX Février 1875. Sur' les espèces médit. du genre Eusyllis p. 498.) Die eine Art hält er fiir identisch mit E. monilicomis II grn., die andere nemt er E. Iamelligern. Ob die E. assimilis mihi etwa mit dieser zusammenzufallen habe, wird erst in der Folge entschieden werden können, da die bisherigen Angaben Marion's zu einer Artbestimmung nieht geniigen.

\section{Odontosyllis brevicomis.}

(Taf. IV, Fig. 1.)

Syllis brevicornis Grube, Beschreib. nener oder wenig bekannter Anneliden. Archiv f. Natmrg. 29. Jahrg. 1863, p. 44, Taf. IV, Fig. 1. Die Insel Lussin. Breslau 186t, pag. 84.

Im Hafen von Lussin piccolo fand ich wiederholt eine Odontosyllis, in der ich die Syllis brevicomis Grube wieder erkannte, wemn anch Grube des Wimperlappens und der eigen - 
thiimliehen Bewaffuung der Schlundröhre - also der Gattungscharaktere der Odontosyllis - keine Erwïhnmg that und die oben eitirten Figuren nieht ganz dem Befunde am lebenden Thiere entsprechen. Ieh halte es daher fïr zweckmässig, nene Abbildungen und eine ausfiihrliche Besehreibung zu gehen.

Das grösste Exemplar war $6.5 \mathrm{Mm}$. lang, mit den Rudern $1 \mathrm{Mm}$. breit und zählte 27 Segmente. Farbe des Körpers weisslich-bräunlich; der Darm schimmert in der Mittellinie gelblich dureh. Die Hant des Riiekens jedes Segmentes, der Vorderhälfte des Kopflappens, die Ruderriieken, die Spitzen der Palpen, der Wimperlappen, der mpare Stirnfühler in sciner ganzen unteren Hälfte, die paarigèn Stirnfiihler, Fiihlercirren und Riickencirren an umschriebenen Stellen ihrer äusseren Hälfte, enthalten opake, kreidcartige Einlagerungen und erscheinen darmm im auffallenden Lichte weisslieh, im durehfallenden sehwärzlich. Von der Grundfarbe des Leibes heben sich dorsal bramriolette Pigmentpunkte in unregelmässiger Vertheilung ab. Nur in dem äusseren Viertel der vorderen Segmente häuft sieh das Pigment, den Eindruck rielfach unterbroehener Längsstreifen herrorrufend, ausserdem an Vorderrande einzelner Segmente in Gestalt grösserer medialer Flecken, mnd hie und da an der Basis der Riickencirren oder in den einspringenden Winkeln zwischen zwei Segmenten.

So trug in einem Falle das 9., 11., 13., 15., 18. und 20. Segment medial einen nach hinten offenen Ring; oder einen dieken, etwas geschwmgenen Querstreif, sowie Pigmentanhäufungen an der Basis der Ruickeneirren. An einem anderen kleineren Exemplare waren mediale quergezogene Flecken zwischen dem 9. und 10., dem 11. und 12. und vor dem Anfange des 13. Segmentes und jeder einspringende Winkel zwischen 2 Segmenten war dureh einen dunklen Fleek markirt.

Der Körper nach vorne wenig, nach hinten stärker verjïngt. Der Kopflappen (Fig. $1 k$ ) stumpf-sechseckig, $1_{1 / 2}^{1}$ mal so breit als lang, stark gewölbt, in der Mitte vertieft, die beiden seitlichen Hälften wieder ans zwei schief nach anssen gestellten polsterartigen Erhabenheiten bestehend. Der Vorderrand ziemlich gerade, der Hinterand eingebuehtet. In halber Höhe des Kopflappens ein die Coneavitït nach vorne kelurender halbinond- 
förmiger Fleck jederseits. Zwei Paare dunkelrother Augen. Die vorderen nur wenig ron dem Vorderrande entfernt, grösser; die hinteren dieht an den rorderen, aber mehr nach innen geriickt, kleiner. Wimperbisehel an den Seitenrändern.

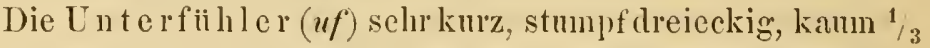
so lang als der Kopflappen, an der Basis in ganz unbedentender Ausilelmung" verwachsen, sonst getrenut, bald dicht aneinander liegend, bald etwas auseinanderfahrend. Die abgermdete Spitze mit einigen steifen Haaren besetzt.

Der un parre Stirnfühler (us) nicht ganz so lang als Kopflappen und Unterfihler zusammengenommen, in gleicherHöhe mit dem vorderen Angenpare ron der Fläche des Kopflappens entspringend, leicht spindelförmig, da er iiber der Basis etwas breiter wird und sich dann gegen das stumpfe Ende verschmälert, ungegliedert mit relativ langen steifen Haaren besetzt, in seiner unteren Hälfte ron kreideartigen Einlagerungen undurehsichtig.

Die parrigen Stirnfiihler ( $p s)$ etwas kiirzer als der unpare, eben so weit als dieser rorragend und ron gleicher Gestalt. Die kreideartigen Einlagerungen beschränken sich auf cinen in geringer Entfernung von dem Ende liegenden Fleck.

Die Segmente nach rome weniger, nach hinten stärker rerschmälert (das 2. $0 \cdot 41$, das $7.0 \cdot 7$, das $24.0 \cdot 3 \mathrm{Mm}$. breit), beilïnfig $3 \frac{1}{2}$ mal so breit als lang. Die Segmentränder springen sehr deutlich ror, an ihrem Hinterrande Flimmerbewegmig.

Das Buecalsegment (b) ron oben sichtbar, doch kaum halb so lang als das folgende. Es träigt zwei Paar Fi hl le r c i r re 1. Der dorsale Fühlercirrus (df) $1 \frac{1}{2} 2^{\text {mal }}$ so lang als der unpare Stimfiihler, der ventrale $(v f)$ nur etwas länger als dieser. Ihr Aussehen gleicht dem der mparen Stirnfuilıler.

Unmitielbar an der Grenze des zweiten nit dem ersten Segmente liegt der Wimperlappen $(x)$. Er ist halbkreisförmig, melı als $1 \frac{1}{2}$ mal so breit als lang und deckt die hintere Hälfte des Kopflappens.

Die Riickencirren (rc) untereinander ziemlich gleich lang (circa $0.3 \mathrm{Mm}$.) olne eigene Träger iiber den Rudern entspringend, conform den paarigen Stirnfiihlern und Fiihlercirren; nur sah ich rom vierten Segmente an ihre Oberflaiche etwas 
runzlig werden. Sie erreichen nicht das Ende der langen Borstenbiindel.

Die Ruder(Fig. 1 A) sind lang, nur vorne etwas kuircer. cirea dreimal in der Segmentbreite enthalten. Der obere Rand der Vorderlippe geht in einen abgerundeten fingerförmigen Fortsatz aus. Ebenso endet der Rand der küirzeren Hinterlippe mit einem kleinen Knöpfehen. Eine am Ende etwas rerbreiterte quer abgeschnittene Acicula. 10-16 selı feine, znsammengesetzte Borsten. An den vorderen Rudern ragen die Borsten weniger weit (0.09 Mm.) vor, als an den hinteren $(0 \cdot 24 \mathrm{Mm}$.). Die Stäbe sind nur $0 \cdot 0024$ Mm. stark. Das messerförmige Eude geht in eine zarte gekriimmte Spitze ans, unter weleher ich aber bei meinen Vergrösserungen (Hartnack, Imm. 9) keinen Ansatz zu einem zweiten Zähnchen zn bemerken im Stande bin. Die Selneide ist bebartet. Die Länge des Messers ist in einem Biindel rerschieden. Sie erreicht 0.04 $\mathrm{Im}$.

Die Banchcirren (bc) stumpf-lanzettlieh, länger als das Ruder, mit breiter Basis der Unterfliche des Ruders, dem sie dieht anliegen, angewachsen. Erst ihre äussere Häilfte beiläufig wird frei.

Das Aftersegment abgertudet rechteckig, circa zweimal so breit als lang; mit zwei ziemlich weit ron einander entfernt stehenden Cirren. Diese kiirzer (0.23 Mm.) als die Riickeneirren, aber ron demselben Habitns.

Der Mund liegt, anf der Bauchfläche, in der Gegrend der linteren Hälfte des Kopflappens. Von hier fiilnt die Riisselröhre zur kurzen (0.15 Mm. lang) nur ein segment eimnehmenden Schlundröhre, deren Eingang mit dem charakteristisehen Apparate im dritten Segmente liegt. Er besteht in 6 (orler 7 ) mit der Spitze nach hinten gerichteten, rentral gelegenen Zälnen und zwei grösseren horizontalen dorsal gelegenen Chitinplatten, je eine lateral. Der Driisenmagen nimmt das 4., 5., 6. Segment ein und ist $0.44 \mathrm{Mm}$. lang, $0.23 \mathrm{Mm}$. breit. Die Dicke seiner Wand beträgt $0.46 \mathrm{Mm}$. Die Driisenreihen sind nicht sehr deutlich. Ich ziililte 32.

Röthliehe Eier (ron 0.08 Mm. Durchmesser) erfiulten die Seiten des 6 . bis 20 Segmentes.

Diese Art lebt in einer Tiefe ron 2-3 Meter zwischen Algen. 
Odontosyllis lrevicormis weicht in Habitus und dureh die Gestalt der Borsten ron den andern bisher bekannten Arten dieser Gattung ab, bis auf Odontosyllis gibbu Claparede (Beobachtg. iiber Anatom. und Entwicklung'sg. wirbelloser Thiere a. d. Kiiste der Normandie. Leipzig 1863, pag. 47. Tafel XII, Fig. $7-8)$. Diese Art ist der unserigen iiberhanpt sehr ïlulich. Doch stehen der Identification einige Schwierigkeiten entgegen. Besser noch passt anf 0 . Irevicornis in demselben Werke die Abbildung einer anderen weiters nicht benamnten Odontosyllis (Taf. XII, Fig. 9). Im 'Texte wird diese Figur nicht beriilurt. Man kaun also nicht wissen, ob und welche Bemerkungen uiber andere neben O. giblu in St. Vaast la Hongue rorkommende Odontosyllis-Arten darauf passen. Sind die Borsten der Fig. 9 ebenso lange als die der adriatischen Art, dann kann man wohl aunehmen, dass. o. brevicornis anch an der französischen Westkiiste rorkomme.

\section{Procercuea. Ehlers.}

In der Charakteristik dieser mit Autolytus rerwantten Gattung wird von Ehlers das Fehlen der Unterfuihler angeführt und ich habe mich bei der Beschreibung meiner nenen Arten in gleichem Sinne ausgesprochen. Seitdem latte ich Gelegenheit Procerrer pictı Ehlers, Procermea luxurus Marenz. abermals, mon eine weiter unten beschriebene nene Art zu untersuchen. Ich bin nummehr anderer Ansicht. Betrachtet man eine Proceraea von der Riickenfliche, so fiillt anf, dass die paarigen Stirnfiihler entfernt ron dem vordersten Contur, welchen man bei dem Fehlen von Unterfithler als Vorderrand des Kopflappens anzusehen genöthight wird, entspringen, dass der vor der Ursprumg'sstelle liegende Theil diinn ist und lureh eine helle Mittellinie in zwei Hälften getheilt wird. Die dahinter liegende Fläehe ist gewölbt, compacter, traigt vorne die parigen Stimfihller, weiter nach hinten den unpaaren, endlich die Angen. Was die helle Vittellinie bedentet, wird klar, wenn man das Thier auf den Riicken legt. Sie setzt sich bis zur II undïfinung nach hinten fort, (Siehe meine Zeiehnung der Procerner luxurins l. e. 'Taf. VI, Fig. $1 \mathrm{ID}$,) und ist der Ausdruck des Contactes zweier der Ventralfliche des Koptlappens aufliegenden bis zum Buccalsegmente sich erstrekkenden Gebilde, die ilıre Analogie nur in den Unterfiihlern anderer 
Syllideen finden kömnen. Die Diagnose der Gattung Procernen wäre also folgendermassen richtig zu stellen:

Unterfïhler fehlennicht. Sie sind aber rulimentiir und unter sieh und mit dem Kopflappen rerwachsen, doch ragt ihr Vorderrand als eine dinne kurze Platte iiber den dureh die Ansatzstelle der unparrigenstirnfuiluler gekennzeichneten Vorderrand des Kopflappens ror. Eine lielle Mittellinie zeigt die Contactstelle der beiden Unterfiithler an'.

Bei der Gattung Autolytus diirlte wohl dasselbe Verhalten sein.

\section{Proceraea macrophthalma n. sp.}

(Taf. IV, Fig. 2.)

Drei Exemplare ans dem Hafen ron Litssin piccolo lagen vor. - Der Körper $6 \mathrm{Mm}$. lang, 0.4-0.5 . Mm. breit, ans 40-45 Segmenten zusammengesetzt. Dic Farbe des ziemlich gleich breiten Leibes licht orangeroth, Stirnfuiller, Fiihlereiren, Riickencirren des zweiten und dritten Segmentes weisslich. Die übrigen Riickeneirren etwas röthlich angehancht. Bei einem Individunm war die hintere Leibeshälfte von angehäıften Eiern röthliehviolet.

Der Kopflappen (Fig. 1k) rundlich, breiter als lang, gewälbt, sein Vorderrand von den vortretenden verwachsenen

1 Ich kann nicht umhin, hicr meiner Vermuthung Raum zu geben, dlass wir in der mehrfach missdenteten syllime Grobe's (Beschr, nener oder wenig bekannter Annel. Arch. f. Naturg. 1860, pag. 87. 'Tat. I II Fig. 8; Ausflug nach 'Triest 1861, pag. 144. Taf. III. Fig. 8) nichts als eine Proceraca zu sehen haben. Die Diagnose der Gattung Sylline wiurde nach meineu obigen Angaben iiber die Unterfühler bei Procerae ohme weiters auf diese passen. Der Gesammthabitus, die Ventralansicht des Kopflappens (Fig. \&a) entspricht vollkommen. Befremdend ist die Länge des ïber den Kopflappen vorragenden 'Tlueiles der Unterfühler, dis Felılen der ventralen Fiihlercirren, die Länge der Rïckencirren, endlich die Gestult der Borsten (Fig. 8b). Viclleicht erklürt sich dies durch eine nicht ganz scharfe Wiedergabe des zu Sehenden. Der Erhaltungszustand war, wie Grube selbst bemerkt, ein mangelhafter. Jedenfalls gehört die Sylline flava Grube. (1869) von St. Vaast, St. Mal» und Roseoff nicht in den Formenkreis der Sylline rubropmuctata Gr. 1860; denu sie besitzt getrennte Unterfïhler. 
Unterfiihlern nicht abgesetzt. Fast die ganze Seitenfliche des Kopflappens wird jederseits ron zwei sehr grossen dunkel-rothbrannen, dicht aufeinander liegenden Angen eingenommen. Lichtbrechende Körper sah ich nur in den rorderen Augen die verwachsenen Unterfühler ( $\left(1 f^{\prime}\right)$ nur wenig vorragend. Die Contactstelle der beiden Unterfiihler als helle Linie ron oben und namentlich auf der Bauchflïche sehr dentlich.

Der unpare Stirnfithler (us) entspringt mit breiter Basis ron einem Wurzelgliede in der hinteren Hälfte des Kopflappens. Er ist der längste Anhang des ganzen Körpers, fast zweimal so lang als die paarigen Stirnfühler, $1^{1}{ }_{i 2}$ mal so lang als der Riickencirrus des zweiten Segmentes. Er verjüngt sich etwas gegren das Ende zu. Zuriickgelegt wïrde er bis ins 9. Segment reichen. Seine etwas runzelige Oberfäche ist mit steifen Härchen besetzt. Dasselbe Verhalten auch bei den iibrigen Fiihlern und Cirren.

Die parrigen Stirnfühler (ps) sind nur unbedeutend länger als die dorsalen Fïhlereiren, cirea $3 / 4$ so lang als der Riickencirus des zweiten Segmentes.

Die Segmente sind durehsehnittlich 3mal so breit als lang, in der Vitte des Leibes um die Hälfte breiter als hinter dem Kopfe und ror dem Leibesende. Das Buccalsegment ist von oben sichtbar, halb so lang als das folgende.

Der dorsale Fiihlercirus ( $(f)$ zweimal länger als der rentrale $\left(v f^{\prime}\right)$, um Weniges kiirzer als die paarigen Stirnfiihler.

Der Ritickencirrus ( $r c)$ des zweiten Segntentes steht an Länge dem unparen Strinfiihler nach. Er ist $2 \frac{1}{2} \mathrm{mal}$ lïnger als der etwas schmächtigere Cirrus des dritten Segmentes. Dieser ist $1 \frac{1}{2}$-2mal länger als der des vierten Segmentes. Die Ruickencirren des ersten und zweiten rudertragenden Segmentes haben die Gestalt der Stirnfiihler und Fühlercirren. Verschieden sind aber die der folgenden Segmente. Der Riickencirus des vierten Segmentes bereits ist breiter als der liiugere des dritten, plump, dick an der Basis, gegen das abgerundete Ende ein wenig verschüïlert. In dem ron mir abgebildeten Falle betrug: seine Länge ${ }^{2} / 3$ der Segmentbreite, an den zwei anderen Exemplaren die Hïlfte. Die Riickencirren sind stärker als die ron $P$. lu.emians und P. pirta, 2-3mal kiirzer als die Segmente breit 
und sitzen kurzen Wurzelgliedern vor dem äusseren Ende der Segmente auf.

Die Ruder etwas länger als breit, relativ stark, 4-5mal in der Segmentbreite enthalten. Die Vorderlippe ist etwas kiirzer und viel schwächer als die Hinterlippe, so dass hinter dem zwischen beiden anstretenden Borstenbündel mehr als drei Viertel der ganzen Breite der Ruder zu liegen kommt. Zwei spitze A eiculen.

Circa 10 Borsten in einem Bïndel, das etwas weiter vorragt, als das Ruder lang ist. Die Borsten von der gewöhnlichen ler Gattung eigenthiimlichen Gestalt (Fig. 2A). Die zweite Form der Borsten, jene mit gertenförmigem Ende, sehe ich vom 11. Segmente an auftreten. Es ist nur eine in einem Biindel vorhauden.

Batucheirren fehlen.

Das stumpfeonische $\mathrm{A}$ ftersegment trägt 2 dicke Cirren welche etwa so lang sind, als die 5 dem Aftersegmente vorangehenden Segmenten. Lage der Mundüffnung wie bei Proceraca luxuriuns. Auch hier ist das Buccalsegment anf der ventralen Seite länger, als auf der dorsalen. Desgleichen ist das Verhältniss der Riisselröhre $(r)$ zur Schlundröhre $(s)$ dasselbe. Der Eingang in diese liegt kurz vor dem Ende des dritten Segmentes und ist mit einem Kranze ron eirca 20 ungleich grossen, bald mehr dreieckigen, bald mehr lanzettlichen Zähnen bewaffnet (Fig. $2 \boldsymbol{B}$ ). Die Schlundröhre ist sehr lang, ein- oder zweimal in Schlingen gelegt. Der Driisenmagen wal $0.18 \mathrm{Mm}$. lang, $0.12 \mathrm{Mm}$. breit und $0 \cdot 24 \mathrm{Mm}$. lang, $0 \cdot 18 \mathrm{Mm}$. breit. Er nahm nieht ganz zwei Segmente ein. So lag er im 8. Segmente und reicht noch etwas in das 9. und 10. oder er nahm das 9. ein und erstreckte sich noch in das 8. und 10. Die Dritisenzonen sind lang und darum nur späirlich. Ieh zählte 15 . Die Wände sind sehr dick $0 \cdot 05$ $0.07 \mathrm{Mm}$.

Bei einem Exemplare lagen rom 16. bis inclusive 35. Segmente röthlich-violete Eier in den Seiten der Segmente.

Proceraea macrophthalma wurde nahe der Kiiste, zwischen Algen lebend, angetroffen. 


\section{Varzeichniss}

der in Betracht gezogenen Gattungen und Arten.

(Die Synonyme sind durchschossen gedruckt.)

Alentin Mgrn. . . . . . . . . . . . . . 130

Anoplosyllis Clap. . . . . . . . . . . . 154

Aphrodita clava llont... . . . . . . . . 129

Aphrodite squamata L. . . . . . . . . . . 130

Autolytus Gr. . . . . . . . . . . . 165

Enmolpe squamata Delle Chiaje . . . . . . 130

Eusyllis assimilis n. sp. . . . . . . . . . 158

" Blomstrandi II grn. . . . . . . . . . . 160

" lamelligera Marion. . . . . . . . 160

" monilicornis Mgrn. . . . . . . . . 160

Hurmothoë imbricatu L. . . . . . . . . . . . . . . 138

Hermadionfragile Clap............. . 141

Hermadion pellucidum Ehl. . . . . . . . . . 141

Lagisca Ehlersi Mgrn. . . . . . . . . . . 133

extenuatu Gr. . . . . . . . . . . . . 133

Leanira tetragona $\mathrm{O}$ erst. . . . . . . . . . . 143

Yhlehni Mgrn. . . . . . . . . . . . . 142

Lepidasthenia elegans $\mathrm{Gr}$. . . . . . . . . . . . 139

Lepidonotus clave Mont. . . . . . . . . . . . 129

clypeatus Gr. . . . . . . . . . 132

squamatus L. . . . . . . . . . 130

Odontosyllis brevicornis Gr. . . . . . . . . . 160

gibba Clap............. . 164

Oxydromus (1... . . . . . . . . . . . 143

flaccidus $\mathrm{Gr}_{\mathrm{r}} \mathrm{O}$ ersd. . . . . . . 143

" fiuscescens $\mathrm{n} . \mathrm{sp}$. . . . . . . . . . 143

$" \quad$ longisetis Gr. Oersil. . . . . . . . 143

Polynö̈ cirrutu O. F. Miill. . . . . . . . . . 138 


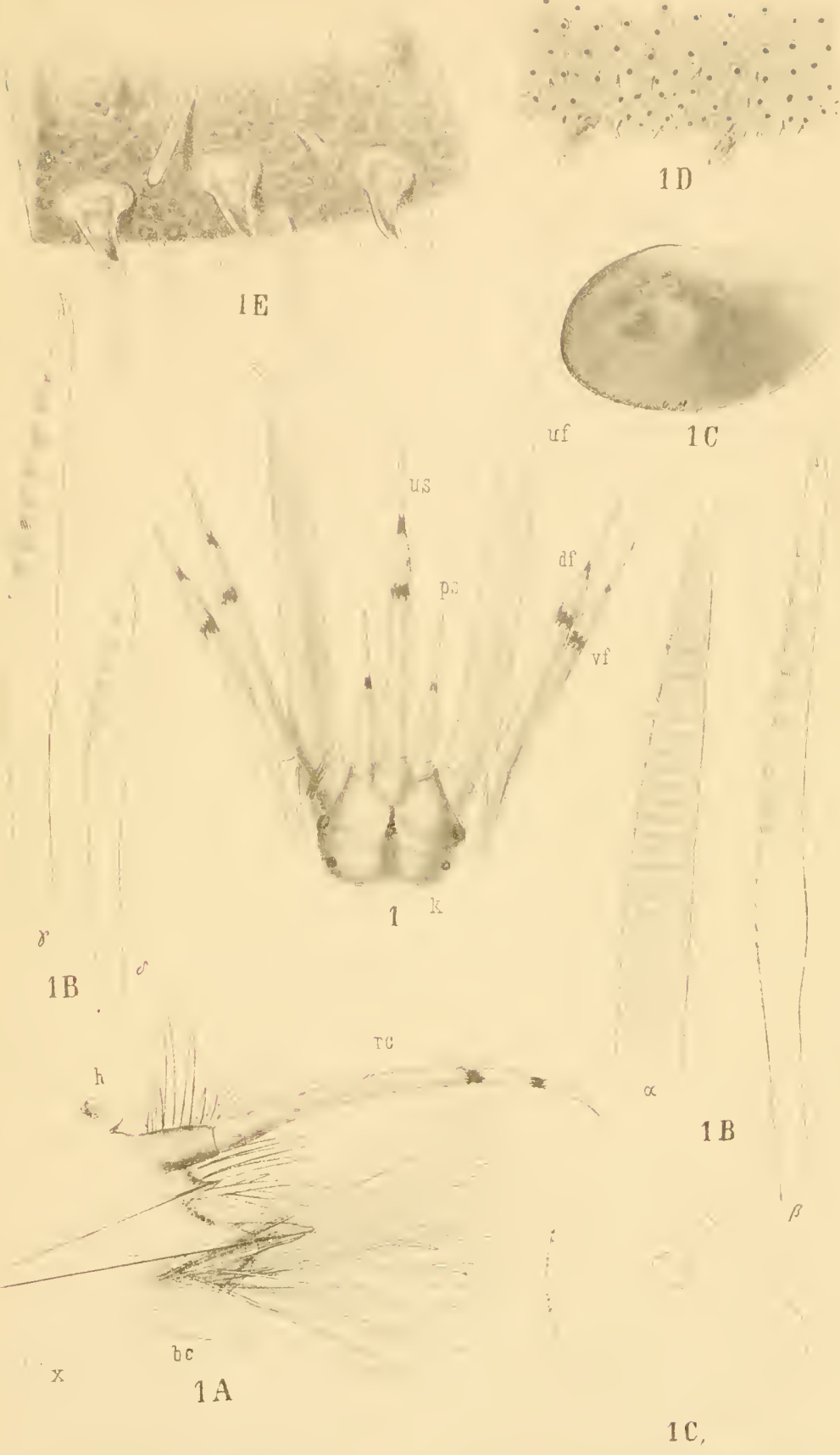

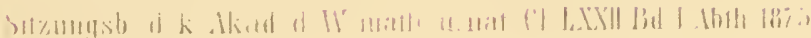





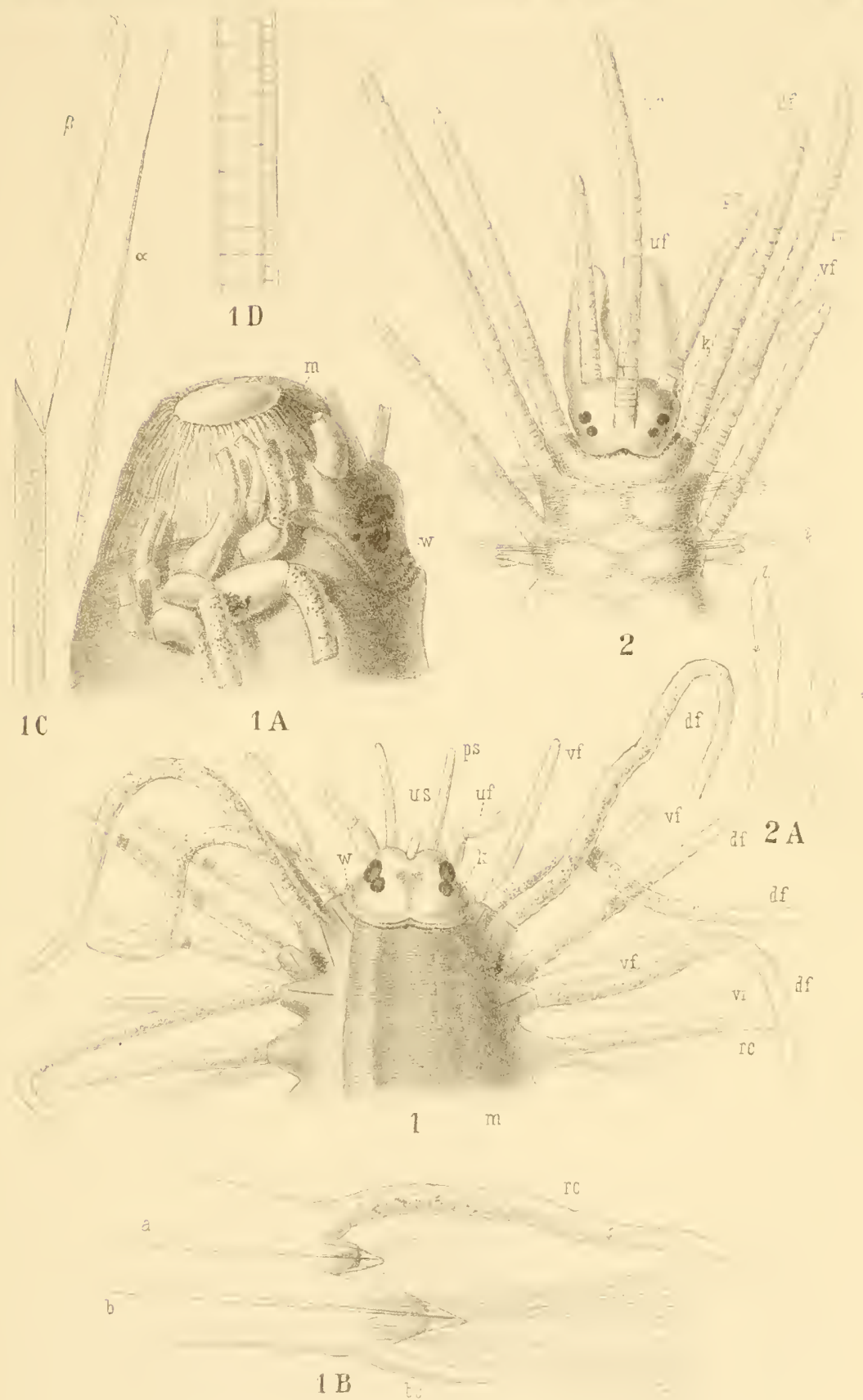





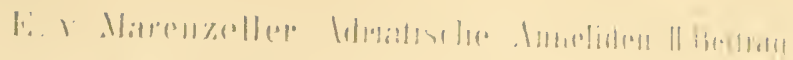

us

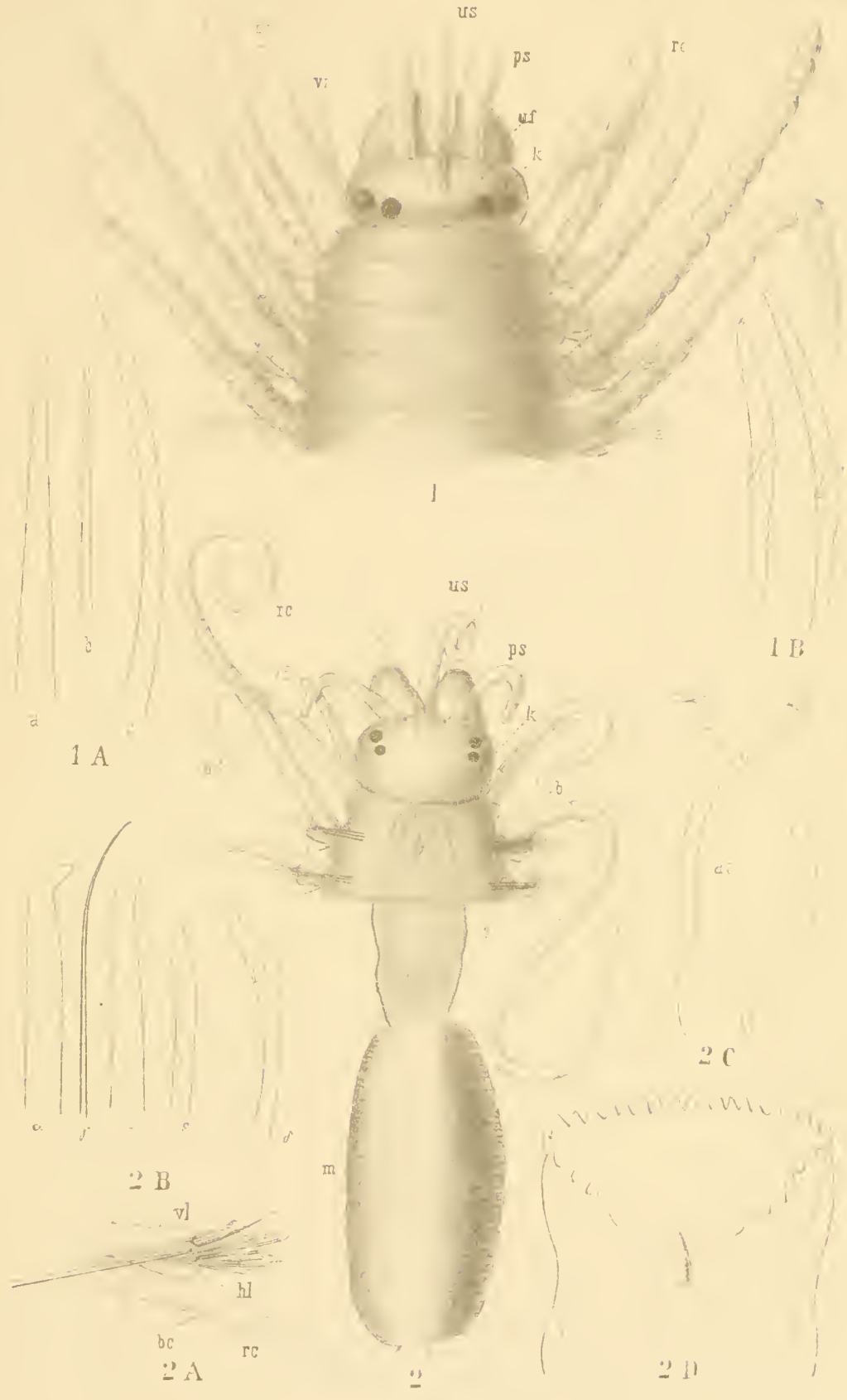

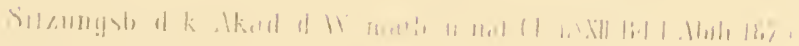




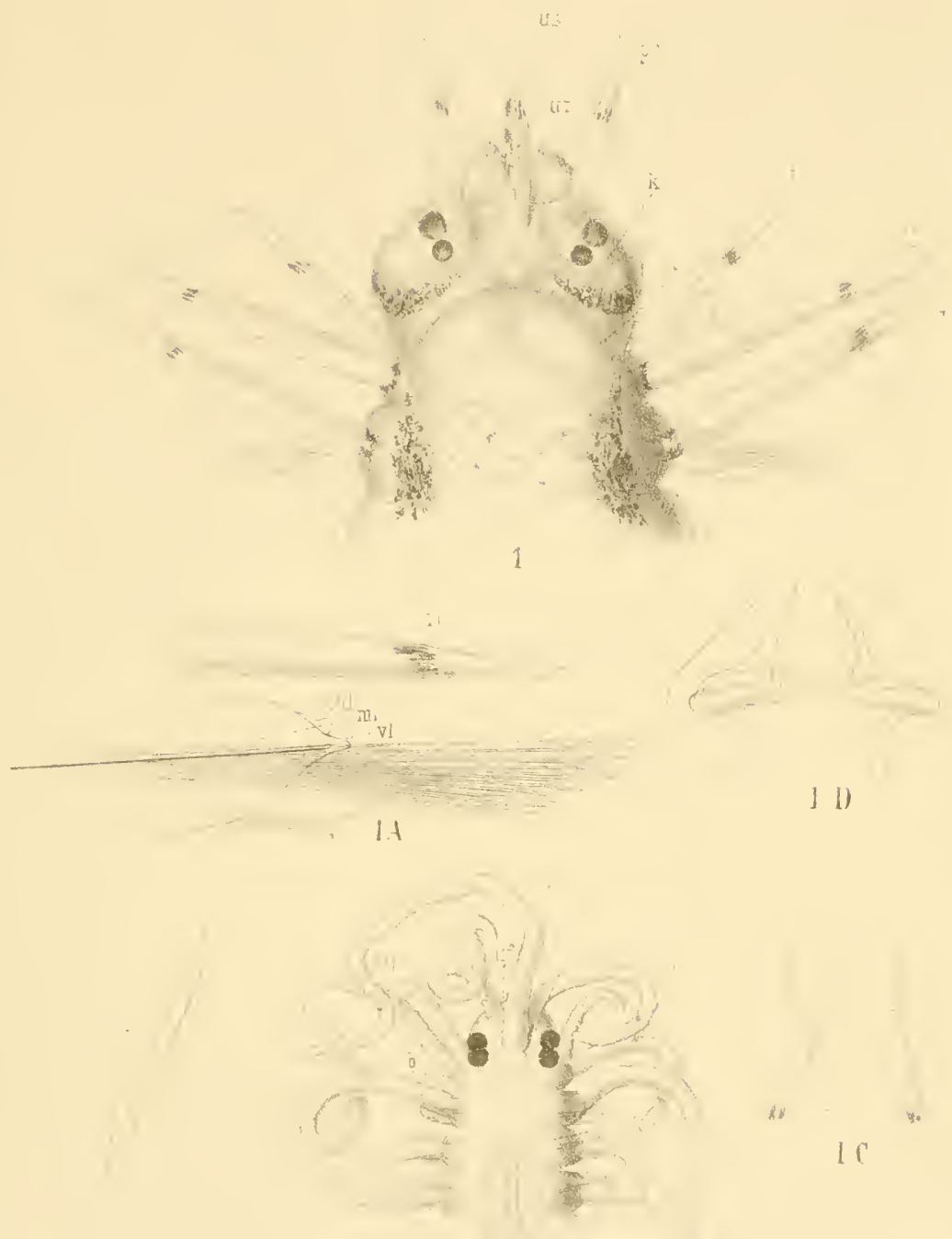

113

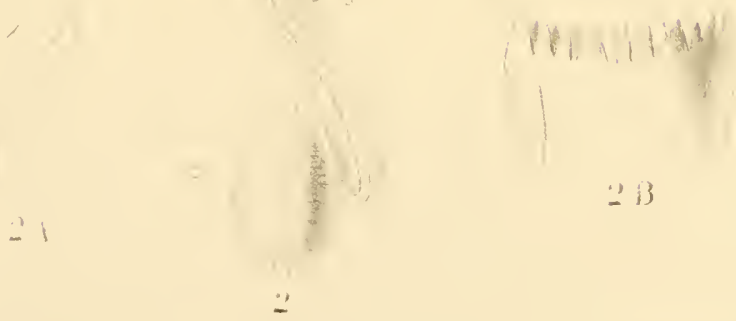



Polynö̈ clypeata Gr. . . . . . . . . . . . 130

dorsulis Quatref. . . . . . . . . 133

eleguns Gr. . . . . . . . . . . 139

extenu ut "Gr............. . . 133

fuscescens Quatref. . . . . . . . . 133

Grubianu Clap............ . 130

lamprophtlalma Marenz. . . . . . . 139

longisetis Gr. . . . . . . . . . . . 133

modest "Quatref. . . . . . . . . 130

pellucidu Ehl. . . . . . . . . . . 141

scutellutu Risso...... . . . . . 129

squamutu Sar. . . . . . . . . . 130

Proceraea Ebl. . . . . . . . . . . . . . . 164

luaviuns Male $1 \mathrm{z}$. . . . . . . . . . 164

macrophthalma 11. sp. . . . . . . . . . 165

" picta Ehl. . . . . . . . . . . . . . 161

Pseudosyllis brevipennis Gr. . . . . . . . . . 153

Sylline Gr. . . . . . . . . . . . . . . . 165

" flave Gr. . . . . . . . . . . . . . 165

, rubropunctutu G 1. . . . . . . . . . . 165

Syllis brevicornis Gr. . . . . . . . . . . . 160

. brevipennis $\mathrm{Gr}$. . . . . . . . . . . 153

. hyalina Gr. . . . . . . . . . . . . . 150

m macrocola Marenz. . . . . . . . . . 150

" ochracea n. sp. . . . . . . . . . . . 155

" pellucida Elll. . . . . . . . . . . . $\$ 50$

"scabra Ehl. . . . . . . . . . . . 153

"variegata Gr. . . . . . . . . . . . . . 147

Tetraglene rosacea Gr. . . . . . . . . . . . . . 153 


\section{Erkläirung der Abbildungen.}

k. Kopflappen.

uf. Unterfiihler (Palpen).

us. Unpaarer Stirnfühler.

ps. Paarige Stirnfiihler.

b. Buecalsegment.

df. Dorsaler Fïhlercirrus.

vf. Ventraler Fühlercirrus.

$r c$. Riickencirrus.

$b e$. Batchcirrus. rl. Vorderlippe des Ruders.

$m l$. Mittellippe des Ruders.

$h l$. Hinterlippe des Ruders.

ac. Aftercirus.

$r$ Riissselröhre.

s. Schlundröhre.

¿. Zahn der Schlundröhre.

$m$. Driisenmagen.

\section{Tafel I.}

Fig. 1. Lagisca extenuata $\mathrm{Gr}$. Von oben 20/1.

"1 A. " Hinterfläche des Ruders in Seitenlage 20/1. h. Höcker am Riicken der Riickencirrentragenden Segmente.

"1 B. " $"$ Borsten 140/1. \& Borste des oberen Astes;

$\beta, \%, \delta$. Borsten des unteren Astes.

"1C. " " $\quad$ Elytren $8 / 1$.

$" 1 \mathrm{H}$. " $\quad$ " Rand einer Elytre 90,1.

" 1 E. $" \quad$ " Oberfläche einer (gefalteten) Elytre 330/1.

\section{Tafel II.}

Fig. 1. Oxydromus fuscescens 11 . sp. Von oben 20/1. $u$. wimpernder kragenartiger Wulst.

, 1.7 Profilansicht des Kopflappens und der ersten vier Segmente mit abgeschnittenen Anhängen. Der Magen $(m)$ ist vorgestiilpt. $30 / 1$.

" $1 \mathrm{~B}, \quad$, Ruder von vorne $40 / 1$.

$" 1 C \quad " \quad$ B Borsten 330/1. $\alpha$. Borste des oberen Astes. B. Borste des unteren Astes.

"1 I \# \# Ein Stïck cles Borstenstabes 630/1.

"2. Syllis variegata $\mathrm{Gr}$. Von oben 50,1 .

"2A. " " Borsten 330/1. 


\section{Tafel III.}

Fig. 1. Syllis achracea n. sp. Von oben $90 / 1$.

"1 A. " " $\quad$ Aciculen $650 / 1$.

"1 R. , , " Borsten 630/1.

. 2. Eusyllis assimilis 1 . sp. Von oben $50 / 1$.

"2A. " " " Ruder von oben 901.

$" 2 I . \quad " \quad \Rightarrow \quad \alpha, \beta, \%$ Aciculen; $\%$, s. Borsten 630/1.

"2C. $\quad " \quad$ " Aftersegment $50 / 1$.

. 2 D. " $\quad " \quad$ Zahnkrone am Eingange in die Schlundröhre $330 / 1$.

\section{Tafel IV.}

Fig. 1. Odontosyllis brevicornis Gr. Von oben $70 / 1$; $x$. der Wimperlappen.

"1. $" \quad$ \# Ruder von vorne $90 / 1$.

" 1 R. $\Rightarrow$ Borsten $630 / 1$.

" $1 \mathrm{C}$. $\quad$ " Aftersegment $70 / 1$.

"1 D. " " Eingang in die Schlundröhre 180/1.

"2. Proceraea maerophthalma n. sp. Von oben $45 / 1$.

, 2 A. " " $"$ Borsten 630/1.

" 2 B. " " " Zahnkrone am Eingang in die Sehlundröhre $630 / 1$. 
XVIII. SITZUNG VOM 15. JULI 1875.

Der Secretär theilt die eingelangten Dankschreiben mit, und zwar: vom Herm A. Des Cloizeaux in Paris für seine Wahl zum ansländischen correspondirenden Mitgliede, ron den Herren Professoren Camil Heller in Innsbruck und Emil Weyr in Prag für ihre Wahlen zu inlïndischen correspondirenden Mitgliedern der Classe, und rom Herm Prof. Boltzmann fiur den ihm zuerkannten Freih. r. B a $n \mathrm{mg}$ art $\mathrm{n}$ er'schen Preis.

Herr Dr. G. Schweinfurth, Präsident der neu gegriindeten „Société Khédiviale de Géogriaphie" zu Cairo iibersendet die Statuten dieser Gesellschaft nebst einem Exemplare der bei ihrer Inanguration ron ilm gehaltenen Rede und stellt an die Akademie das Ausuchen, mit der Gesellschaft in wissenschaftlichen Verkehr und Schriftentausch zu treten.

Herr Martin Egger, Professor der Physik zu Mariaschein,

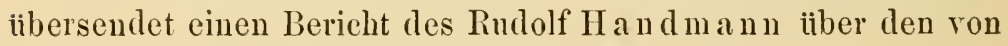
ihm erfundenen elektromagnetischen Motor, nnd ersucht um eine Subrention zum Zwecke der exacteren Ausfïhrung desselben.

Das c. M. Herr Prof. Pf a und ler in Innsbruck iibersendet eine Untersuchung ron H. Ha mmerle: "Über die Löslichkeit des Chlorealciums in Wasser".

Herr C. Puschl, Professor und Capitular in Seitenstetten, iibersendet eine Note iiber ${ }_{n}$ Erniedrigung der Temperatur des Dichtigkeitsmaximums des Wassers dureh Druck".

Das w. M. Herr Prof. C. Langer legt eine Abhandlung ror unter dem 'Titel : „ய̈ber das Gefässsystem der Röhrenknochen mit Beiträgen zur Kenutniss des Banes und der Entwicklung der Knochen".

Der Secretär iiberreicht eine Abhandlung: "Tersuche iiber das Wärmeleitungsrermögen ron Gasgemengen“, ron Herrn J. Plank, Assistenten am k. k. physikalischen Institute. 
Herr Dr. Sigmund Ex ner legt eine Abhandlung ror, betitelt : "Über das Sehen ron Bewegnngen und die 'Theorie des zusammengesetzten Anges".

Herr Dr. Ernst F I e is c h I legt cine Abhandlung ror, betitelt : „Über die Graduirung ron Inductions-Apparaten".

Herr Professor IV iesner ibergibt eine Abhandlumg unter dem Titel: „Untersuchungen iiber die Bewegung des Imbibitionswassers im Holze und in der Membran der Pflanzenzelle“.

Derselbe legt ferner eine Arbeit des Herm Gottlieb $\mathrm{H}$ a be rI andt iiber die Horphologie und Biologie der Lenticellen ror, welche im pflanzenphysiologisehen Institute der Wiener Universitait ansgefülnt wurde.

An Druckschriften wurden vorgelegt:

A potheker-Verein, Allgem. isterr.: Zeitschrift (nebst Anzeigen-Blatt). 13. Jahrgang, Nr. 20. Wien, 1875; 8".

Beobachtungen, Meteorologische, angestellt in Dorpat im

Jahre 187t. IX. Jahrgang. II. Band, Heft 4. Dorpat, 1875; gr. 8 .

Brasilien, Das Kaiserthmu —, im Jahre 1873. Rio de Janeiro, $1874 ; 8^{\circ}$.

Commission de Météorologie de Lyon: $1873.30^{\circ}$ Année. Lyon $1875 ; \mathrm{gr}^{\circ} .8^{0}$.

Comptes rendus des sćances de l'Académie des Sciences. Tome LXXX, Nr. 25. Paris, $1875 ; 4^{\circ}$.

Cooke, Josiah P., Melanosiderite: A New Mineral Speeies, from Mineral Hill, Delaware Connty, Pennsylrania. s". $^{0}$

Dolkowski, Eduard ron, Beitrag zur Histologie der Tracheobronehialsehleimhant ete. $1875 ; 8^{n}$.

Gew e rbe-Verei n, n. - ̈̈.: Wochenschrift. XXXVI. Jahrgang, Nr. 28. Wien, 1875; $4^{\prime \prime}$.

Institut, k. k. Militï - geographisches, in Wien: Die astronomisch-geodätischen Arbeiten desselben. III. Band. Wien, $1875 ; 4^{0}-$

Jordan, Alexis, Remarques sur le fait de l'existence en socièté, a l'ètat sanvage des expèces régétales affines et sur d'autres faits relatifs id la question il'espece. Lyon; $5^{0}$.

Lyman, Theodore, Commemorative Notice of Louis $A$ gassiz. 80. 
March and, Eugène, Etude sur la force chimique contenue daus la lumière du soleil ete. Paris; $8^{0}$.

Maschek, Luigi, Nanuale del Regno di Dalnazia per l'anno 1875. Anno V. Zara, 1875 ; 8".

Mensbrugghe, G. van der, L'électricité statique exeree-telle une influence sur la tension smperficielle d'un liquide? Bruxelles, $1875 ; 4^{0}$. - La théorie capillaire de Gauss et l'exterision d'un liquide sur un autre. Bruxelles, $1875 ; 8^{0}$. Milberg, Herman, Das Gesetz des Wasserlaufes. Hamburg, $1875 ; 8^{0}$.

Mi th th il unge n des k. k. techn. \& administrat. Militair-Comité. Jahrgang' 1875, 6. Heft. Wien; $8^{0}$.

N a turc. Nr. 297, Vol. XII. London, $1875 ; 4^{0}$.

Omboni, Giovanni, Di alcuni oggetti preistorici delle carerne di Velo nel Veronese. Milano, $1875 ; 8^{0}$.

Peabody Institute: Eight Ammual Report of the Provost to the Trustees. Baltimore, $1875 ; 8^{0}$.

Regel, E., Alliorum adhuc cognitorum monographia. Petropolis, $1875 ;$ kl. $4^{0}$.

"Revue politique et littéraire" et "Revue scientifique de la France et de l'étranger". Ve Anncé, 2e Série, Nr. 2. Paris, $1875 ; 4^{\circ}$.

Soeiété des Ingénieurs civils: Mémoires et Compte rendu des travaux. $3^{\text {e }}$ Série. $28^{\mathrm{e}}$ Amméc, $1^{\text {er }}$ Cahier. Paris, 1875; $8^{0}$. - Séances du 8 Janvier all 18 !nin 1875. $8^{0}$.

W a re 1 , G. K., An Essay concerning Important Physical Features exlibited in the Valley of the Hinnesota Rirer and upon their Signification. Washington, 1874; $4^{0}$.

Weyr, Em., Principes d'une thèorie des systèmes symétriques d'éléments. Bordeaux, 1874; $8^{0}$.

W i e e r Medizin. Wochenschrift. XXV. Jahrgang, Nr. 28. Wien, $1875 ; 4^{n}$. 


